\title{
Carbon emission reduction progress of pledging New Zealand corporates
}

By: Adam Crisp

A thesis submitted to Victoria University of Wellington in partial fulfilment of the requirements for the degree of:

Master of Environmental Studies

Victoria University of Wellington

2022 


\section{Abstract}

This thesis examines the progress of New Zealand's thirteen founding members of the Climate Leaders Coalition in reducing greenhouse gas emissions from 2010 to 2020 inclusive. The thirteen corporates' associated emissions are equivalent to half of New Zealand's total emissions; therefore their progress is influential on New Zealand's national progress. A known issue with corporate emissions is the paradox that whilst awareness and support for reducing emissions increase, corporate emissions also continue to increase. Understanding the carbon emission reduction paths of these publicly pro-mitigation New Zealand corporations provides further insight into this paradox and potential ways to alter the trend of increasing corporate emissions.

A corporate emissions progress framework was constructed to define and capture the corporate emission reduction paths. The framework recognises eight stages of progress, including corporate emissions, strategies, actions, and communications as characteristics of progress. Semi-structured interviews with sustainability staff, corporate reports, press releases and corporate submissions to government were analysed to form a picture of progress within and across the corporates. A shared pathway was identified across the corporates, with comparable sequence and focus of strategies, action areas and progress. All corporates achieved relative emission reductions with some low emitters achieving absolute emission reductions. The path had characteristics that are transferable to other corporates regardless of sector. The reporting standard used by all corporations strongly influenced the path, with multiple implications. No corporates were identified as being in the top three stages of progress, as all corporates remained within a non-transformational range. Being a foundational pledge member of the Climate Leaders Coalition seemed influential in terms of progress for some corporates, and more a reflection of their existing approach for others. 


\section{Acknowledgements}

The patience and persistence of many people in supporting me in finishing this has been amazing and much appreciated: Greg for his sharp eye and quick wit, my supervisor Associate Professor Ralph Chapman for his calm guidance and acceptance of my disorganised enthusiasm, Penny and Jo for their help with morale and organising, Diana for maintaining my sanity, my flatmates for being easy to be around when most needed, and my workmates for being supportive when I had to disappear into study world. 


\section{Table of Contents}

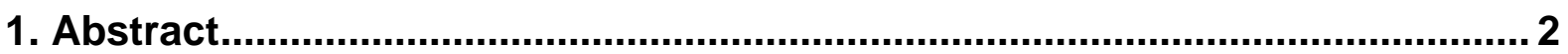

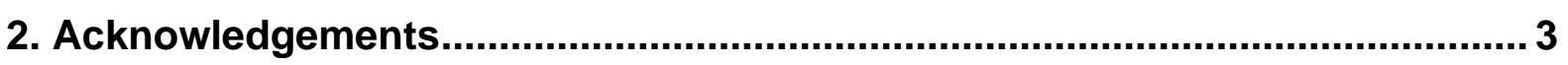

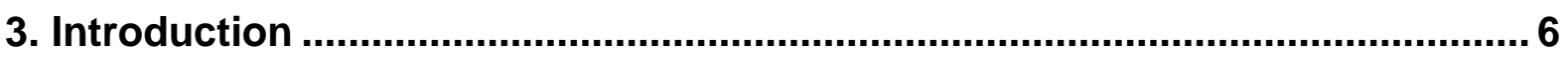

4. Literature Review ............................................................................................ 11

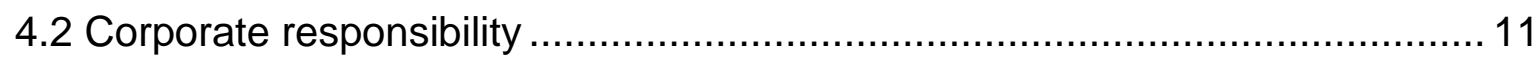

4.3 Corporate emission reduction strategy ………..................................... 17

4.4 Determining emission reduction progress.................................................. 31

4.5 COVID-19 Effects on corporate decarbonisation ........................................... 33

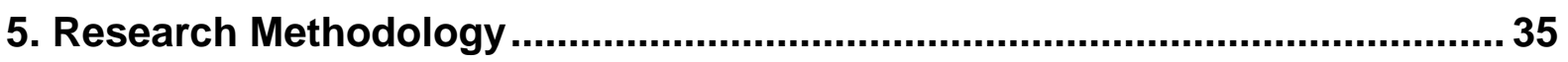

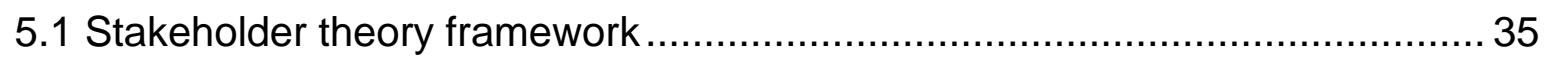

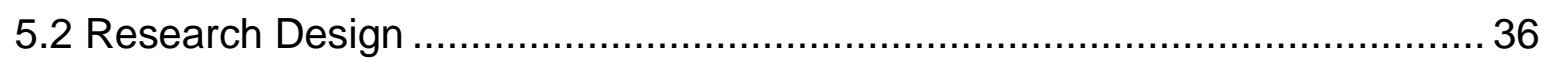

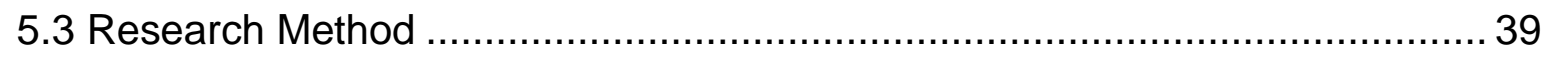

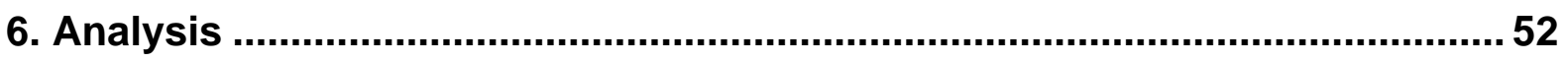

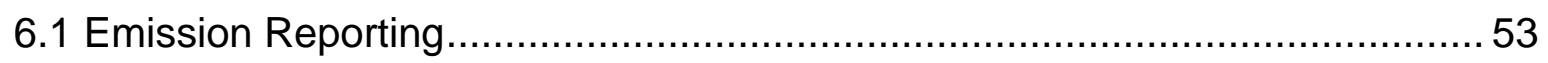

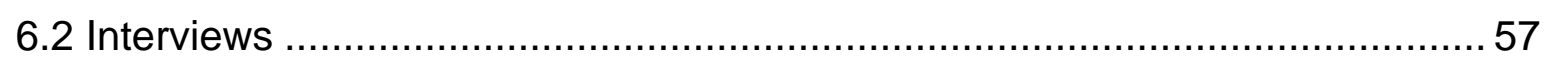

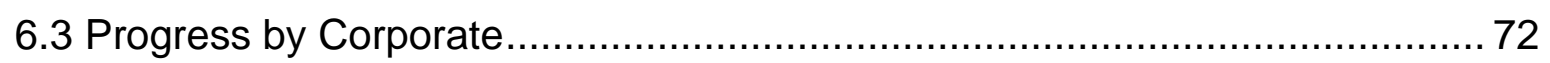

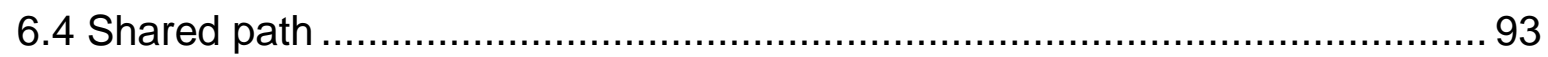

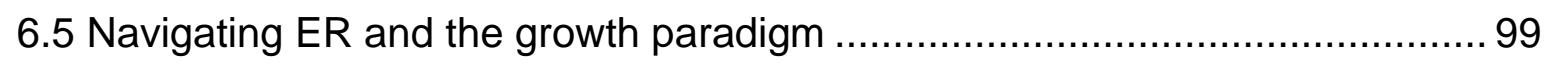

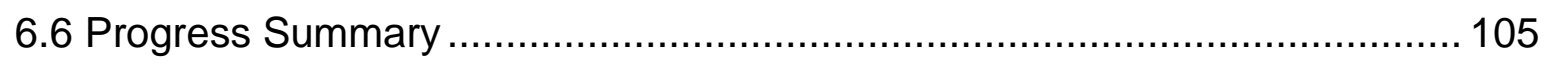

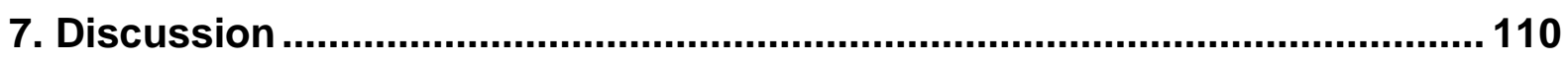

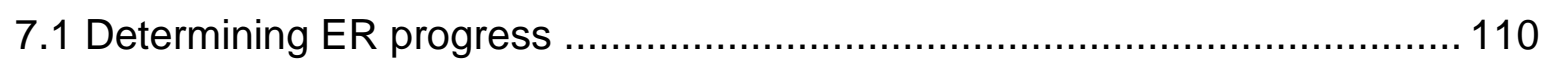

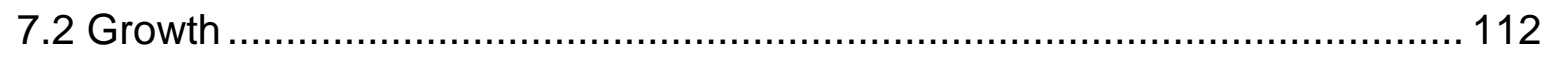

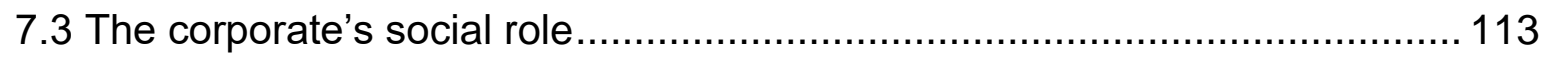

7.4 The New Zealand and global context ....................................................... 114

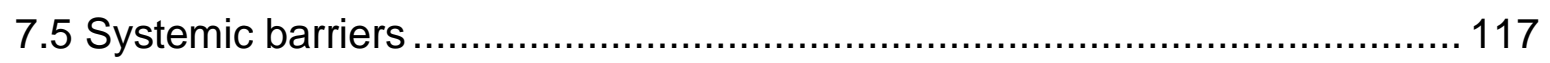

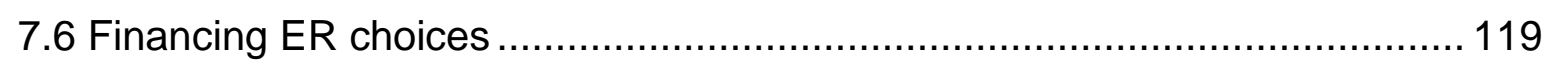

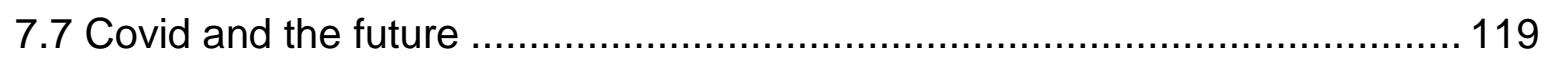

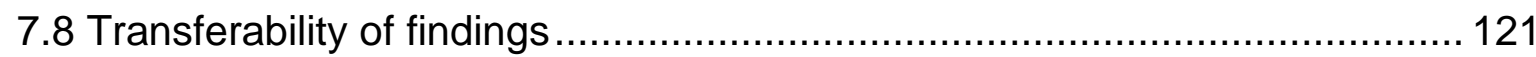

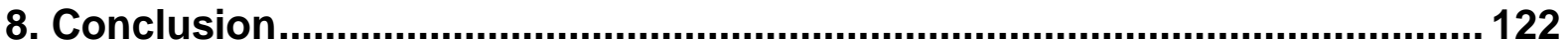

9. Appendices

Appendix 1: Corporate environmental progress frameworks ............................. 124

Appendix 2: Corporate Emission Reduction Activity Descriptions ..................... 125 


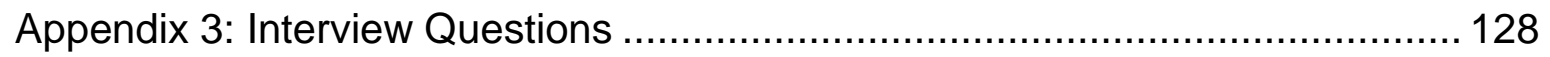

Appendix 4: Relevant corporate submissions to government ............................ 129

Appendix 5: Corporate emissions figure coverage …................................... 132

Appendix 6: CLCF Reported emissions at key points throughout 2010-2020, by

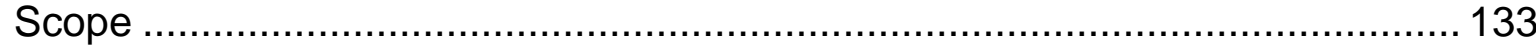

Appendix 7: Annual/Sustainability/Environmental Reports coverage ................ 134

Appendix 8: Press release coverage …....................................................... 135

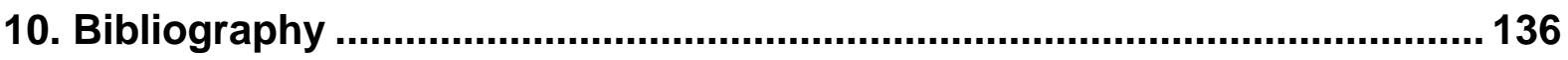




\section{Introduction}

Human-induced climate change can be viewed as the largest issue facing humanity (Klein, 2014; Sklair, 2017; Stern, 2006; World Economic Forum, 2018), despite the immediacy of COVID-19 and its economic aftermath (NZ Herald, 2020a; UN News, 2020). The release and accumulation of greenhouse gases due to human activity drives climate change, to which carbon dioxide $\left(\mathrm{CO}_{2}\right)$ is the largest contributor (MfE, 2019f). Record-breaking average temperatures, frequent extreme weather events, ice melt, and sea-level rise are already happening (American Meteorological Society, 2018; Harvey, 2021; MfE \& Stats NZ, 2017; NIWA, 2020). The struggle now is to keep future warming below $2^{\circ} \mathrm{C}$ because "future climate-related risks ... are larger if global warming exceeds $1.5^{\circ} \mathrm{C}$ " (IPCC, 2018, p. 7). Current projections, however, expect this threshold will be exceeded between 2030 and 2035 (IPCC, 2021). Yet global and New Zealand emissions continue to increase (IPCC, 2018; MfE, 2019f) and the likelihood of the world staying below the target is diminishing rapidly (Climate Action Tracker, 2020). COVID-19 disruption made negligible difference to the overall emission reductions (ER) required (UN News, 2020). The time for a "business-as-usual" approach has gone (United Nations Development Programme, 2019).

While public and corporate consciousness has been increasing since 2010, the 2015 Paris Agreement, when almost 200 countries, including New Zealand, committed to ER as expressed in 'nationally determined contributions' (UNFCCC, 2015) has been considered ground breaking in changing perceptions. Public pressure on the New Zealand government and corporates to act upon climate change has been visible ever since (Hutt, 2021; MfE, 2018a; Stewart, 2016; Wannan, 2015). More than $80 \%$ of New Zealanders now agree that business ER need to be in line with global targets (IpsosIAG, 2021).

Corporations are forming groups to act upon ER. The Climate Action 100+ initiative, started just after the Paris Agreement, now has 545 investor signatories (Climate Action $100+, 2020$ ). New Zealand based corporates, representing over $50 \%$ of New Zealand's emissions (CLC, n.d.-a), have signed a 'Climate Leaders Coalition' pledge to reduce emissions (MfE, 2018a). Their 2018 pledge was heralded by the Secretary for the Environment as "a significant step forward for New Zealand as we move to address climate change" (MfE, 2018a).

Page $\mid 6$ 
Despite support for these initiatives, (ACCSR, 2017; KPMG, 2017), corporate emissions are actually increasing (Cadez et al., 2019; MfE, 2020). In New Zealand, "a large number [31 of the top 50 NZX listed companies]... [are] failing to disclose any climate-related information in their public reports" (Pham, 2021). The paradox of increased corporate support but emissions still increasing is similar to the international experience (Cadez et al., 2019). Since the pledge, the Climate Leaders Coalition's reported emissions have not markedly reduced with a founding corporate leader stating outcomes thus far are "not the greatest in the world" (Steeman, 2020). Projections indicate that emissions need to be "about $65-90 \%$ (interquartile range) lower in 2050 relative to 2010 " to avoid exceeding $1.5^{\circ} \mathrm{C}$ of warming without emissions overshoot (IPCC, 2018, p. 17). Given the reductions required and associated scale of change (Hickel \& Kallis, 2020) it is not clear the Coalition's actions will meet the requisite $65 \%$ reductions ${ }^{1}$ of their emissions by 2050 .

Possible reasons for this disconnect have been explored. Corporate emission reporting and target setting may not drive significant ER (Tang \& Demeritt, 2018). Corporate recognition of the need to reduce emissions, communicating this in corporate strategy, creating an emission inventory, reporting emissions, setting targets, and undertaking actions to reduce emissions, is a common framing of the path to decarbonisation (SBNNZ, 2021). However there are multiple potential points where deviation from ER may occur. There is considerable evidence that a corporate's public position or reporting on ER may not be reflected in its strategies (Testa et al., 2018; Walker \& Wan, 2012), its actions (Haack et al., 2012), internal communications (Supran \& Oreskes, 2017), or a reduction in emissions (Damert et al., 2017; Doda et al., 2016; Qian \& Schaltegger, 2017; Tang \& Demeritt, 2018). Reasons include, but are not limited to, reporting approaches, inconsistencies between communicated position and reduction efforts (Thaker, 2019), conflicting motivations, strategies or actions (Busch et al., 2020; Hahn et al., 2014), and systemic interdependencies preventing desired change (Hickel \& Kallis, 2020; Patel \& Moore, 2018).

To illustrate, Air New Zealand (Air NZ) is a founding member of the coalition (CLC, n.d.-a) and received numerous awards for its sustainability efforts (Scoop, 2016). But,

\footnotetext{
${ }^{1}$ A $50 \%$ reduction by 2050 (vis a vis 2010) is the approximate figure cited by the IPCC, while as noted in the text above, $65 \%$ is the minimum reduction if overshoot is to be avoided.
}

Page $\mid 7$ 
its annual use of jet fuel was trending up prior to COVID (Air NZ, 2020b) and absolute emissions had been increasing because business growth was outweighing the efficiencies gained from upgrading its fleet, or practices like de-icing wings in-flight (Air $\mathrm{NZ}, 2019 \mathrm{~b})$. While the company has also tried to obtain a reliable source of biofuel which could halve its use of non-renewable fuel (New Zealand Government, 2016) and reduce emissions, there are still substantial emissions associated with biofuels, especially if land-use factors are included (Bailis et al., 2016; Francis, 2019). Technology advancements such as non-emitting planes (e.g. electric) exist but not at the size or range to meet more than short-distance low-passenger capacity journeys (Carrington, 2020), an area in which alternative transport exists. The company has also been described as the "least unsustainable" airline by one of their sustainability board members (Mitchell, 2019), emphasising that while its efforts may be industry leading, they are still a substantial cause of emissions.

Numerous corporate carbon management or sustainability progress frameworks have been created to help implement decarbonisation. These frameworks typically cover a spectrum of stages that may not extend into the required level of change to achieve decarbonisation $^{2}$ (Landrum, 2018). They also largely reflect a profit-driven business model, with environmental (and social) considerations secondary (Carroll, 2016; Ihlen \& Roper, 2014). Such frameworks are designed to resist change or produce actions that do not challenge the purposes of profit and growth (Landrum, 2018). It therefore may prove more useful to look at sustainability frameworks not focused on corporate entities (Landrum, 2018).

Corporates, however, have also recognised they hold responsibilities beyond profit and growth (Bullis \& le, 2007; Carroll, 2015). The presentation of carbon reductions as mutually beneficial to the environment and a business's financial performance is common (Bullis \& le, 2007; de los Reyes et al., 2017; Porter \& Kramer, 2011) and is popular in business communications (Breeze, 2013). In some instances, stakeholders

\footnotetext{
2 Decarbonisation as used here means that a business in operating does not emit greenhouse gases or if it does, directly sequesters them as part of their operational process. Offsetting is excluded as over $70 \%$ of certified Clean Development Mechanism projects invested in to sequester emissions have poor to no evidence that emissions have been sequestered beyond what would have happened anyway (Cames et al., 2016).
}

Page | 8 
have forced major corporate repositioning: for example, the head of BP has declared it has to move away from oil to be able to employ and retain staff (Shah, 2020).

Evidence to link financial and environmental performance is mixed (Lu et al., 2014), with some research showing decarbonising companies performing financially better on average than other companies (e.g. Trumpp \& Guenther, 2017). How much weight can be put on the findings is questionable. Better financial performance by environmentally better-performing companies may reflect other aspects, such as corporates utilising resource slack (e.g. Dang et al., 2019), or non-causal factors, such as investors financially penalising poor environmental performance (Lourenço et al., 2012; Trumpp \& Guenther, 2017). As businesses grow, so too do associated emissions, unless their products or services have been decoupled from producing emissions; or emission efficiency gains outweigh volume increases. Signs of technological intervention or consumer behavioural change at the scale required to give sufficient efficiencies or decouple emissions from existing processes are not promising (Bjørn et al., 2018). Decoupling emissions from growth is difficult, and calculations indicate this will take longer than the timeframes available for ER (Hickel and Kallis, 2019). It appears then that to decarbonise sufficiently, a greater shift in business focus is required. Landrum (2018) proposes there are further stages in corporate sustainability beyond profit or growth, which are yet to be focussed on within the models. The business strategy of a corporate might instead look externally for environmental and social guidance or validation as to its primary purpose.

There is some suggestion the COVID-19 pandemic could be a catalyst for the shift in focus required (Moon, 2020; Rosenbloom \& Markard, 2020). The evidence so far, however, suggests a temporary reduction in carbon emissions, followed by a return to close to pre-COVID emission levels, is most likely (Le Quéré et al., 2020). Initially analogies with the "Global Financial Crisis" (GFC) in 2007/8 were drawn (BBC, 2020). But those findings indicate path dependency -- the corporate sustainability strategies embedded before the crisis, continued afterwards (Bansal et al., 2015; Barnett et al., 2015). Whether these findings are transferable to the COVID context is uncertain and as the pandemic continues, it has less commonly been viewed as comparable (Hepburn et al., 2020). 
The aim of the present study is to explore whether there has been a noticeable shift over time amongst the thirteen founding Climate Leaders Coalition corporates regarding their communications, strategies, actions and emissions, up to when this study was conducted in the final quarter of 2020.

Accordingly, the research question is:

"What are the carbon emission reduction paths since 2010 of publicly pro-mitigation New Zealand corporates?"

To assist answering this question the following sub-questions are asked:

- What are the disclosed carbon emissions and related actions since 2010 of NZ's corporates that were founding signatories of the Climate Leaders Coalition (CLC)? (SQ1)

- How have CLC founders' public communications regarding carbon emissions changed since 2010? (SQ2)

- What have been the CLC founders' public positions in government consultations involving climate mitigation since 2010? (SQ3)

- Taking into account the lessons of COVID-19, what does each business consider their future emission targets to be and their dependencies in achieving this? (SQ4)

D Does being a founding member of the CLC appear to have any effect on their behaviour? (SQ5)

A mixed methods approach based on stakeholder theory has been taken. Many aspects of understanding ER progress are non-numerical, and actors both internal and external to a corporation are recognised as able to impact ER. 


\section{Literature Review}

Corporations are an integral part of developed society and interact with multiple stakeholders in diverse ways which can impact on corporate carbon emissions. Within a corporation there are many aspects that may come into play for an emission reducing outcome to occur. This chapter outlines the relevant theories and literature that helped frame the research questions set out in the previous chapter. There are multiple perspectives on defining and applying corporate responsibility for emissions, how corporates ${ }^{3}$ approach ER, how to determine progress, and what is known thus far about the possible impact of COVID on current and future progress.

\subsection{Corporate responsibility}

There is an extensive and growing literature on perceived business responsibilities for the environment and how far they extend (Bullis \& le, 2007; Carroll, 1999, 2015; CDP, 2020c). Business responsibilities are increasingly recognised across Annex 1 countries $^{4}$ to include environmental considerations (Eccles \& Klimenko, 2019; Schaltegger et al., 2014), even if some only see these through a financial lens (Ihlen \& Roper, 2014). Carbon emissions management towards decarbonisation is often recognised as one of these environmental responsibilities, either directly in corporate communications or strategy e.g. Toyota NZ (2018), or tacitly through the agreement to report on emissions (e.g. CDP, 2019). External factors that drive corporate recognition of carbon reduction responsibilities have been extensively explored, including but not limited to government policy, competitor activity, consumer behaviour, pressure from non-governmental organisations, energy prices, technology, financial and reputational risk avoidance, and societal norms (Cadez et al., 2019; Damert et al., 2017; Khan \& Lockhart, 2019; Tang \& Demeritt, 2018; Walker \& Wan, 2012). Views on responsibility may vary across and within corporates by country, site, business role, and personal beliefs (Dawkins \& Fraas, 2011; Roulet \& Touboul, 2015; Schreck \& Raithel, 2018). New Zealand businesses predominantly accept they have

\footnotetext{
${ }^{3}$ Whilst the terms corporate and corporation are often used interchangeably, throughout this study the term corporation is used to refer to the legal, financial or physical entity, and corporate to the broader concept of a large company, its associated people, activities, and responsibilities.

${ }^{4}$ Annex 1 countries are those as defined by the Paris Agreement, see UNFCCC. (n.d.). UNFCCC Process: Parties. Retrieved 22 Jul 2021 from https://unfccc.int/process/parties-non-partystakeholders/parties-convention-and-observer-states
}

Page $\mid 11$ 
environmental responsibilities, including decarbonisation (Gartenberg \& Serafeim, 2019; Khan \& Lockhart, 2019). But on the whole New Zealand business emissions have increased markedly (MfE, 2020), perhaps in part due to low or in some cases absent regulatory carbon costs (Hopkins et al., 2015). The European Union countries (EU) have reduced their emissions 25\% from 1990 to 2018 (p iv, EEA, 2020a), mainly through switching from coal to gas as an energy source as well as energy efficiencies (EEA, 2020a).

Corporates use different terms to explain their responsibility towards the environment which may not reflect the terms' formal meaning nor an underlying change in perceived responsibility. How a business expresses its responsibilities beyond profit-making is couched in terms such as: corporate citizenship, the adoption of goals of sustainability, sustainable development, "people, profit, planet", triple bottom line, business ethics, corporate environmental responsibility, corporate social responsibility, shared value, reputation, stakeholder management and even risk management. In the academic context the terms suggest different reasons for corporates to state responsibility, and this is likely to be linked to their motivation to act. At the risk of oversimplification, terms such as shared value and sustainable development in the corporate context have been framed such that reducing environmental impact and financial performance are compatible and in fact may be mutually reinforcing (Dyllick \& Muff, 2016; Porter \& Kramer, 2011). Evidence that environmental and financial performance are correlated has been common but inconsistent, and when a connection is present it is hard to isolate it from other factors that may be causal, such as superior corporate governance (Endrikat et al., 2014; Tang \& Demeritt, 2018; Trumpp \& Guenther, 2017). Risk, reputation and stakeholder management recognise that a corporation has external stakeholders, such as consumers, advocacy groups and civil society organisations, which can negatively communicate about them, often with a negative financial impact (Elijido-Ten \& Clarkson, 2017; Harrison \& Freeman, 1999). This can, at one end of the spectrum, explain 'greenwashing' - corporates communicating in ways that lead external stakeholders to see their environmental behaviour more positively than it is (Walker \& Wan, 2012). Risk management also considers potential supply chain failures due to more extreme climatic events if decarbonisation does not occur (Baskin, 2020; Elijido-Ten, 2017), and the risk of regulatory actions by central government or investor abandonment which could also have a negative financial impact if they occur 
(Elijido-Ten, 2017). Thus far, the motivations of businesses have largely centred on finance. But corporate citizenship and business ethics tend to emphasise more the role of a corporate in society and the responsibilities this entails (Crane \& Matten, 2016), even if a weak interpretation of corporate citizenship can be seen as akin to reputation management. In fact, many of these terms have been used by businesses interchangeably and may simply indicate nomenclature trends rather than any underlying change in understanding or approach (Carroll, 2015; Milne \& Gray, 2013). Analysis of corporate terms and their used (rather than academic) meaning bears this out (Dobers \& Springett, 2010).

Whilst each term has its own (academic) interpretation, most if not all of the terms mentioned above can usefully be considered under the concept of corporate social responsibility (CSR) (Carroll, 2015). CSR has had many definitions (Carroll, 2015; Crane \& Matten, 2016; Rahman, 2011) but Carroll's (1979) four-category definition is often used: "Corporate social responsibility encompasses the economic, legal, ethical, and discretionary expectations that society has of organizations at a given point in time" (Carroll, 2016, p. 2). Perhaps this is partially because the categories are distinct, wide-ranging, and open to reinterpretation. The order in which the categories are listed is a hierarchy which Carroll makes explicit. The belief that a business's primary purpose is to make a profit is long-standing and underpins the definition (Crane \& Matten, 2016; Friedman, 1970). The definition disregards (or at best fudges) environmental and social obligations, despite a widely recognised need to maintain a social licence to operate, and a growing recognition of the critical importance of the environment. Moreover, viable non-profit centred business models exist in new and existing companies (Carroll, 2015).

Rahman's (2011) review of CSR definitions across the decades indicates that expectations of CSR have increased. Ethical and discretionary expectations since 2000 encompass "integration of social and environmental concern; voluntariness; ethical behaviour; [...] improving the quality of life of the citizens; human rights; labour rights; protection of [the] environment; fight against corruption; transparency and accountability" (Rahman, 2011, p. 173). A similar CSR definitional expansion has been witnessed in New Zealand (Lawrence et al., 2013). Rahman's (2011) voluntariness refers to a returning 1980 s concept that a corporate should perform actions because it feels obliged to rather than because it is legally required to.

Page $\mid 13$ 
The temporal expansion in CSR's meaning is mirrored by sustainability's increased business recognition. Sustainability frames environmental, economic, and social considerations (encompassing legal and ethical) as inseparable requirements (IIRC, 2019; Lawrence et al., 2013; Schreck \& Raithel, 2018), and recognises the increasing ability and range of internal and external entities, including of staff, consumers and NGOs, to impact corporate profitability (Aguinis \& Glavas, 2012). Crane and Matten (2016) postulate that this increase in recognised corporate responsibilities is at least in part due to the presence of corporations in western society broadening into services (for instance electrical utilities) and locations that necessitate wider concerns than profit. This may hold true in some cases; however location may also diminish perceived responsibilities; CSR principles upheld in one country may not be applied consistently by a company when operating internationally (Ortiz-de-Mandojana et al., 2016), and some operations may be located in a different country for this very reason.

\subsubsection{Corporate carbon legalities}

A corporation may be forced into considering emissions reduction a legal, or human rights issue, or both, though nothing currently dictates that a NZ corporation must constrain their emissions. Numerous attempts to formalise international corporate environmental and social responsibilities have occurred, especially since the rapid increase in number and scale of companies with internationally spread operations since the early 1990s has highlighted inconsistencies in corporate practices in different countries (Ruggie, 2013). Climate change related litigation has grown internationally (Setzer \& Byrnes, 2020; Setzer \& Vanhala, 2019) and 'carbon majors' - corporates with operational emissions that are considered large internationally have been targeted, with scale tending to assist causal arguments (Ekwurzel et al., 2017). Courts have also drawn links between IPCC-published scientific findings of the risks to humanity of exceeding $2 \mathrm{C}$ warming, human rights, corporate responsibilities and a country's declared Nationally Determined Contribution (NDC) (Peel \& Osofsky, 2018; Setzer \& Vanhala, 2019). Within NZ, 19 climate change related litigation cases existed prior to 2021, with 13 involving corporations in some capacity (Grantham Research Institute, 2021). But, the legal situation is evolving rapidly and the existing and potential use and impact of litigation on ER is yet to be fully understood (Setzer \& Vanhala, 2019). 
The NZ government's policy approach can be considered comparable to that of many Annex 1 countries, with an Emissions Trading Scheme (NZ ETS) and an independent Climate Change Commission. NZ corporations within the high-emitting sectors must purchase NZ ETS units to 'pay for' their carbon emissions (MfE, 2021a). In sectors outside the ETS, consideration of climate-related risks is required under more general company-related legislation law.

NZ corporations' legal emission obligations centre around the CCRA (Climate Change Response Act 2002). The NZ ETS, located within the CCRA, is currently seen as the primary mechanism by which company emissions are regulated. Companies decide whether to reduce or pay for their emissions, with a 'cap' - a limit in the number of available emission trading units - now in place (MfE, 2021a).

The NZ Parliament supported without opposition ${ }^{5}$ an amendment to the CCRA in November 2019, that established a NZ Climate Change Commission (NZCCC) with a key responsibility of providing advice on mitigation targets and their adequacy, and monitoring government policy performance (CCRA 2002, s. 5 (J)). The NZCCC's 2021 advice includes sector-specific ER recommendations (NZ Climate Change Commission, 2021), notably agriculture and energy (predominantly transport and electricity generation) which constitute $48 \%$ and $41 \%$ respectively of NZ's emissions (MfE, 2020). Additionally NZ's Minister of Climate Change Hon. James Shaw has stated it will become mandatory for the financial and insurance sectors to disclose climate change risk, in accordance with the Task Force on Climate-related Financial Disclosures framework (Shaw, 2020c). For other sectors, a director's duty of care obligations under the Companies Act 1993 to consider foreseeable risk becomes relevant (Chapman Tripp, 2019). The law firm's advice, however, suggests consideration does not necessitate action (Chapman Tripp, 2019, p. 16).

It appears the foreseeable NZ government policy approach will be largely that sectors, except farming, find their own solutions to reducing emissions within their targets, with the government preferring not to prescribe how to reduce emissions (James Shaw, personal communication, August 11, 2020). The reasoning given was that more explicit requirements may cause unintended consequences such as offshoring carbon-intensive operations to less regulated countries. Shaw's stated concern of

\footnotetext{
${ }^{5}$ However the ACT Party absented itself from Parliament for the vote.
} 
offshoring or more broadly 'carbon leakage', where stricter regulations in one country cause carbon activities to occur elsewhere (Aguilera \& Jackson, 2003), puts aside that there are also proposed solutions (Cosbey et al., 2019). The NZCCC, for example, recommends the ruminant livestock population should be decreased to bring methane emissions within targets because suppression advancements are too slow (NZCCC, 2021). So, it currently remains in the hands of each NZ company how much they reduce emissions versus adopting offsetting or avoidance strategies, notwithstanding stakeholder pressure or government ownership pressure.

\subsubsection{Responsibility theories}

Three dominant theories associated with how corporates consider their environmental and social responsibilities are Legitimacy, Institutionalism and Stakeholder theory. Fernando and Lawrence (2014) advocate for the use of all three. Legitimacy theory centres on corporates wishing to act or be perceived as acting within societal expectations, to maintain societal support for business (Dowling \& Pfeffer, 1975). A legitimacy lens has proven useful in explaining when ER or actions do not match climate mitigation rhetoric (Breeze, 2013; Hrasky, 2011), but is less suited to explaining why some corporates make greater efforts than others. Institutionalism recognised, persistent norms or rules (Ostrom, 2000; Selznick, 1996) - plays a significant role in influencing corporate attitudes and behaviour (Caprar \& Neville, 2012; Corbett et al., 2015; Daly, 2007; Ortiz-De-Mandojana et al., 2016). This theory is well suited to explaining corporate resistance to change (Selznick, 1996), and whilst some later variants such as discursive institutionalism (Schmidt, 2010) illustrate how change can occur within an institutional framework, it is not recognised as this framework's strength. Lastly stakeholder theory centres on the (potentially conflicting) objectives of stakeholders: the internal or external entities that have an effect on or are affected by corporate actions, directly or indirectly (Cadez et al., 2019; Donaldson \& Preston, 1995). Legitimacy and institutionalised power structures can be reasonably considered within the stakeholder relationship (Harrison \& Freeman, 1999). Stakeholder theory also explains inconsistencies in behaviour under the same market conditions, and understanding systemic issues that may involve many entities (Crane \& Matten, 2016). Stakeholders' ability to influence corporate views and behaviour can vary widely, and can be corporate or industry sector specific (Boiral et al., 2017; Galbreath, 2010; Sprengel \& Busch, 2011). So, whilst the actions of external Page $\mid 16$ 
stakeholders across corporates may be similar, the outcome in terms of corporate behaviour will vary.

A corporate's motivations affect the range of responses to the need to decarbonise, where CSR motivations reach beyond profit. Business purpose is taken as a useful representation of business motivation, with strategic priorities being the corporate's application of that purpose (Crane \& Matten, 2016). If the business purpose is profitoriented, then strategies and resultant actions will be prioritised that align with or are perceived to align with profitability (Landrum, 2018). Strategies can still generate positive outcomes, but are based upon corporate self-interest, rather than recognising a responsibility to act on emissions (Lantos, 2001; Okereke, 2007). This limits decarbonising actions to those that provide business gain, which may manifest as purely a marketing strategy with no decarbonisation involved, right through to business transformation as decarbonising is seen as a competitive advantage (Landrum, 2018). By contrast, altruism is independent of business gain. It can be seen as a particular form of ethical recognition, which - whilst extending the range of motivations beyond business gain - may or may not result in greater action depending upon other strategic priorities (Okereke, 2007). Given this constraint, the type and pace of change will be limited to decarbonisation actions of a nature and scale that do not threaten, are perceived to support, or are necessary to achieve ongoing profitability. This places certain strategies and actions as infeasible, as they directly conflict with the profitability purpose (Landrum, 2018).

\subsection{Corporate emission reduction strategy}

Even if all options are 'on the table', many recognise that corporate ER have complex interdependencies, including internal and external stakeholders (Köhler et al., 2019; Landrum, 2018; Patchell, 2018). A rapid growth in the last 10 years in the scope and volume of 'sustainable transition' literature confirms corporations' interdependencies, and concludes that systemic change is needed to achieve the scale and speed of ER required (Köhler et al., 2019). As typically more than half of a corporation's associated emissions are generated by suppliers, (Blanco et al., 2016; Huang et al., 2009) most corporates must interact with others to achieve sizeable ER. Many businesses internationally have formed or joined corporate groups aimed at ER, but whether ER actually extends beyond the initial alliance creators is in doubt (Delmas \& Montes- 
Sancho, 2010). Also, consumers must be engaged, as there must be willingness to purchase new or altered products/services and participate in reuse or recycling options (Liu et al., 2017). Any study of corporate carbon strategy must consider these stakeholder interdependencies.

Within a corporation, strategy is an important determinant of ER as it articulates the general business direction (Cadez et al., 2019; Kolk \& Levy, 2001; Kolk et al., 2008). Senior decision-makers, typically executive level management, shape the strategy and direct it (Rickards et al., 2014). Their strategic support is essential for ongoing ER progress (Banerjee et al., 2003; Rickards et al., 2014), but does not guarantee it. Other factors, including corporate culture, management skills and interpretation, industry and market conditions, country specific cultural norms and government policies, to name a few, can come into play (Busch et al., 2020; Corbett et al., 2015; Dean \& Sharfman, 1996; Hahn et al., 2014; Kolk \& Levy, 2001; McNally, 2014; Mitchell et al., 2011).

Whilst the defined scope of a corporate ER strategy varies, four strategic areas keep re-emerging as critical in terms of supporting ER:

- carbon governance,

- direct actions aimed at reducing carbon emissions,

- carbon compensation, and

- carbon positioning.

Weinhofer and Hoffmann (2010, p. 78) define corporate carbon strategy as "a pattern in action over time intended to manage a company's direct and indirect $\mathrm{CO}_{2}$ [or $\mathrm{CO}_{2}$ equivalent] emissions". This definition is notable in accurately identifying those actions must be repeated or sustained for them to be considered part of a strategy, as opposed to a short-term tactic, or isolated action. Buying a few energy saver bulbs cannot be considered a strategy; replacement of (almost) all lighting to achieve lower energy illumination can. Strategically managing emissions is thus broader than isolated steps of reduction/elimination, and the encompassing of these four strategic areas has proven repeatedly useful in understanding a corporate's progress on ER (Cadez et al., 2019; Jeswani et al., 2008; Lee, 2012; Penz \& Polsa, 2018). Each strategic area is described briefly below. 


\subsubsection{Carbon governance}

To ensure a corporation is meeting its stakeholder responsibilities, in this case ER, corporate governance is required. The Organisation for Economic Co-operation and Development (OECD) describes corporate governance as involving:

a set of relationships between a company's management, its board, its shareholders and other stakeholders. Corporate governance also provides the structure through which the objectives of the company are set, and the means of attaining those objectives and monitoring performance are determined. (OECD, 2015, p. 9)

The definition highlights both parts of governance - those shaping governance and deeming how well governed a corporation is, and the systems required to execute and measure governance. Having a diverse board of directors including people external to the company has been recognised as an important governance mechanism. New Zealand governance guidelines also indicate "conduct towards stakeholders ... [should be] within broadly accepted social, environmental, and ethical normsgenerally subject to the interests of shareholders." (FMA NZ, 2014, p. 38). Comparable progress of governance including stakeholders beyond shareholders has also occurred within other jurisdictions such as the USA and UK (Gartenberg \& Serafeim, 2019; ICSA | The Chartered Governance Institute, 2017).

That stakeholders include those with indirect or non-financial interests in the company is not new (Donaldson \& Preston, 1995), but the proposition has had to compete for business support with the popularisation of neoliberalism and Friedman's (1970) 'profit is the sole purpose' mantra. Where each board member and senior executive sits in this belief spectrum will differ. Accordingly, the degree to which a sustainability board influences corporate environmental behaviour on ER or risk disclosure is known to vary across countries, its size, level of expertise, gender mix, independence, frequency of sitting, and surrounding normative or regulatory pressures (Amran et al., 2016; Elsayih et al., 2018; Ortiz-De-Mandojana et al., 2016; Peters \& Romi, 2014).

Governance involves assigning responsibility for managing emissions, and a supporting set of processes (sometimes identified as an Environmental Management System) (Baumgartner, 2014). Senior decision-makers' strategic support for ER is 
important, but may not result in ER (Banerjee et al., 2003; Rickards et al., 2014). Multiple factors may intervene: leaders feeling unable to make changes, dilution of strategic intent, managerial avoidance of pro-ER decisions due to complexity and conflicts with other business goals, and lack of strategic planning effectiveness, amongst others (Corbett et al., 2015; Dean \& Sharfman, 1996; Hahn et al., 2014; McNally, 2014). Placing sustainability roles within Marketing and Communications is not unusual in NZ. This placement can be interpreted as positioning of emissions action (or inaction) with stakeholders as being more of a focus, than actual ER. Regardless, if project-oriented thinking, time-pressures or lack of a detailed understanding of climate change mean senior decision-makers view climate change in a non-systemic way, this has been shown to adversely affect progress (Rickards et al., 2014). Corporations in the EU appear more advanced, as more than a decade ago most of those responding to the 2007 CDP report had assigned a senior manager with responsibility for managing climate change (Sullivan, 2009). Additionally, sustainability interviews conducted in 2009 with 15 major NZ corporations revealed "managers do agree that they have to improve on their initiatives to be on the same par [sic] with their global competitors" (Eweje, 2011, p. 131). More recent comparisons based upon corporate reporting and communications indicate NZ corporations are still lagging those in the EU, US, and Australia (Thaker, 2019).

\section{Governance - Carbon reporting}

Corporate governance mechanisms can increase emissions disclosure (Peters \& Romi, 2014), but may not result in ER (Qian \& Schaltegger, 2017). There is considerable evidence that a corporate's public position or reporting on ER may not be reflected in its strategies (Testa et al., 2018; Walker \& Wan, 2012); actions (Haack et al., 2012); internal communications (Supran \& Oreskes, 2017); emission reporting representativeness (Hrasky, 2011); or reduction in emissions (Damert et al., 2017; Doda et al., 2016; Qian \& Schaltegger, 2017; Tang \& Demeritt, 2018). These disconnects may not necessarily be considered a governance failure, as governance may focus on managing reputational and/or regulatory requirements, rather than ensuring operational change (Peters \& Romi, 2014). In the absence of business purpose being aligned with ER, governance mechanisms may be for compliance only. 
Reporting on emissions is useful in helping quantify emissions and is necessary for emissions trading schemes and potentially other government policies. A popular business and consultancy solution framing is that quantifying emissions, then reporting on them, will naturally lead to reduction or elimination (e.g. Toitū Envirocare, n.d.). But, the impact of environmental reporting over the last quarter century is 'woeful' as environmental issues relating to companies have continued to escalate (Deegan, 2017). More specifically, over 20 years of increased emissions reporting (ACCSR, 2017; KPMG, 2017) has not resulted in a noticeable reduction in absolute emissions by businesses (IPCC, 2018; MfE, 2019f). To further complicate the issue, there are also questions as to how much of the emissions should be attributed to an individual, business or infrastructure, such as energy use when working from home.

Defining and measuring a corporation's emissions is maturing, but it is difficult to discern a definitive improvement. In 2001 the WBSCD and WRI finalised the Greenhouse Gas Protocol -- a philosophy and standard for determining a corporation's emissions (WBCSD and WRI, 2015). The term 'carbon footprint' -- derived from the term 'ecological footprint' (Rees, 1992) -- became popularised during the 2000s, aided by extensive use in marketing by BP (Safire, 2008). How best to define and calculate a carbon footprint is a matter of ongoing debate (Wegener et al., 2019; Wiedmann, 2009; Wiedmann \& Minx, 2008), although it has been defined as "a measure of the exclusive total amount of carbon dioxide emissions that is directly and indirectly caused by an activity or is accumulated over the life stages of a product" (Wiedmann and Minx, 2008 p.4). Whilst Wiedmann sought to limit applicability to $\mathrm{CO}_{2}$ he simultaneously acknowledged a carbon footprint is commonly used to refer to all greenhouse gases recognised in the Kyoto Protocol (UNFCCC, 1998). The contrast between 'directly and indirectly caused by' and 'accept varying degrees of responsibility for' is notable. Both highlight difficulties in emissions reporting. Exclusivity omits emissions that can be associated with more than one party for clarity and to avoid double-counting (Wiedmann \& Minx, 2008), but this leads to undercounting and unattributable emissions. 'Degree of responsibility' is equally problematic, opening the questions of who defines, and how to define, the degree and how this can be resolved without emissions being double-counted or conversely, again left unattributable. 
The current, inadequate resolution of an internationally adopted standard that lets each corporate decide aspects of the reporting coverage and emission calculations, makes comparisons problematic across corporations and time periods. Corporations in Annex 1 countries predominantly use the 'Greenhouse Gas Protocol's Corporate Accounting and Reporting Standard' ('GHG Protocol') (WBCSD and WRI, 2015; Wegener et al., 2019), as is the case in $\mathrm{NZ}^{6}$. Through the GHG Protocol a corporate determines responsibility scope through their choice in reporting boundaries. The GHG Protocol divides emissions into three scopes ${ }^{7}$ (WBCSD and WRI, 2011), which determine the mandatory reporting emission boundaries (Figure 1). Boundaries can be chosen on the basis of financial (equity share) or operational control (WBCSD and WRI, 2015). For NZ, with legal requirements for emitters to pay for emissions directly or through a mechanism, this can be a substantial financial decision, as the option must reflect whether it is legally mandatory to report (WBCSD and WRI, 2015). With operational control, a corporation "has the full authority to introduce and implement its operating policies at the operation" (WBCSD and WRI, 2015, p. 18). In practice this typically involves the corporation having a controlling interest (50\% or more) in a legal entity, which opens up the possibility of shared operational emission sources being created by multiple companies and owned by no-one (with each having less than $50 \%$ ), which is more likely in complex financial structures such as large corporations.

Estimating emissions can be complex, and the resource required to produce accurate emission information substantial, which may constrain corporate resources available to reduce emissions (Patchell, 2018; Wegener et al., 2019). Results vary significantly based upon the information available, estimation method, and temporal changes as knowledge improves in regard to both the tables for emission source estimation and tables for converting non-carbon greenhouse gases into tCO2e (metric tonnes $\mathrm{CO} 2$ equivalent) (IPCC, 2019; MfE, 2019e; WBCSD and WRI, 2016; Wegener et al., 2019). Calculation changes sometimes alter reported emissions dramatically (e.g. aviation fuel emission estimates). The GHG Protocol also allows choices in how GHG emission

\footnotetext{
${ }^{6}$ The ISO standard 14064-1 is consistent with the GHG Standard (ISO, 2008; Wegener, 2019) and in turn the NZ Government's departmental guide to calculating corporate emissions states its compatibility with both these standards (MfE, 2019c).

${ }^{7}$ Scope 1 and 2 emissions are mandatory and are directly created by the corporation, or indirectly through purchased energy, respectively. Many scope 3 emissions are optional, covering emissions before (upstream) or after (downstream) the corporation's activity.
}

Page | 22 
data is collected, estimated and reported, which can vary within, as well as across, corporates (WBCSD and WRI, 2015; Wegener et al., 2019). Therefore comparing emissions over time becomes meaningless unless the same conversion factors and estimation methods are used (Wegener et al., 2019).

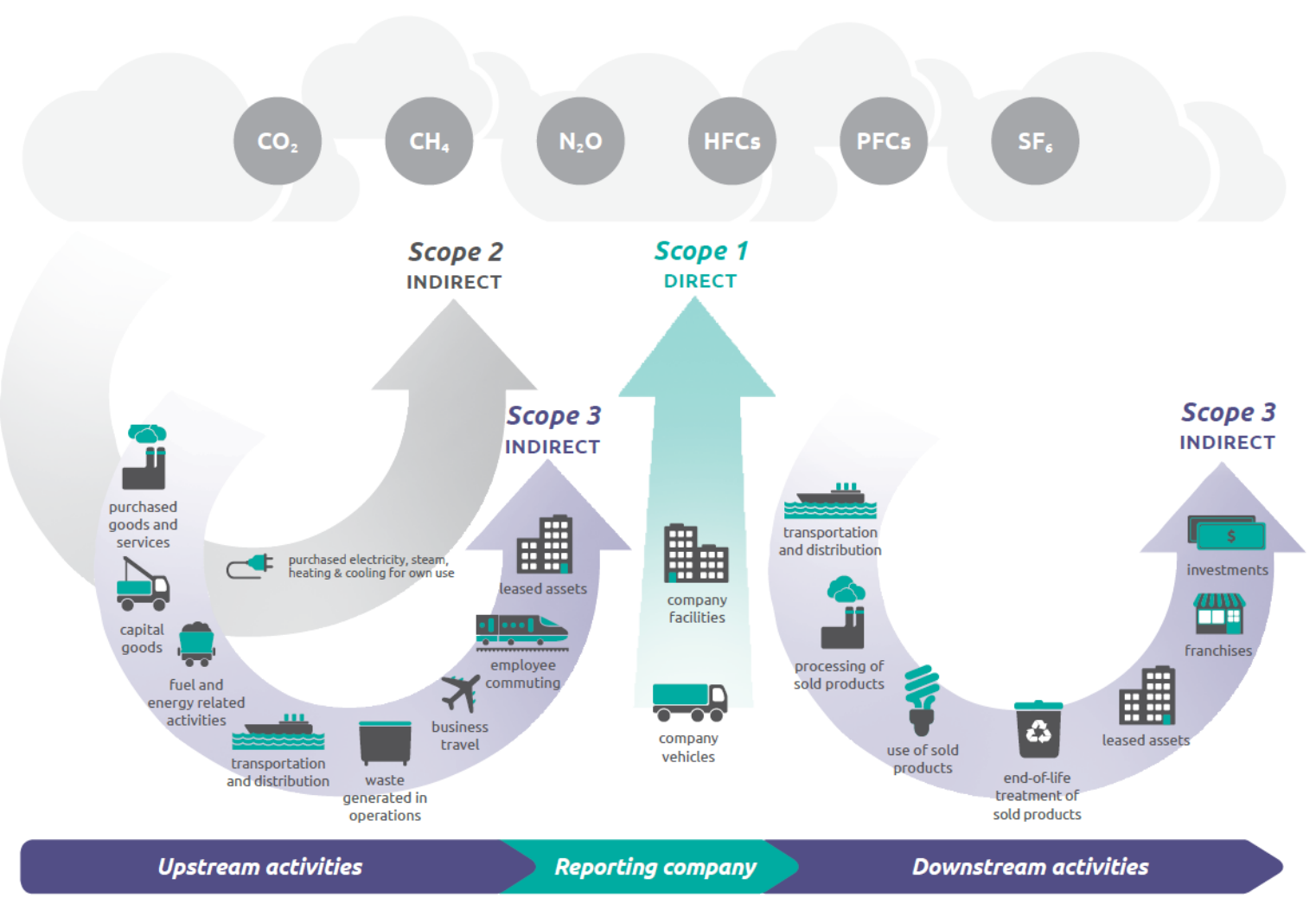

Figure 1. Overview of GHG Protocol scopes and emissions (Source: WBCSD and WRI, 2011, p. 5)

Scope 3 emissions are the largest category, and growing. By being treated separately, reporting reinforces isolated approaches rather than systemic change. Typically more than half of a company's emissions are generated indirectly by upstream suppliers (Huang et al., 2009). Corporates must disclose at least 95\% of all Scope 1 and 2 emissions; however many Scope 3 emissions are optional to report (WBCSD and WRI, 2015). As a consequence, Scope 3 reporting remains under-represented, inconsistent and of lower quality than Scope 1 and 2 (Blanco et al., 2016; Li et al., 2020; Patchell, 2018). Thus GHG Protocol based reporting is framing limits to climate responsibility and accountability, and appears to be reinforcing non-systemic thinking (Patchell, 2018; Walenta, 2018). 
Alternatives to the scope-based approach have not been given the same status, either in governance terms or in corporate actions. The GHG Protocol's strength appears to be assisting corporations identify emissions within their defined responsibility, not on identifying the largest sources of emissions. Lifecycle analysis clearly identifies where emissions are greatest in the process. In fact a lifecycle reporting framework, an internationally recognised standard since 2008 (BSI's PAS-2050) has existed within the GHG Protocol since 2011, providing a method to work out the footprint of a product or service (BIS, 2011). It is placed as complementary to the GHG Protocol (WBCSD and WRI, 2015) i.e. assisting the quantification of Scope 3 emission sources, rather than clarifying or impacting emission responsibilities. Corporate resources required to conduct emission lifecycle analysis across products, especially in the retail sector, are currently onerous (Walenta, 2018) although consistent with an appropriate knowledge of supply chains. In some cases such an analysis would take a coordinated shift in approach, such as the use of blockchain technology, to address (Tang \& Tang, 2019).

\section{Governance - Emission reduction targets}

As with reporting, target setting by companies is not enough to achieve ER (Dahlmann et al., 2019). Targets that entail very small reductions, are vague, dominated by offsets, are relative rather than absolute, include emissions avoided due to already choosing a lower emission option than available alternatives, or use a base year from which to calculate ER that is unusually high, or apply a sector target rather than business specific. All are used to minimise or nullify ER needed (Dahlmann 2019, Wright 2017). For instance, relative reduction targets such as those based upon emissions per unit produced, or emissions per unit of revenue, can mean that targets are met whilst total emissions for a company rise. To combat this the concept of 'science-based targets' (SBTs) was created: targets that are company-specific, ambitious, absolute or path-based, do not use offsets, and have a longer time frame (5+ years) so are more likely to result in real emissions reductions (Dahlmann et al., 2019; Science-Based Targets initiative, 2020). Targets to be recognised as sciencebased must align with a pathway to no more than $2^{\circ} \mathrm{C}$ but ideally $1.5^{\circ} \mathrm{C}$ warming in accordance with IPCC's 2018 Special report (IPCC, 2018), ignore offsets and include scope 3 emissions if they exceed $40 \%$ of the corporation's total emissions (SBTi, 2020, p. 29). 
Trying to measure whether a corporate is on a path to emissions reduction is relatively recent. The SBT initiative (SBTi) recognises that for certain sectors emissions may not decrease initially even when a company is taking actions to decrease emissions, due to technological ER dependencies (SBTi, 2020). Not all sectors have a SBT decarbonisation path option. A path approach also aligns with CDP's survey evolution: CDP now also place emphasis on understanding the path to emissions reduction (CDP, 2020a). Whilst an SBT approach is a definite improvement, there are concerns it may limit ambition in regard to $1.5^{\circ} \mathrm{C}$ warming, which for corporates from wealthier countries is not enough to compensate for those unable to fund decarbonisation (Watt, 2018), and an issue which has yet to be addressed (SBTi, 2020). Another difficulty is that previous ER achievements are not recognised (SBTi, 2020), so companies which have already substantially reduced emissions may feel penalised by being ahead of the curve, perhaps slowing adoption of SBT until other corporates have 'caught up'. There are also more general concerns that efforts to collect emission information to meet target and reporting standards' requirements could distract from, or be an unnecessary prerequisite to ER actions (Chrun et al., 2016).

\subsubsection{Carbon reduction / elimination}

Carbon reduction/elimination includes strategies and actions directly aimed at reducing or eliminating emissions produced before, during, and after a corporation provides goods and/or services (WBCSD and WRI, 2015). A useful way to conceptualise carbon reduction/elimination areas ${ }^{8}$ that directly impact a corporation's emissions is:

- what is offered and how many (product)

- internal processes (operations)

- what occurs before operations (upstream supply)

- what occurs after operations (downstream supply and use)

\footnotetext{
${ }^{8}$ See, for instance Cadez, S., \& Czerny, A. (2016). Climate change mitigation strategies in carbonintensive firms. Journal of Cleaner Production, 112, 4132-4143.

https://doi.org/https://doi.org/10.1016/j.jclepro.2015.07.099 Their 'climate change mitigation strategy framework' is similar excepting product offered is grouped in with other internal processes, which underplays its emissions importance.
}

Page $\mid 25$ 
The reason this split is useful is these areas can be considered quite distinct, involve different stakeholder blends, have differing potential levels of impact and challenges, the amount of control a corporate has over them varies, and (as explored shortly) are focussed on discretely, when corporates try to reduce emissions.

Carbon reduction / elimination outcomes highlight the impact of the GHG protocol approach. An emerging trend is that companies are reducing their Scope 1 and 2 (operational and product) emissions whilst simultaneously their Scope 3 (upstream/downstream) emissions grow (Walenta, 2018). Several explanations exist. As a corporate and its suppliers mature in emission reporting, the GHG inventory expands as more sources are identified, driving up reported scope 3 emissions (Blanco et al., 2016; Liu \& Yang, 2018; Tang \& Demeritt, 2018). This implies many corporates are still grappling with quantifying scope 3 emissions. Another possibility is strategic: actions reducing mandatory emissions are being prioritised over others, effectively reducing financial risk and overall visibility between emission responsibility and cause (Walenta, 2018).

Operational outcomes may diverge from an optimal ER strategy. Operational actions may increase emissions, or reduce emissions by less than if another action was chosen; or may occur due to conflicts with other strategies, priorities, business purpose, or a lack of perceived support (Qian \& Schaltegger, 2017). The most fundamental way for a corporate to reduce emissions is to alter the product(s) and the quantity, as this impacts all parts of the business. This can also be the most challenging. Some companies are calculating and reducing the product carbon footprint internationally, however this is not as frequent as companies focussing on operational efficiency (Penz \& Polsa, 2018). Volume reducing ER strategies are rare even amongst high emitters (Cadez \& Czerny, 2016). For instance emissions associated with NZ domestic air transportation has grown substantially due to increased passenger numbers driven by a growth strategy (Air NZ, 2020b), despite a $20 \%$ improvement in Air NZ's fleet fuel efficiency over 10 years (NZ Government, 2016, p. 20). Reducing or varying production may be limited by external factors, such as long-term contracts or legislation. Less problematic is improving operational efficiency, as this usually reduces costs as well as emissions: the 'win-win'/shared value scenario (Porter \& Kramer, 2011). A significant emissions source for many Page $\mid 26$ 
businesses is energy use (Ritchie \& Roser, 2020). As energy use is cut, so does associated cost. For high-energy use corporates, as the potential savings are far greater, a competitive advantage can be gained (Porter \& Kramer, 2011). Many energy efficiency changes also require no reflection on business purpose or broader operational processes, hence avoiding conflict with other business objectives. However, capital expenditure considerations of more expensive ER options, such as the initial cost of switching to an electric vehicle fleet, or boiler modification/replacement, may prevent or significantly delay the ER option, despite possible ongoing cost savings.

Supply alterations can drastically alter the emissions or shift responsibility. For instance the majority of NZ's electricity is from hydropower, however as hydropower supply fluctuates so too does the associated emissions, as a coal-fired power station is used to avoid any shortfall (Neilson, 2021). Outsourcing, where an external company delivers formerly internal operations, moves emissions to being a supplier's responsibility, which may result in associated ER opportunities being deprioritised (Patchell, 2018). Downstream changes involving lower emission use/recycling/reuse/repurposing of products can receive less attention, with statistics and existing product design illustrating we are a long way from circular product systems (Haffmans et al., 2018).

\subsubsection{Carbon compensation}

Studies indicate carbon compensation is best considered separate to carbon reduction due to its strategic importance, as corporates may have activity in this area and no others, and its presence can be independent of other strategic areas. There are two types of carbon compensation - offsetting and balancing. Carbon offsetting involves a business investing in a scheme external to the company such as carbon sequestration or ER initiative, allowing a company to claim a negative amount of carbon - the amount of carbon estimated to be sequestered or reduced due to the external activity. 'Balancing' is internal offsetting, i.e. instead of an external investment the business itself performs an action that will absorb carbon that has no direct link to operational emissions but will absorb or cause a future reduction in emissions more generally. Carbon offsets were introduced in 1995 to lower the cost of climate change mitigation (UNFCCC, 1998). The theory behind the Kyoto Protocol 'offset' flexibility 
mechanism is that wealthier countries may pay for carbon-reducing projects in poorer countries to help global decarbonisation, with the Clean Development Mechanism set up to facilitate this (Cames et al., 2016).

Offsetting encompasses a broad range of possible techniques, technologies and outcomes that are often vulnerable to over-claiming or under-delivery on estimated carbon reductions (Lovell 2010). Estimates place additionality - offsets that would not have happened otherwise - as much less than offsets claimed: " $73 \%$ of the potential 2013-2020 Certified Emissions Reduction (CER) supply have a low likelihood that emission reductions are additional and are not over-estimated." (Cames et al., 2016, p. 11). The biggest problem with offsetting is that it weakens the incentive for an entity (a corporate or even a country) to find creative ways to reduce emissions. Offsetting is also vulnerable to failure due to the long timeframes: there is a need for policy stability to ensure carbon offset projects are not abandoned; project based offsetting by implication has a definite timespan of support and focus; carbon unit pricing needs to be and remain sufficient to support offsetting; technological advances in ER can be overstated due to knock-on impacts in consumer behaviour; and offsets may be double-counted (Cames et al., 2016; Campbell et al., 2018; Gillenwater \& Seres, 2011; Mason \& Plantinga, 2013)). Unsurprisingly, the value of corporate ER progress involving offsets has been brought into question.

\subsubsection{Carbon positioning}

Numerous studies have indicated that positioning of carbon emissions can be part of a corporate carbon strategy (e.g. Damert et al., 2017; Greenberg et al., 2011). Positioning involves communications, whose purpose includes to position stakeholders' emission expectations and perceptions so the corporate carbon strategies and activity are viewed as favourably as possible (Greenberg et al., 2011; Grunig \& Hunt, 1984). Examples include press releases, reports, and lobbying government to influence emission policies. Interactions with external entities are an important part of the corporate carbon strategy (Damert et al., 2017; Okereke \& Russel, 2010; Paul et al., 2017; Yunus et al., 2016), to such an extent that arguably these entities' activity must be at least considered in conjunction with the corporate's activity (Paul et al., 2017). 


\section{Public positioning}

External communications can vary from one-way promotional content through to a sustained two-way dialogue (Grunig \& Hunt, 1984). Corporate communications may frame ER responsibilities as mutually advantageous to the environment and corporate: increasing business opportunities and reducing operating costs and emissions (Cadez et al., 2019; Ihlen, 2009). This framing is also supported in some academic literature, notably Porter and Kramer (2006), and may be realised in corporate actions (Penz \& Polsa, 2018; Porter \& Kramer, 2011), although they may not adhere to this pattern (Penz \& Polsa, 2018). Accordingly, business growth or profit narratives may remain unchallenged (Ferguson, 2016; Ihlen, 2009). Some corporates adopt sustainability language (Dobers \& Springett, 2010), or appearances of being environmentally sustainable without any shift occurring (Bonn \& Fishe, 2011; Gray \& Milne, 2002; Roulet \& Touboul, 2015). Relatively high mentions of environmental terms can indicate either high activity, or rhetorical aims to appear environmentally supportive (Ihlen, 2009). Reports and media releases may differ from internal or lobbying content, especially for high emitters (Supran \& Oreskes, 2017). The extent to which the public can generate ER progress in corporates is unclear: Hyatt and Berente (2017) found evidence that internal stakeholders could drive commitments to change whereas external stakeholders thought the changes appeared symbolic; however a study more focussed on this aspect found the extent to which external stakeholder pressure was effective related to the depth of corporate commitment, with no significant impact at lower levels of pressure (Cadez et al., 2019). Very few studies have been done on the impact of comparing general signatories to pledges to reduce emissions (Delmas \& Montes-Sancho, 2010).

\section{Government lobbying}

Central government policy and legislation is recognised as a powerful tool in supporting ER, but it is also open to business lobbying in its scope, formation, and interpretation in efforts to slow or avoid ER, or make it financially more attractive for corporates. Aragòn-Correa et al.'s (2019) review indicates government intervention is effective and seen as an essential factor in corporations achieving significant ER. The United Kingdom has had climate mitigation legislation in place for over a decade (Climate Change Act, 2008), which is providing an effective framework for national 
emission policies (Fankhauser et al., 2018). Despite an ineffectual Emissions Trading Scheme being in place since 2008 (MfE, 2019c; Richter \& Chambers, 2014), NZ has recently enacted its own framework for climate change policy creation ("Climate Change Response (Zero Carbon) Amendment Act," 2019). However, corporates' ability to influence a government's climate mitigation policies is also evident (Brulle, 2018; Bui \& Houqe, 2015; Greenberg et al., 2011).

Policy in NZ is open to influence from advocacy sources that may supplant expert advice both in forming and exercising policy (Bui \& Houqe, 2015; Morris, 2011; OPMSAC, 2013). The NZ ETS's slowness to come into effect, protracted exclusion (until 2025, at time of writing) of the agricultural sector, generous allocation of ETS units, lack (until the latest amendment takes effect) of a cap, a limit to the number of trading units, and complexity of the scheme, may all be seen as examples of corporate influence (Mitchell, 2020; Richter \& Chambers, 2014). These influences made predicting policy outcomes difficult and added to a lack of clear policy direction (OPMSAC, 2013). It is ironic then, that one of the most stated barriers by corporates for ER, is a lack of policy certainty in the long term (MfE, 2019c; Okereke, 2007). Without certainty the ability for a corporate to make long-term (10+ years) decisions is compromised, due to the difficulty in being able to place a value on decarbonising, or knowing policy conditions so as to remain competitive against other similar organisations (MfE, 2019c; Okereke, 2007).

Corporate support for, or resistance to, policy directions and legislation that promote rapid climate change mitigation can help identify a corporate's 'true' position on ER. In shaping policy, the NZ government often asks for public submissions on direction and content (MfE, 2019b). From efforts to alter the Emission Trading Scheme, it is known NZ corporates' lobbying activity is industry dependent, and increases with company size and the more lobby groups a corporate belongs to (Bui \& Houqe, 2015). Delmas et al. (2016). This illustrates that lobbying intensifies at the extremes - where ER policies are most advantageous or disadvantageous for a company. Accordingly, the Carbon Disclosure Project asks about "activities that could either directly or indirectly influence public policy" to ascertain the congruency of exercised corporate influence with their decarbonisation position and targets (CDP, 2020a). 


\subsection{Determining emission reduction progress}

Determining when a corporate has moved to a state that is more advanced in terms of realised or future ER is not simple. The variety of factors aiding or hindering progress identified in the literature indicate the variety of processes, actors and internal and external factors that can impact whether ER occurs. Whilst reported emissions give a sense of progress, previously mentioned reservations about interpretation of reported figures are important, along with a need to understand other (contextual) factors, for instance strategic or infrastructural changes influencing where associated ER may yet to be realised. Despite the complexity, ER and sustainability progress models are numerous; for several collations of models see Gunarathne and Lee (2019) and Landrum (2018).

Business change undertaken to reduce emissions can reasonably be categorised into stages to illuminate any progress. Most categorisations of corporate environmental management are 'progressive' -- the framework implies changes can be represented by a progression through identifiable stages (Garcés-Ayerbe et al., 2016). Whilst these stages have been re-labelled and subdivided to suit differing foci or contexts (Landrum, 2018), the concepts underlying the stages of corporate environmental activity advancement have stood the test of time. Carroll (1979) labelled these stages as reactive, defensive, accommodative, and proactive. These characterise the corporate as moving from resistance to admitting environmental issues, to admission but taking minimal action, through to beginning to address the issue, and then lastly making more active efforts to mitigate than comparable companies. Many later models echo this progression (Benn et al., 2014; Garcés-Ayerbe et al., 2016; Jeswani et al., 2008; Kolk \& Pinkse, 2005; Ormazabal et al., 2017; Ormazabal \& Sarriegi, 2012).

Frameworks from different research areas and time periods have different starting or end stages (Landrum, 2018). More recent frameworks focus more on the accommodative and proactive stages, perhaps in recognition that corporate environmental responsibility has become more common, and the climate change crisis has moved on dramatically. Benn et al. (2014) categorise whether strategic centring on sustainability is present and whether that has extended into innovation by corporates; similarly Garcés-Ayerbe et al. (2016) find that high ER activity and high 
activity through innovation are distinct groups. Despite this increased focus on the latter stages, corporate-centred or data-constructed models exclude more advanced proactivity that corporates could exhibit. Importantly, Landrum (2018) recognises that 'regenerative' and 'coevolutionary' stages, which realign business focus to prioritise environmental needs over other areas, are not previously recognised in the corporate frameworks, let alone studied (see Table 1). With this omission, the profit and growth narratives are again not challenged (Landrum, 2018), precluding acknowledgment of the systemic nature of the change required to fully address corporate environmental impacts. Approaches need to extend beyond the 'business-centred' sustainability paradigm (Bjørn et al., 2018; Dyllick \& Muff, 2016) for the necessary reductions to occur. This required paradigm shift necessitates an ethical shift in business purpose (de los Reyes et al., 2017).

\begin{tabular}{|c|c|c|c|c|c|c|}
\hline $\begin{array}{l}\text { Stage } \\
\text { Landrum (2018) }\end{array}$ & Non-participatory & Compliance & Business-centred & Systemic & Regenerative & Coevolutionary \\
\hline $\begin{array}{l}\text { Business goal } \\
\text { Landrum (2018) }\end{array}$ & Business-oriented & $\begin{array}{l}\text { Business- } \\
\text { oriented }\end{array}$ & Business-oriented & $\begin{array}{l}\text { Business- } \\
\text { oriented }\end{array}$ & Ecology-oriented & $\begin{array}{l}\text { Ecology- } \\
\text { oriented }\end{array}$ \\
\hline $\begin{array}{l}\text { CSR equivalent } \\
\text { Carroll (1979) }\end{array}$ & reactive & defensive & accommodative & proactive & & \\
\hline $\begin{array}{l}\text { Growth } \\
\text { Landrum (2018) }\end{array}$ & $\begin{array}{l}\text { - Pursuit of } \\
\text { production, } \\
\text { consumption, and } \\
\text { growth }\end{array}$ & $\begin{array}{l}\text { - Pursuit of } \\
\text { production, } \\
\text { consumption, } \\
\text { and growth }\end{array}$ & $\begin{array}{l}\text { - Pursuit of } \\
\text { production, } \\
\text { consumption, and } \\
\text { growth }\end{array}$ & $\begin{array}{l}\text { - Pursuit of } \\
\text { production, } \\
\text { consumption, } \\
\text { and growth }\end{array}$ & $\begin{array}{l}\text { - Qualitative } \\
\text { development } \\
\text { without } \\
\text { production, } \\
\text { consumption, and } \\
\text { growth } \\
\text { - Steady-state } \\
\text { growth }\end{array}$ & $\begin{array}{l}\text { - No growth in } \\
\text { production } \\
\text { or } \\
\text { consumption }\end{array}$ \\
\hline $\begin{array}{l}\text { Sustainability } \\
\text { concerns } \\
\text { Landrum (2018) }\end{array}$ & $\begin{array}{l}\text { - Resistant to any } \\
\text { sustainability } \\
\text { responsibility }\end{array}$ & $\begin{array}{l}\text { - Externally } \\
\text { enforced or } \\
\text { regulated } \\
\text { activities } \\
\text { - Defensive } \\
\text { actions } \\
\text { regarding } \\
\text { economic, } \\
\text { environmental, } \\
\text { or } \\
\text { social } \\
\text { concerns }\end{array}$ & $\begin{array}{l}\text { - "Business case" is } \\
\text { the motivation and } \\
\text { measure of success } \\
\text { - Adoption and } \\
\text { internal enforcement } \\
\text { of activities } \\
\text { - Incremental } \\
\text { improvements to } \\
\text { business-as-usual } \\
\text { - May focus on one or } \\
\text { more realms of } \\
\text { sustainability } \\
\text { (economic, } \\
\text { environmental, social) }\end{array}$ & $\begin{array}{l}\text { - Integrates } \\
\text { three realms of } \\
\text { sustainability } \\
\text { (economic, } \\
\text { environmental, } \\
\text { social) } \\
\text { - Work with } \\
\text { other human } \\
\text { systems }\end{array}$ & $\begin{array}{l}\text { - Integrates three } \\
\text { realms of } \\
\text { sustainability } \\
\text { (economic, } \\
\text { environmental, } \\
\text { social) } \\
\text { - Work with } \\
\text { human and non- } \\
\text { human } \\
\text { systems }\end{array}$ & $\begin{array}{l}\text { - Work in } \\
\text { balance with } \\
\text { other systems } \\
\text { - Contribute to } \\
\text { flourishing of } \\
\text { other systems }\end{array}$ \\
\hline
\end{tabular}

Table 1: Stages of Corporate sustainability (Source: adapted version of Landrum (2018) Table 4.)

Progression through the stages may be non-linear and vary depending upon the business aspect under consideration. Different areas of the business for instance may be at different stages. Marketing and sales departments traditionally have low 
engagement with sustainability (Hörisch \& Windolph, 2014). Even if this were not the case, none of the above necessitates that corporates will tidily or systematically progress through the stages. Internal changes in focus, leadership, or external changes in societal values, government policy, market conditions and the physical environment can impact progress unevenly (Benn et al., 2014; Garcés-Ayerbe et al., 2016; Jeswani et al., 2008; Lee, 2012). One corporate area or more may regress, due to changes in leadership, strategy or shifts in responsibility boundaries for major emission sources due to outsourcing (Jeswani et al., 2008; Lee, 2012). It is common that areas where least effort (least cost and least change to existing operations) is required are prioritised (Lee, 2012). Corporates may take different actions or similar actions in a different order. Different industries have differing emission sources and proportions, and a corporate in one industry may use a supplier for an emission intensive process that another corporate in that industry does not (Lee, 2012). Accordingly, various progressive models point out the possible non-linear processes of change - where relapse into higher emitting states may occur or the process of change generates inefficiencies (Ormazabal et al., 2017) or unexpected opportunities during the transition.

\subsection{COVID-19 Effects on corporate decarbonisation}

Both the NZ Climate Change Commission and the climate change minister Hon. James Shaw see COVID economic stimulus as a chance to invest in moving towards a lower-emissions economy (Climate Change Commission, 2020; Shaw, 2020a), thus aiding corporate ER by providing infrastructure aligned with lower energy and transportation related emissions. The international and NZ government responses, however, have not prioritised decarbonisation initiatives. The NZ government's response since COVID's NZ peak in March/April 2020 until this study's end in 31 December 2020 has been mixed in regard to aligning with ER. The NZ government's immediate mid-2020 budget response to COVID largely reaffirmed the business sector status quo, with the COVID recovery package did not target lowering emissions (Hall, 2020; NZ Government, 2020c), mirroring recovery packages elsewhere (Laville, 2021). It is estimated that globally only $2 \%$ of the USD 16 trillion stimulus spend was on low or zero carbon energy initiatives (IEA, 2021). Before NZ's COVID peak (March/April 2020) the government committed support for numerous initiatives to 
achieve ER (NZ Government, 2019). After the peak, the NZ government made various changes to the NZ ETS scheme, the legislated dairy co-op scheme that Fonterra manages, and made climate change financial risk reporting compulsory (NZ Government, 2020a; Shaw, 2020b, 2020c), though these were not linked to any COVID recovery package or strategy. Given the recency of these changes it is too early to ascertain their impact; however relevant submissions from the CLC founders have largely been supportive of the policy framework and the increased certainty of the NZ ETS unit price.

Hopes of COVID altering, transformational, business strategies towards a low-carbon outcome appear optimistic. There has been discussion that COVID enforced disruptions to 'business-as-usual' would stimulate businesses to envisage a path to zero emissions, rather than a return to pre-COVID behaviour (e.g. Prideaux et al., 2020; Rosenbloom \& Markard, 2020). As Rosenbloom (2020) observes, COVID disruption has markedly increased remote working, online meetings and purchases, and reduced air travel, and presented an opportunity to consider addressing higheremission intensity practices, such as using coal-fired boilers. Prideaux (2020) highlights the opportunity to re-visit tourism strategies to align with the ER needed to become carbon-neutral. In contrast, the International Air Transport Association (IATA) has urged that ER targets as part of the carbon offsetting and reduction scheme for international aviation (CORSIA) be slackened due to the airline industry being under financial duress (Topham \& Harvey, 2020). Whether COVID will alter the paths New Zealand businesses are on towards accelerating ER remains to be seen, but at this stage it appears unlikely. 


\section{Research Methodology}

As indicated, there is more to determining carbon reduction progress than looking at changes in reported carbon emissions. Changes in corporate communications, disclosed actions, emissions, and intentions all contribute to understanding carbon ER 'paths', as reflected by the research question and sub-questions (Figure 2). Paths comparisons over time across these factors to illuminate changes and their sequence - provide an understanding of consistency, trends, commonalities, and differences within and across the selected corporates. Given the COVID-19 disruptions impacting upon NZ businesses (Gemmell, 2020; Gluckman \& Bardsley, 2020; Lacina, 2020; Shaw, 2020a), COVID-19 effects on recent and intended corporate paths are also included in this study.

What are the carbon emission reduction paths since 2010 of publicly pro-mitigation $\mathrm{New}$ Zealand corporations? (RQ)
What are the disclosed carbon emissions and related actions since 2010 of NZ's corporations that were founding signatories of the Climate Leaders Coalition (CLC)? (SQ1)

\begin{tabular}{l}
$\begin{array}{l}\text { How have their public communications regarding } \\
\text { carbon emissions changed since 2010? (SQ2) }\end{array}$ \\
$\begin{array}{l}\text { What have been their public positions regarding } \\
\text { government consultations involving climate } \\
\text { mitigation since 2010? (SQ3) }\end{array}$ \\
$\begin{array}{l}\text { Considering the lessons of COVID-19, what does } \\
\text { each business consider their future emission } \\
\text { targets to be and their dependencies in achieving } \\
\text { this? (SQ4) }\end{array}$ \\
$\begin{array}{l}\text { Does being a member of the founding CLC appear } \\
\text { to have any effect on their behaviour? (SQ5) }\end{array}$ \\
\hline
\end{tabular}

Figure 2: Research question and sub-questions

\subsection{Stakeholder theory framework}

The research question's focus was on understanding corporate change. As stakeholders include internal and external agents trying to interpret and sometimes influence change (Baumgartner, 2014; Harrison \& Freeman, 1999), stakeholder theory was a useful lens to explore the research question. Stakeholder theory centres on the Page | 35 
potentially conflicting objectives of stakeholders: the internal or external entities that have an effect on or are affected by corporate actions, directly or indirectly (Cadez et al., 2019; Donaldson \& Preston, 1995). Stakeholder theory also recognises that corporate material - reports, media releases, parliamentary submissions, and disclosed actions, are communications to corporate stakeholders intended to influence stakeholder opinion. A corporate is operating within an interdependent system involving other stakeholders like central government, consumers, and other businesses. Key considerations of other dominant theories, namely legitimacy and institutionalism, could also coherently be considered within the stakeholder theory framework.

\subsection{Research Design}

The research design applied to this study is outlined below.

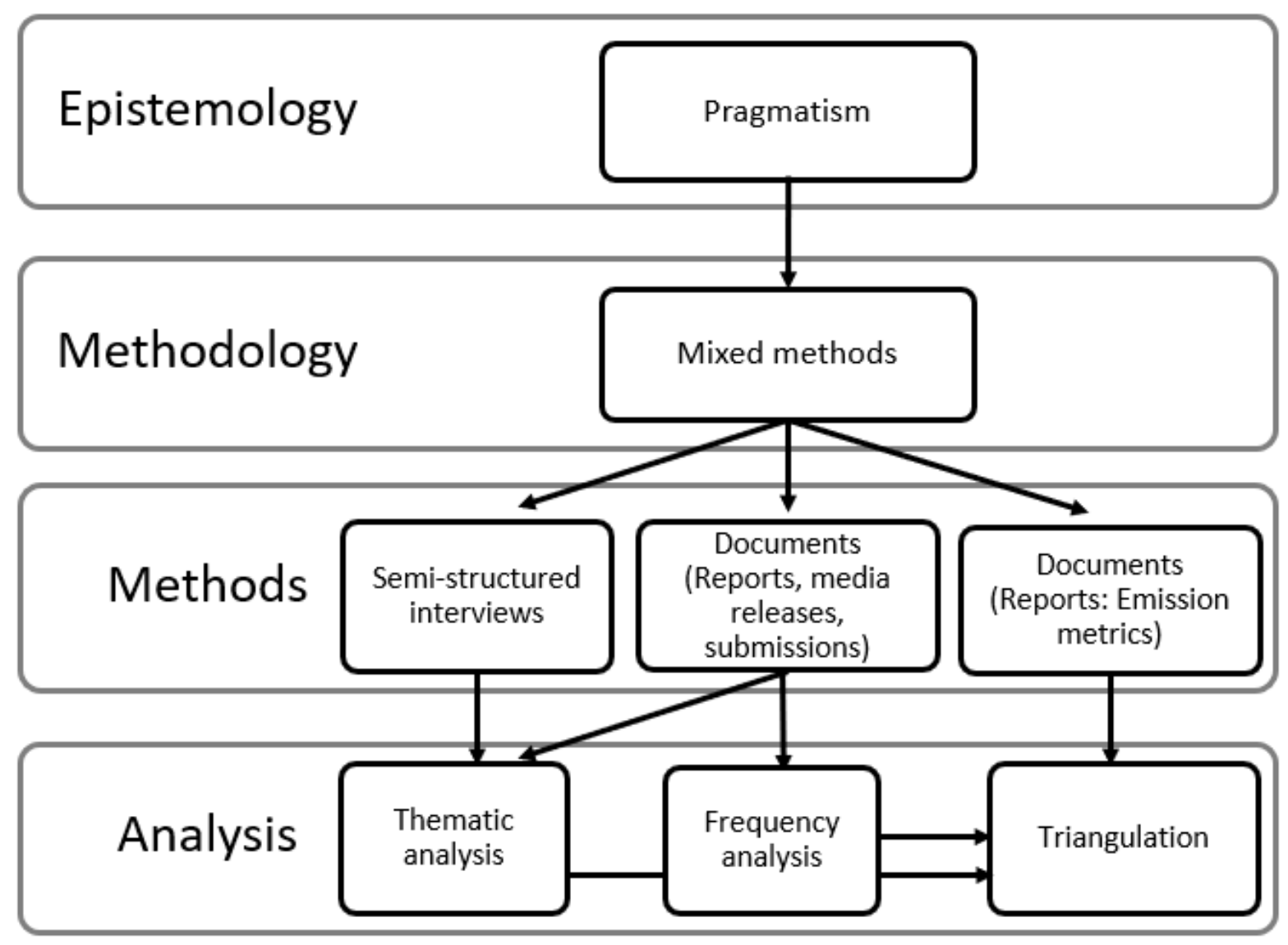

Figure 3: Research Design

All aspects of the research design were chosen considering existing studies and their merits. Post-positivist quantitative studies focussing on reported emissions have the 
advantage of identifying general changes, being able to be applied at scale and readily aiding meta-analysis (Skjott Linneberg \& Korsgaard, 2019). However, they can give a false impression of accuracy, given what is known about emission reporting complexities such as changing boundaries, base years and estimations (Dragomir, 2012; Wegener et al., 2019). Purely qualitative case studies, whilst allowing rich insight into corporate behaviour, are harder to transfer or generalise to other corporates (Skjott Linneberg \& Korsgaard, 2019). Differing corporate conditions due to everchanging geo- and socio-political factors add to the difficulty of generalising findings, and this is likely to increase given further changes in climatic patterns (IPCC, 2021; Swiss Re Institute, 2021). Therefore, a design that focuses on qualitative aspects whilst being mindful of the ability to apply any findings elsewhere has been chosen.

\subsubsection{Epistemological Position}

A Pragmatist perspective was taken (Patton, 2014), supportive of the stakeholder framework. Pragmatism recognises that there are differing views possible in problematic situations (Geiselhart, 2020), such as identifying a corporate's ER progress. Pragmatists also recognise that commonly shared perspectives are useful for research purposes (Patton, 2014). This allowed recognition that whilst there can be contrasting stakeholder views as to the role of corporates, their responsibilities and what the progress within that responsibility constitutes, there are common corporate and cultural concepts that are 'in play' (Breeze, 2013).

A competing theory, positivism, seeks to identify relationships through reducing behaviours and outcomes to quantitative variables (Creswell, 2014), a poor fit for the current study given the importance of understanding how corporate frames -- a qualitative attribute -- determine the perceived limits of their ER responsibilities. Postpositivism recognises that both qualitative and quantitative methods have a role, but still generally holds to the concept of getting closer to a 'truth', be it a shared subjective truth or an underlying reality (Creswell, 2015; Russ-Eft et al., 2017). In contrast, pragmatism uses both qualitative and quantitative methods for the most useful way to consider corporate ER progress without claiming a truth, for potential reapplication (Russ-Eft et al., 2017). 


\subsubsection{Mixed Method Inquiry strategy}

When studying complex systems such as corporates and their strategic behaviour it is not realistic to analyse all factors (Köhler et al., 2019; Vergragt et al., 2014). A mixed methods approach was considered the best fit (Figure 3), using thematic analysis as the central method (Patton, 2014), aided by quantitative analysis. Using multiple methods and data sources enabled robust analysis as findings were triangulated findings were compared for conflicts and the source with the most insight or relevance dominated interpretation (Patton, 1999).

Thematic analysis that is mindful of communication intent was considered a robust analytical approach to identify and analyse text used to construct frames without undue risk of subjectivity, if existent themes and the possibility of emergent themes are acknowledged (Van Gorp, 2010). Reports and other communications can reasonably be considered a public relations exercise (Grunig \& Hunt, 1984), offering potentially tendentious representations of corporate behaviour. Analysing themes avoided the limitations of analysing the surface meaning of words without contextualising their purpose (Mishler, 1986).

Thematic framing constructs a worldview and places the corporate as an actor with a certain relationship to other actors (e.g. the government) (Lefsrud \& Meyer, 2012; Van Gorp, 2010; Wright \& Nyberg, 2017). Major qualitative differences may reflect different sectoral contexts and factors, such as variable impacts of the enforced COVID-19 temporary business closures and New Zealand's international border restrictions (NZ Government, 2020a). Accordingly, for this research, thematic analysis also includes theme combinations and their contextual use, thus recognising context whilst maintaining analysis replicability and potential transferability.

To aid in minimising subjectivity and increasing robustness, triangulation using quantitative analysis was also conducted (Creswell, 2014). Quantitative analysis included key word frequency counts and rankings. This provided a numerical perspective for comparing theme emphasis and changes as well as the qualitative findings. 


\subsection{Research Method}

This section outlines the mixed methods approach undertaken. The rationale for the corporates' selection process is detailed along with the key decisions made during the interview process, secondary data collection and a filtering process. The construction and use of the analytical framework determining how ER progress is determined will then be discussed, and how this aligns with the interview design and secondary data collection.

\subsubsection{Corporate selection}

To gain the most benefit from the study, the thirteen corporations that formed and cosigned the founding statement for the Climate Leaders Coalition (CLC, n.d.-b) were chosen. (See the start of section 6 for a list of the founding CLC members). Being founding signatories, they are the most likely to have acted upon the pledge (Delmas \& Montes-Sancho, 2010). The corporations vary by industry sector, emissions volume, national/multinational operating presence, and ownership model (shareholder, cooperative, partly/fully local/central government owned), so any path commonalities could be considered more likely to be applicable to other corporates. Differences can also help identify any cross-sector relevancies and limitations. Each corporate is amongst the largest, if not the largest, corporation in their NZ industry sector, ensuring the businesses were of a scale to be comparable internationally.

The NZ focus of the study was also seen as advantageous as multiple factors may have made change more likely. When the pledge was signed, NZ corporate carbon ER lagged well behind those of numerous other western countries (MfE, 2018b), while public support for climate action was high (Colmar Brunton, 2018), adding impetus for change. Also, until recently government legislation and related policy had provided little reason to reduce emissions (Leining et al., 2020), meaning that corporate choices were generally voluntary.

The corporations chosen were defined as the parent legal entity within NZ, with the corporate being the associated people, activities and responsibilities based upon the companies within this definition. A country specific focus was chosen because findings across corporates could be more reasonably compared, based on the same legislative policy and reporting context. Most stakeholders are all consistent in the national 
context. For multinationals, the influence of the global parent company was included only if influential; otherwise only the governance, strategies and actions of the NZ entity were considered. Where the NZ entity is the global head, then activities outside NZ were only considered where relevant or communicated in the secondary data: such as upstream (supplier) and downstream (business and consumer) emission activities, and movement of an emitting operation from NZ to overseas.

\subsubsection{Data collection}

The diversity of indicators of corporate change is reflected in the data collection. The primary data sought were interviews with corporate staff managing ER. Documentary evidence also was collected from periodic (typically annual) reports, government submissions, and media releases related to climate change mitigation, and emission reports relating to the period 1 January 2010 to 31 December 2020.

\section{Primary data}

Semi-structured interviews were conducted with a member of the sustainability/environment team who was involved with carbon ER at six corporations. Additionally two indicated they did not wish to participate due to staff time pressures and five did not respond. Interview consent at both corporate and individual level was obtained. Interviewees varied by industry sector, emission volumes from low to high intensity, and Covid impact and accordingly gave a reasonable representation of the range of CLC founders. Given the disparateness of the thirteen CLC founders it was appreciated that certain industry sectors will only be represented through secondary data. Given the richness of secondary data this was not seen as a reason to exclude non-interviewed corporations from the analysis and helps preserve the confidentiality of interviewees. Also, this allowed the interview focus to be on changes which interviewees saw as important in their ER progress, rather than an attempt to provide information on all reduction actions taken. Staff members interviewed varied in seniority or duration in position. In two cases due to their recency of appointment or their organisational responsibilities the interviewees could not comprehensively answer all questions. However, these interviewees signposted gaps in knowledge, and secondary data was subsequently used to check facts or fill in gaps, related to details of actions rather than strategy. 
A semi-structured interview format containing 10 questions was used (Appendix 3). The semi-structured approach supported the exploratory nature of the study and the need to ask open-ended questions and permit specific follow-up questions based upon what is most compelling and useful (Patton, 2015). As the questions indicate, the interviews sought to illuminate the impact of CLC founder involvement and COVID, and enablers and barriers to progress, in accordance with the research question, subquestions and literature findings. Interviews varied between just over 30 minutes to just over an hour.

As many of the questions had interrelated aspects it was typical for answers to overlap to other questions, so that question order and style of asking some of the main questions would change to maintain interview cohesion, depending upon aspects already responded to. To allow for this inconsistency, interviewees were asked to cycle back to questions where briefer answers were given, and if time permitted explore any areas where they wished to add more detail (Mishler, 1991). All interviews were recorded and transcribed with prior consent. Interviews were recorded using a mobile phone-based recording application.

\section{Documentary evidence}

A consistent process was used to locate and identify relevant content for all corporations. The relevant locations within each corporate website were sought and used for identifying media releases, relevant periodic reports, and emission figures (which may or may not reside in a separate report). Where coverage was incomplete specific web searches were done for missing reports, and searches using the internet archive website http://web.archive.org/. For absent older media releases with no historic access available, enquiries were made to several corporates regarding accessing archives; however, in some cases this was not fruitful. Appendices 4,5,7 and 8 outline documentary evidence coverage.

Corporate responses to government or government entities' legislative bills and reviews open to public submissions that directly deal with emissions or fuel sources were also included ${ }^{9}$. Whilst the complex interdependencies of changing corporate emissions is noted, corporate responses to submission opportunities that might

\footnotetext{
${ }^{9}$ For a complete list of included submissions, see Appendix 4.
} 
indirectly impact NZ's corporate carbon emission paths are excluded. The reasoning is that the study's scope is focused on evaluating the corporates' support (or not) for policy directly aimed at reducing corporate carbon emissions, rather than policies that were more general, such as transport and urban development planning. Submissions by associations or similar bodies were not included as they did not add coverage nor applicable insight. Three corporates who had little to no submissions - NZ Postal Group Limited, Spark NZ and Ports of Auckland Limited (PoAL) - could not be considered represented by any alternative submitting organisations. For instance although Auckland Council made numerous submissions and owns PoAL, it is not controlled by the Council nor were council submissions claiming to represent PoAL (Auckland Council, 2018; PoAL, 2021). Similarly, associations represent multiple corporates, so extrapolating an insight from an association's submission to a specific corporate would be problematic.

\subsubsection{Analysis framework}

To deal with the complex multi-faceted nature of determining corporate change that directly or indirectly progresses ER, an analysis framework was constructed based upon the literature. Eight progress stages were identified in a corporate ER stages framework (Table 2). To support this main framework an ER strategy and action classification (Figure 4) was also constructed to aid with evaluating the progression of ER strategies and actions within the business.

\section{Progress Stages}

To understand progress means understanding ER changes in the wider sense, including any limiting business approaches or positioning as well as more direct strategies and actions. A sustainability framework, rather than a carbon ER framework, was chosen as the base structure, to address the paradox of increasing corporate emissions against the rhetorical concern for the environment and efforts to reduce those emissions. Landrum's (2018) stages of corporate sustainability framework was the main source, with eight rather than six stages. This framework recognises that ER approaches need to extend beyond the 'business-centred' sustainability paradigm (Dyllick \& Muff, 2016). The same framework can be used across industry sectors as similar patterns exist (Garcés-Ayerbe et al., 2016; Gunarathne \& Lee, 2019; Ormazabal et al., 2017).

Page $\mid 42$ 
The first two stages correspond directly to Landrum's framework. Landrum's 'business-centred' stage was subdivided into three because progress at this juncture is of particular interest, and it appears as multiple stages in multiple alternative carbon and sustainability strategy models (Benn et al., 2014; Garcés-Ayerbe et al., 2016; Jeswani et al., 2008; Lee, 2012). 'Integrated', named the 'strategic proactivity' stage by Benn et al. (2014), can be furthered through being 'Saturated' - exhausting all possibilities within the current business model and technology - which doesn't require a transformative process shift (Garcés-Ayerbe et al., 2016). 'Transformative' change (called 'Systemic' in Landrum's model) is then needed to progress - where innovation drives decarbonisation - though still within a non-holistic paradigm of carbon emission ownership, so carbon may still be emitted in some parts of the product/service lifecycle. In this context transformative change is limited to the corporate offering, rather than a broader change in corporate purpose. The final two stages, 'Regenerative' and 'Coevolutionary', are shown as detailed by Landrum (2018) and exist outside the corporate growth model. It was recognised in consolidating this framework across these sources that progress may be non-linear (Ormazabal et al., 2017), and that a corporate may not be in the same progress stage across all business facets or locations.

\begin{tabular}{|c|c|c|c|c|c|}
\hline Stage & $\begin{array}{c}\text { Emissions } \\
\text { management }\end{array}$ & $\begin{array}{l}\text { Business } \\
\text { approach } \\
\text { change }\end{array}$ & Business goal & $\begin{array}{l}\text { Sustainability } \\
\text { position }\end{array}$ & Compatible themes \\
\hline $\begin{array}{l}1 . \\
\text { Compliant }\end{array}$ & $\begin{array}{l}\text { Minimum activity } \\
\text { to meet } \\
\text { regulatory } \\
\text { requirements }\end{array}$ & Very low & \multirow[t]{2}{*}{$\begin{array}{l}\text { Pursuit of } \\
\text { production, } \\
\text { consumption, } \\
\text { and growth }\end{array}$} & $\begin{array}{l}\text { Externally } \\
\text { enforced or } \\
\text { regulated } \\
\text { activities, } \\
\text { defensive } \\
\text { actions } \\
\text { regarding } \\
\text { environmental } \\
\text { concerns }\end{array}$ & $\begin{array}{l}\text { Market solution, } \\
\text { government } \\
\text { intervention } \\
\text { unwanted, change too } \\
\text { costly, await } \\
\text { technology solution, } \\
\text { energy } \\
\text { trilemma(sustainability, } \\
\text { affordability, and } \\
\text { security) prevents shift } \\
\text { from carbon }\end{array}$ \\
\hline $\begin{array}{l}2 . \\
\text { Active }\end{array}$ & $\begin{array}{l}\text { Limited to } \\
\text { process } \\
\text { improvements } \\
\text { and management } \\
\text { involvement. }\end{array}$ & Low & & $\begin{array}{l}\text { Internal firm- } \\
\text { centric view } \\
\text { for defining } \\
\text { sustainability, } \\
\text { "business } \\
\text { case" is the } \\
\text { motivation and }\end{array}$ & $\begin{array}{l}\text { Market/business holds } \\
\text { solution, government } \\
\text { policy barriers, change } \\
\text { too costly, await } \\
\text { technology solution, } \\
\text { carbon as transition } \\
\text { enabler, risk avoidance }\end{array}$ \\
\hline
\end{tabular}




\begin{tabular}{|c|c|c|c|c|c|}
\hline Stage & $\begin{array}{l}\text { Emissions } \\
\text { management }\end{array}$ & $\begin{array}{l}\text { Business } \\
\text { approach } \\
\text { change }\end{array}$ & Business goal & $\begin{array}{l}\text { Sustainability } \\
\text { position }\end{array}$ & Compatible themes \\
\hline \multicolumn{3}{|r|}{$\begin{array}{l}\text { Systemically } \\
\text { non- } \\
\text { challenging }\end{array}$} & & \multirow{3}{*}{$\begin{array}{l}\text { measure of } \\
\text { success, } \\
\text { adoption and } \\
\text { internal } \\
\text { enforcement } \\
\text { of activities, } \\
\text { incremental } \\
\text { improvements } \\
\text { to business-as- } \\
\text { usual, may } \\
\text { focus on one } \\
\text { or more } \\
\text { realms of } \\
\text { sustainability } \\
\text { (economic, } \\
\text { environmental, } \\
\text { social) }\end{array}$} & $\begin{array}{l}\text { Business holds } \\
\text { solution, journey } \\
\text { without destination, } \\
\text { win-win, eco-efficiency, } \\
\text { opportunities, } \\
\text { government policy } \\
\text { barriers, systemic } \\
\text { change too costly, } \\
\text { seek/assist technology } \\
\text { solution, carbon as } \\
\text { transition enabler, risk } \\
\text { avoidance }\end{array}$ \\
\hline $\begin{array}{l}4 . \\
\text { Integrated }\end{array}$ & $\begin{array}{l}\text { Carbon reduction } \\
\text { activities are } \\
\text { integrated into } \\
\text { the overall } \\
\text { business } \\
\text { strategy. } \\
\text { Environmental } \\
\text { management } \\
\text { seen to affect } \\
\text { competitiveness } \\
\text { as has economic } \\
\text { and strategic } \\
\text { benefits. }\end{array}$ & $\begin{array}{l}\text { Isolated } \\
\text { systemic } \\
\text { challenges }\end{array}$ & & & $\begin{array}{l}\text { Business holds } \\
\text { solution, journey } \\
\text { (with/without } \\
\text { destination), win-win, } \\
\text { eco-efficiency, } \\
\text { opportunities, } \\
\text { government policies } \\
\text { unreliable, competitive } \\
\text { advantage, seek/assist } \\
\text { technology solution, } \\
\text { carbon as transition } \\
\text { enabler }\end{array}$ \\
\hline $\begin{array}{l}5 . \\
\text { Saturated }\end{array}$ & $\begin{array}{l}\text { Increasing the } \\
\text { intensity of the } \\
\text { different } \\
\text { measures } \\
\text { adopted in } \\
\text { previous stages. } \\
\text { Reaching the } \\
\text { "what can we do } \\
\text { now?" point }\end{array}$ & $\begin{array}{l}\text { Isolated } \\
\text { systemic } \\
\text { challenges }\end{array}$ & & & $\begin{array}{l}\text { Business holds } \\
\text { solution, journey with } \\
\text { destination, win-win, } \\
\text { eco-efficiency, } \\
\text { opportunities, } \\
\text { government policies } \\
\text { unreliable, competitive } \\
\text { advantage, } \\
\text { collaboration, } \\
\text { technology solution }\end{array}$ \\
\hline $\begin{array}{l}6 . \\
\text { Systemic }\end{array}$ & $\begin{array}{l}\text { Large shift in } \\
\text { products/services } \\
\text { offering to lower } \\
\text { emissions } \\
\text { through } \\
\text { innovation }\end{array}$ & Intermediate & & $\begin{array}{l}\text { Looks } \\
\text { externally in } \\
\text { defining } \\
\text { sustainability, } \\
\text { business is } \\
\text { part of a larger } \\
\text { industry and } \\
\text { community } \\
\text { working } \\
\text { together } \\
\text { toward } \\
\text { systemic } \\
\text { change }\end{array}$ & $\begin{array}{l}\text { New business model, } \\
\text { opportunities, } \\
\text { transformation, } \\
\text { collaboration, carbon } \\
\text { decoupling, multi- } \\
\text { faceted solution } \\
\text { (may/may not involve } \\
\text { technology) }\end{array}$ \\
\hline
\end{tabular}




\begin{tabular}{|c|c|c|c|c|c|}
\hline Stage & $\begin{array}{c}\text { Emissions } \\
\text { management }\end{array}$ & $\begin{array}{c}\text { Business } \\
\text { approach } \\
\text { change }\end{array}$ & Business goal & $\begin{array}{c}\text { Sustainability } \\
\text { position }\end{array}$ & Compatible themes \\
\hline $\begin{array}{l}7 . \\
\text { Regenerative }\end{array}$ & $\begin{array}{l}\text { Zero to negative } \\
\text { carbon emissions } \\
\text { for the entire } \\
\text { product and } \\
\text { service lifecycles, } \\
\text { historically } \\
\text { created } \\
\text { emissions are } \\
\text { addressed. }\end{array}$ & High & $\begin{array}{l}\text { Qualitative } \\
\text { development } \\
\text { without } \\
\text { production, } \\
\text { consumption, } \\
\text { and growth, } \\
\text { steady-state } \\
\text { growth }\end{array}$ & $\begin{array}{l}\text { Part of the } \\
\text { natural world, } \\
\text { operate within } \\
\text { planetary } \\
\text { boundaries, } \\
\text { manage and } \\
\text { repair }\end{array}$ & $\begin{array}{l}\text { Themes unknown - } \\
\text { some possible themes } \\
\text { could include positive } \\
\text { ecological impact } \\
\text { before profit, } \\
\text { regenerative, serving } \\
\text { environment and } \\
\text { society }\end{array}$ \\
\hline $\begin{array}{l}8 . \\
\text { Coevolutionary }\end{array}$ & $\begin{array}{l}\text { Completely } \\
\text { decoupled from } \\
\text { carbon emissions } \\
\text { including } \\
\text { upstream and } \\
\text { downstream } \\
\text { dependencies. }\end{array}$ & Very high & $\begin{array}{l}\text { No growth in } \\
\text { production } \\
\text { or } \\
\text { consumption, } \\
\text { qualitative } \\
\text { improvements }\end{array}$ & $\begin{array}{l}\text { Work in } \\
\text { balance with } \\
\text { other (human } \\
\text { and non- } \\
\text { human) } \\
\text { systems, } \\
\text { contribute to } \\
\text { flourishing of } \\
\text { other systems }\end{array}$ & $\begin{array}{l}\text { Themes unknown - } \\
\text { some possible themes } \\
\text { could include evolving } \\
\text { holistic ecology centred } \\
\text { purpose and functions, } \\
\text { maintaining ecological } \\
\text { balance }\end{array}$ \\
\hline
\end{tabular}

Table 2: Corporate emission reduction stages

(Sources: Primarily Landrum, 2018 and Lee, 2012 with aspects from Benn et al., 2014; GarcésAyerbe et al., 2016; and Jeswani et al., 2008)

Within each stage five main facets were identified as being formative for understanding the stage(s) a business was at up to a given time in terms of progressing ER. Three of these facets - business goal, sustainability position and compatible themes - are qualitative and rely upon careful analysis of interviews and documentation to identify existing or emergent themes and positions. Emissions management was deemed to require strategies and actions to be classified and their 'substantiveness' determined so that any patterns could be discerned. The scale of Strategy and Action change would determine the level of 'Business approach change'. 'Emissions management' are adapted from Garcés-Ayerbe et al. (2016), 'Business goal' and 'Sustainability position' are from Landrum (2018), with 'Business approach change' adapted from both. 'Compatible themes' are indicative and not exhaustive.

\section{Strategy and Action classification}

In order that the range of business strategies and actions captured could be understood, summarised, evaluated and compared, an ER strategy and action classification was constructed. 

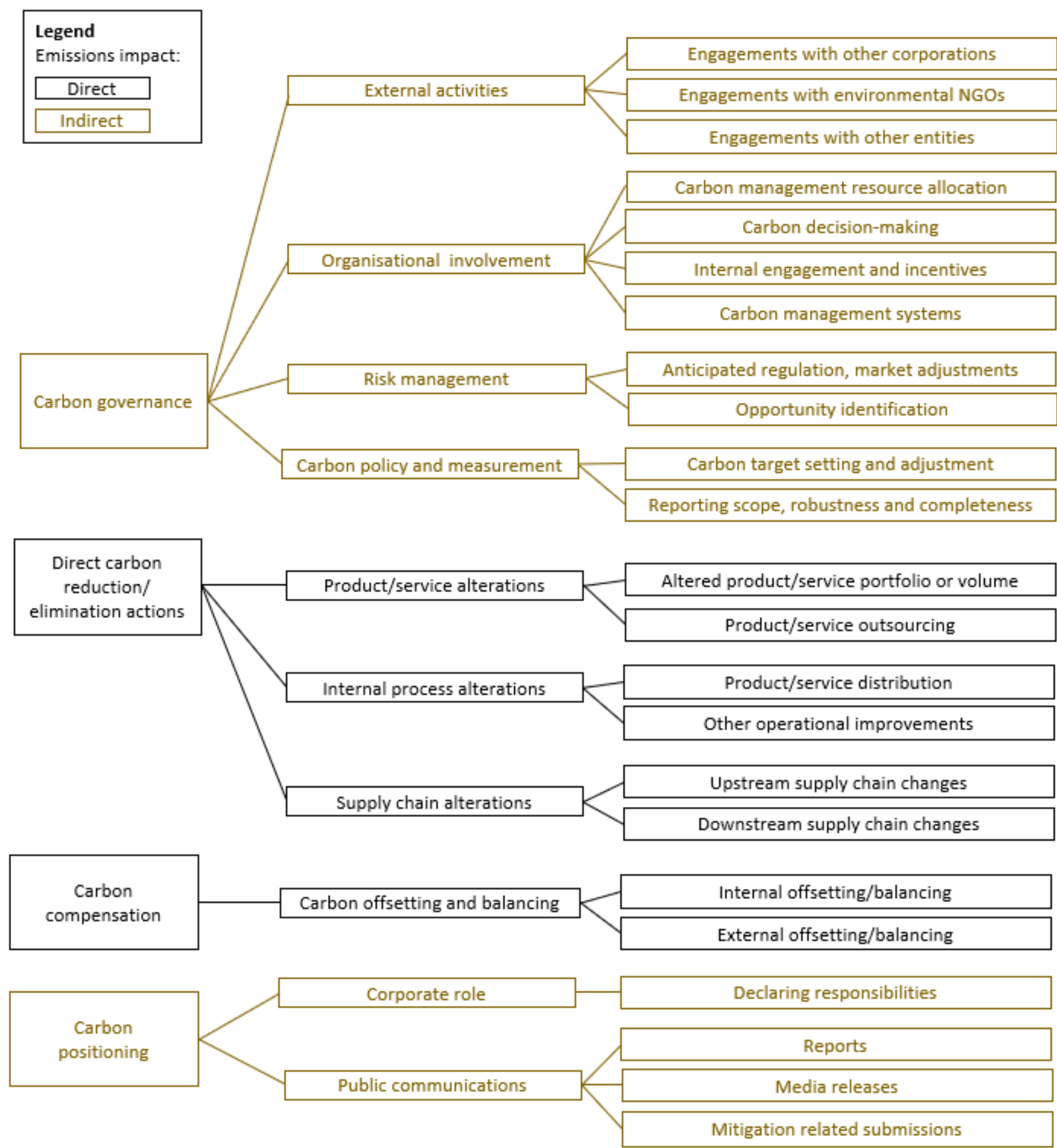

Sources: Blanco et al., 2016; Cadez \& Czerny, 2016; DahImann et al., 2019; Damert et al., 2017; Downie \& Stubbs, 2012; Elsayih et al., 2018; Hyatt \& Berente, 2017; Jeswani et al., 2008; Lee, 2012; Liao et al., 2015; Penz \& Polsa, 2018; Walenta, 2018; Yunus et al., 2016

Figure 4: Emission reduction strategy and action classification

Direct action categories (contained within Carbon reduction/elimination and Carbon compensation) are sourced substantively from Damert et al. (2017), with indirect 
actions assembled from multiple sources as no existing coding framework covered the desired diversity of indirect strategies and actions (Blanco et al., 2016; Cadez \& Czerny, 2016; Dahlmann et al., 2019; Damert et al., 2017; Downie \& Stubbs, 2012; Elsayih et al., 2018; Hyatt \& Berente, 2017; Jeswani et al., 2008; Lee, 2012; Liao et al., 2015; Penz \& Polsa, 2018; Walenta, 2018; Yunus et al., 2016). Strategic and activity areas are largely self-explanatory but definitions of each strategic and activity area are given in Appendix 2.

\subsubsection{Data processing}

The interview audio files were converted into text using Microsoft Word's inbuilt transcribe software. Then all transcriptions were manually corrected for any omissions or mistranslations. In preparation for textual analysis using NVivo 12 Plus, the transcript version was 'cleaned', which involved stripping the words of the interviewer, surrounding notes, speech mannerisms including verbal connectives (um, ah, etc), word repetition, and irrelevant topics. Texts were then grouped into topic areas ready for analysis. Before copying into NVivo the cleaned version was compared with the corrected version to ensure no differences or absences existed other than those intended to aid analysis.

As media releases were sourced from web pages that contained extraneous material, these were manually copied into notepad, with any infographic text if relevant converted to text and added to the same text file using an online converter ${ }^{10}$ and then corrected for any omissions or errors. The text files were then loaded into NVivo. Annual reports/reviews, sustainability/environmental reports or equivalent were predominantly pdf files and loaded directly into NVivo and, if web based only, the same process as for media releases was followed.

Textual content was filtered based upon whether it dealt with carbon emissions. For media releases, relevancy was determined at the article level. For other sources, such as reports and submissions, relevancy was determined at paragraph or section level as appropriate to the data source structure. Relevancy was determined by mention (or otherwise) of carbon emissions, greenhouse gases, climate change or synonymous terms. This was done in two sweeps, firstly using a short list of terms and secondly by

${ }^{10}$ https://smallseotools.com/image-to-text-converter/ 
scanning manually to ensure inclusion or exclusion of content was appropriate. Where topics were covered that had a direct impact upon emissions but no link was drawn in the text these were noted for comment but not included in the thematic and frequency analysis. This was to ensure analysis results remained centred on the corporates' use of words and themes around carbon emissions and did not include activity that incidentally reduced emissions.

Identified relevant textual content in primary and secondary data was divided into three periods based around two events: the Paris Agreement (15 Dec 2015), and the CLC launch (12 July 2018). The practical cut-off date for gathering research material was 31 Dec 2020.

1. 'Pre-Paris': 1 Jan 2010 - 15 Dec 2015

2. 'Post-Paris/Pre-CLC': 16 Dec 2015 - 11 Jul 2018

3. 'Post-CLC': 12 Jul 2018 - 31 Dec 2020 (includes New Zealand's COVID-related national and regional lockdowns of March/April and August/September 2020 (NZ Ministry of Health, 2021)).

Thematic, strategy and action classification, and frequency analysis were then conducted within NVivo.

\section{Thematic analysis}

Thematic coding was done in two stages - descriptive and analytical -- as recommended by Skjott Linneberg and Korsgaard (2019). Descriptive coding was based upon the characteristics that help differentiate stages from one another:

1. ER reasons,

2. envisaged ER solutions,

3. envisaged ER limitations,

4. envisaged role of business,

5. external factors - roles of technology, market, government and/or regulation,

6. internal factors,

7. relationship/hierarchy between environment, people, and finance

and, as they need to be understood in their own right and may impact all other elements, 


\section{COVID impact,}

9. Sustainability position - the perspective and prioritisation of the three sustainability elements - environmental, social and financial.

A piece of text could fit multiple descriptive codings. These descriptive codings were analysed for themes, emission management stage and sustainability position, and whether the text related to an existing or planned action or strategy. This was then cross-checked with the relevant time period and other analysis results (see below) to form a view of progress for pre-Paris, post-Paris/pre-CLC and post-CLC.

\section{Strategy and action classification analysis}

As well as narrative, the spread of strategies and actions was needed to indicate how integrated ER strategies and actions were across the business. To identify the spread of strategies and actions undertaken, text was analysed using the constructed strategy and action classification framework. To filter out inconsequential mentions of activity Beck et al. (2010)'s scale of content type was used. This scale was selected as it considers both qualitative and quantitative aspects. Any content equivalent to solely narrative ('disclosure type 1') was excluded. Reports (or equivalent) were used as the main analysis source for strategies and actions, with a cross-check of results against interviews and recent media articles to ensure strategies or actions were not omitted. This approach had two advantages: report content strategy and action specificity when sampled was consistently greater than other sources; and it aided comparability across all 13 corporates, as not all had comprehensive media releases, nor were all interviewed.

\section{Frequency analysis}

Frequency analysis was completed across relevant text in all secondary textual data sources and divided into the three time periods. NVivo word frequency analysis was run with settings of an exact (i.e. non-stemmed) word match, limited to the top 1000 words. Exact match only was selected (e.g. sustainable), with inclusion of stems on a manual basis where appropriate (e.g. sustainable and sustainability) if word use was consistent. Using NVivo's automatically stemmed word matches (e.g. sustain, sustainable and sustainability) was found to introduce too many word groupings into the frequency count that varied too widely in their associated meaning. NVivo's wordtree and context functionality helped identify changes in meaning and whether Page $\mid 49$ 
grouping was appropriate. (For example, the use of the word sustainable was inappropriate to group with sustainability for some corporates and not others: some used it widely to mean 'able to be sustained' rather than in any environmental context). The frequency analysis for each period and corporate communication type were then exported and scanned for terms relevant to climate change, carbon emissions or sustainability activity or stances that could readily impact carbon emissions. Occasionally, coupling of words was required to capture their use, for instance footprint was used by the same corporate to connote the physical retail space, or the associated carbon emissions volume, within their reports. Similarly, exclusions had to be applied for words that were too prevalent in another context, e.g. the frequency of the term electricity was informative for analysing many corporates but not for Vector, which distributes electricity and gas.

This process resulted in a list of relevant words specific to that corporate and communication type, which then could be compared across time periods, communication types, and corporates. To aid comprehension and comparability, the top 20 most frequent relevant words/word groupings ('terms') from each period were selected. Their rankings were then compared across periods for that communication type. Ranking was done using Microsoft Excel 2012's "Rank.eq" function, which ranks by descending volume, with those having the same count being given an equal rank. Due to the top 20 terms varying across periods the list of ranked terms was greater than 20. These frequency rankings were found useful to understand changes across periods, differences across corporates, and to triangulate thematic findings for each corporate to see if themes and frequency ranks when compared were coherent, increasing analysis robustness (Creswell, 2014).

\subsubsection{Ethical concerns}

Ethical approval was granted for the study by the Victoria University of Wellington Human Ethics Committee (ID: 0000028692). Interviewees needed to remain confidential to ensure they could speak freely without feeling compromised given their status as a current employee. This meant that all interview findings are provided in a format so that an individual or corporate cannot conclusively be identified. This also meant exclusion from the analysis of interview content that would identify a corporate. In almost all cases the material could instead be included as detailed in the 
documentary evidence as it was found to also be publicly available, so this did not weaken the analysis. Both the interviewee and corporate signatory were provided information about the study, the interview questions and the opportunity to ask questions before requesting signoff. Interviewees also had the ability to withdraw from the study after their interview until a set date. 


\section{Analysis}

This study examined the carbon ER paths since 2010 of thirteen publicly promitigation New Zealand corporates, namely the Climate Leader Coalition founders (CLCFs). The CLCFs represent over a third of NZ's emissions (see Table 3). They co-founded a pledge in mid-2018 to reduce emissions in line with the Paris Agreement aim to keep global warming within $2^{\circ} \mathrm{C}$ above pre-industrial levels (CLC, n.d.-b; MfE, 2020). The initial pledge was followed by another, yet to be signed by all, adjusting to a SBT below $1.5^{\circ} \mathrm{C}$ (CLC, 2019a; IPCC, 2018). The CLCFs vary across industry sector, emission intensity, ownership and market geography. The thirteen CLCFs are:

- Air New Zealand, (NZ's largest airline);

- Fonterra Co-operative Group Ltd, (one of the two largest dairy processing companies by milk solid volume globally);

- IAG New Zealand Limited, (NZ's largest general insurance provider);

- KiwiRail Holdings Limited, (NZ's national rail and ferry company);

- New Zealand Post Group, (NZ's largest mail and parcel delivery company);

- Ngāi Tahu Holdings Corporation, (an amalgam of NZ-based companies across several primary industry sectors, property, and tourism);

- Ports of Auckland Ltd, (NZ's busiest import port, near to Auckland - NZ's most populous city);

- Spark NZ, (NZ's largest telecommunications and digital services provider);

- The Warehouse Group, (NZ's largest general retail group);

- Toyota New Zealand (NZ's largest seller of new light vehicles, subsidiary of Toyota Motor Corporation, Japan);

- Westpac New Zealand Limited, (one of NZ's five main banks, subsidiary of Westpac Australia Limited);

- Vector Limited, (NZ's largest electricity and gas distributor by households supplied); and

- Z Energy, (NZ's largest fuel distributor). 
Analysis encompasses six interviews, and publicly available material including emission reports, annual/sustainability reports, media communications, and parliamentary submissions for all thirteen corporates. Interview analysis then explores ER progress in a qualitative capacity. Lastly qualitative analysis of the communicated positions, strategies and actions for each of the thirteen CLCFs are detailed, to inform at the corporate level. An overall summary of findings including reported emissions is in section 6.6 , to help orientate on the relative scale and trend of reported emissions across the corporates.

\subsection{Emission Reporting}

Annual emission figures in $\mathrm{tCO}_{2} \mathrm{e}$ (metric tonnes carbon dioxide equivalent) were sourced from CDP reports, annual/integrated reports, environmental/sustainability reports and emission disclosure certificates, sourced using live web pages or through website archive recovery. Not all CLCFS reported emissions for the full eleven years, especially prior to the Paris Agreement ${ }^{11}$. All CLCFs indicated reporting alignment with the 'GHG Protocol' reporting standard as referred to in section 4.3.1. Reporting data quality when externally assessed varied between 'Reasonable', 'Good' and 'High', with a trend towards improving data quality. Emission figures from the most recent source, ideally comparable to other reported years and with at supporting detail were selected. These criteria tended to favour reports, as they sometimes included several years' worth of emissions, with historical figures adjusted to aid comparability. Figures did not always match across sources. Reasons varied: emission conversion recalculation, a backdated change of scope, a corrected error, improved emission source information or a change in reporting boundaries could all impact historic figures. A summary of reported emission figures is provided in Table 3, using the latest available version of emission figures for each year.

\footnotetext{
${ }^{11}$ Emission figures coverage is detailed in Appendix 5.
} 


\begin{tabular}{|l|r|r|r|r|r|r|r|r|r|r|}
\hline CLCF member & Early 2010s & FY & pre-Paris & FY & $\begin{array}{r}\text { pre-CLC } \\
\text { founding }\end{array}$ & FY & pre-COVID & FY & Current & FY \\
\hline Air NZ & $2,966,648$ & $\mathbf{2 0 1 1}$ & $3,078,998$ & 2015 & $3,733,290$ & 2018 & $3,928,748$ & 2019 & $3,179,466$ & 2020 \\
\hline Fonterra & Unknown & $\mathbf{2 0 1 2}$ & $22,435,229$ & 2015 & $24,806,000$ & 2018 & $23,808,000$ & 2019 & $23,564,000$ & 2020 \\
\hline IAG & 3,941 & 2010 & 6,600 & 2015 & 6,184 & 2018 & 5,975 & 2019 & 4,743 & 2020 \\
\hline KiwiRail & $306,00 *^{*}$ & $\mathbf{2 0 1 1}$ & 272,345 & $\mathbf{2 0 1 6}$ & 227,116 & 2018 & 240,094 & 2019 & 230,046 & 2020 \\
\hline NTHC & - & 2010 & 56,035 & $\mathbf{2 0 1 6}$ & 118,229 & 2017 & 125,921 & 2018 & - & 2020 \\
\hline NZ Post & 75,898 & 2010 & & & & & & & & \\
& 125,906 & 2012 & 113,714 & 2015 & 129,509 & 2018 & 111,208 & 2019 & 106,615 & 2020 \\
\hline PoAL & - & 2010 & 16,208 & $\mathbf{2 0 1 7}$ & 16,799 & 2018 & 16,702 & 2019 & 15,882 & 2020 \\
\hline Spark & 59,479 & 2009 & 28,679 & 2015 & 28,487 & 2018 & 29,508 & 2019 & 28,209 & 2020 \\
\hline TWG & 27,144 & $\mathbf{2 0 1 2}$ & 39,988 & 2015 & 40,852 & 2018 & 39,199 & 2019 & & 2020 \\
\hline TNZ & 8,317 & $\mathbf{2 0 1 1}$ & 22,482 & 2015 & 30,190 & 2018 & 27,298 & 2019 & 26,091 & 2020 \\
\hline Vector & - & 2010 & 373,563 & 2017 & 406,023 & 2018 & 437,352 & 2019 & 334,358 & 2020 \\
\hline Westpac NZ & 5,980 & 2010 & 8,391 & 2015 & 6,332 & 2018 & 7,347 & 2019 & 6,015 & 2020 \\
\hline Z & $7,290,325$ & $\mathbf{2 0 1 2}$ & $6,635,699$ & 2015 & $11,975,999$ & 2018 & $11,958,268$ & 2019 & $12,124,589$ & 2020 \\
\hline CLCF total & Unknown & & $33,087,932$ & & $41,525,010$ & & $40,735,620$ & & $39,620,014$ & \\
\hline NZ gross total & $78,316,410$ & 2010 & $80,724,440$ & 2015 & $80,578,310$ & 2018 & $82,317,880$ & 2019 & unknown & 2020 \\
\hline
\end{tabular}

\begin{tabular}{|ll|}
\hline Legend & Description \\
FY & Financial Year end. For instance the financial year 1 July 2019-30 June 2020 is represented as 2020. \\
Pre-Paris & Total reported tCO2e for the adjacent FY, ideally prior to the December 2015 Paris Agreement. \\
Pre-CLC founding & Total reported tCO2e for the adjacent FY, ideally prior to the July 2018 founding of the Climate Leasers Coalition. \\
Pre-COVID & Total reported tCO2e for the adjacent FY, ideally prior to the March/April 2020 CoVID peak in NZ. \\
\hline
\end{tabular}

Table 3: CLCF Reported emissions at key points throughout 2010-2020

(Source: Numerous carbon, annual and integrated reports and statements across CLC members. Latest figures used wherever available)

If a very simplistic interpretation of figures is taken, then the total emissions across all CLCFs was 33.1 million tonnes $\mathrm{CO}_{2}$ equivalent $\left(\mathrm{mtCO}_{2} \mathrm{e}\right)$ pre-Paris, peaked at $41.5 \mathrm{mtCO}_{2} \mathrm{e}$ around 2018 when CLC was founded, reduced pre-COVID to 40.7 $\mathrm{mtCO}_{2} \mathrm{e}$ and is currently $39.6 \mathrm{mtCO}_{2} \mathrm{e}^{12}$. CLCFs' total emissions are comparable to almost half of NZ's total 2019 annual gross emissions (MfE, 2021c) ${ }^{13}$.

\footnotetext{
${ }^{12}$ Early 2010 and Pre-Paris figures are artificially low due to the absence of figures for some, and emission inventories were not as comprehensive, especially for scope 3 sources. The 2020 figures unavailable for The Warehouse Group (TWG) and Ngāi Tahu Holdings Corporation (NTHC) will only add circa $0.2 \mathrm{mtCO}_{2} \mathrm{e}$.

${ }^{13}$ There will be double-reported emissions (as well as unreported emissions). Z Energy (Z) emissions include non-renewable fuels they supply customers, which encompasses most if not all of the other CLCFs, and Air NZ international flight emissions are not relevant to the NZ gross total. The CLCF total is net emissions, so offsets have been deducted. With all these considerations the CLCF total would still remain greater than $35 \mathrm{mtCO} e$.
} 
Reporting and supporting commentary in annual/sustainability/integrated/ environmental reports ('reports') give a general sense of relative emissions being substantively lower for Scope 1 and 2 emissions than if no interventions had been done, however whether absolute emissions decreased was mixed.

Split by scope the reporting gives a useful sense of emission profiles and larger changes can be seen as reflected in the figures (see Appendix 6). For Scope 1 AirNZ and Fonterra are the only two that are over $1 \mathrm{mtCO}_{2} \mathrm{e}$, emphasising for Fonterra the scale of operations and the associated emissions. Scope 1 emissions were $6.1 \mathrm{mtCO}_{2} \mathrm{e}$ pre-COVID and an estimated $5.3 \mathrm{mtCO}_{2} \mathrm{e}^{11}$ post-COVID, due mainly to AirNZ's COVID-enforced reduction in air travel resulting in a decrease of $0.75 \mathrm{mtCO}_{2} \mathrm{e}$. Also worth noting is Vector's scope 1 emissions reduced in a year by $25 \%\left(0.1 \mathrm{mtCO}_{2} \mathrm{e}\right)$, primarily due to the sale of the Kapuni gas treatment plant early in 2020 (Vector, 2019b). Scope 2 emissions are low (below $0.025 \mathrm{mtCO}_{2} \mathrm{e}$ ) for all but Fonterra, reflecting the large amounts of energy use in their operations and the lack of other large manufacturing or processing plants in the CLCF and their scarcity in New Zealand more generally outside the agriculture and farming sector.

Many of the CLCFS have a downwards trajectory for Scope 2 emissions, reflecting the energy efficiencies made, as scope 2 is purchased energy use, in most cases electricity. Spark's energy use after halving early in the 2010's through replacing more energy intensive communication systems and using more advanced datacentre cooling approaches has gradually increased again due to rapidly increasing use of communication services during and post-COVID (Spark, 2020a). As can be seen in Appendix 6, AirNZ, IAG, NZPost, PoAL, TWG, Vector, WestpacNZ and Z all reported substantial decreases in their scope 2 emissions. Energy efficiencies, fluctuations in New Zealand's renewable electricity proportion of grid supply, as well as and increasing or decreasing service volumes impact Scope 2 emission figures.

$\mathrm{Z}$ and Fonterra are the only two CLCFs with high (over $1 \mathrm{mtCO}_{2} \mathrm{e}$ ) Scope 3 emissions and also happen to provide what can be considered comprehensive coverage of them, totalling over $30 \mathrm{mtCO} 2 \mathrm{e}$ : three quarters of the total emissions across all CLCFs, and well over a third of NZ's emissions (MfE, 2020). The underlying main emission sources, methane from dairy-farmed cows and supply and use of non-renewable fuels respectively, are known systemic sources that both 
Fonterra and $Z$ have sought to address to some degree, through biomethane research and biofuels respectively, and are yet to be successful (Daalder, 2020; Gibson, 2020). More generally there has been a rising trend in reported scope 3 emissions amongst the CLCFs peaking in 2018 and then flat thereafter. Fonterra and $Z$ aside, the main factor appears to be increased coverage of scope 3 emissions.

Differences in reported emissions can also be caused by changes in operating scale or conditions, calculation basis, or a combination, further making temporal and intercorporate comparisons problematic. Reporting scope increased over time for all corporations and will continue to increase for at least some, changing base years. Declaring a base year theoretically helps minimise inappropriate yearly comparisons, as it is supposed to be the earliest comparable year to that being reported on, however a base year may be known to be outdated (Toyota NZ, 2016, p. 22), and may quickly differ again (Toyota NZ, 2017), suggesting a new base year may be needed. Changes in operating scale or conditions have been enough to sharply impact emissions, even without COVID impacts or ER initiatives. IAG for instance bought AMI in December 2011 (Steeman, 2011), Lumley General Insurance in 2014 (Harris, 2014), outsourced jobs overseas in 2018 (Parker, 2018), added a car repair shop to their NZ operation in 2019 (IAG, 2020a), and closed 54 branches in 2020 (IAG, 2020b). Similarly TWG has bought and sold several companies and the number of retail sites changes regularly e.g. (TWG, 2018). Z Energy's fuel outlet footprint has dramatically expanded with them in 2020 commencing supplying Pak'NSave - a nation-wide budget supermarket with self-service petrol outlets, as well as existing Caltex and Z Energy outlets (Z Energy, 2018a). Changes in business size affected emissions far more than reductions achieved.

Reductions of greenhouse gas emissions due to ER initiatives could also be swamped by changing emission estimates and calculations. For instance a ToyotaNZ sea freight recalculation (scope 3 ) added $49.6 \%$ or $7,500 \mathrm{tCO}_{2} \mathrm{e}$ to ToyotaNZ's reported emissions ${ }^{14}$ (Toitū Envirocare, 2012). Domestically ToyotaNZ operations reported ER of $284 \mathrm{tCO}_{2} \mathrm{e}$ over the last 5 years, a sizeable proportional decrease in scope 1 and 2 of $17 \%$ (see 2019/20 figures in Table 3), but swamped by

\footnotetext{
${ }^{14}$ ToyotaNZ's reported emissions exclude vehicle manufacture and use related emissions, so international shipping is the largest reported emission source.
} 
the sea freight emissions and recalculation. More recently New Zealand's Ministry for the Environment (MfE) updated their emissions guide (MfE, 2019e), changing electricity distribution loss figures amongst others, impacting multiple CLCFs' reports. Spark recently changed refrigerant leakage rates to the default rather than supplier-provided estimates, increasing associated reported emissions (Spark, 2020a). ToyotaNZ's 2019/20 Carbon certification indicates Scope 2 total (locationbased method) as $273.98 \mathrm{tCO}_{2} \mathrm{e}$ whereas using the market-based method is 47.75 tCO ${ }_{2}$, different by a multiple of 5 (Toitū Envirocare, 2020). This change impacts ToyotaNZ emissions total by less than $1 \%$, due to ToyotaNZ's relatively large scope 3 emissions. However, for service companies such as IAG and WestpacNZ with low Scope 2 emissions, changes in calculation methods could substantially impact their total emissions figure. This is not to imply that the CLCFs are 'gaming' the GHG reporting standard. Many of the CLCFs' emission reporting is independently audited and all CLCFs interviewed wanted to accurately understand and reflect emissions within their reporting boundaries. However it remains that traversing these details to understand what the underlying change to GHG emissions is when reported emission figures change is problematic.

To further complicate, ER target boundaries are not synonymous with reporting so achieved ER targets may or may not indicate a decrease in total corporate emissions. Fonterra for instance includes farm-based emissions in reporting but excludes these from targets, ToyotaNZ excludes customer vehicle driving emissions from its reporting but has a proportional target of new electric vehicles relative to total light vehicle sales; and TWG (as is permissible under GHG reporting) excludes product manufacturing emissions except for products it creates under reporting and only includes scope 1 and 2 in ER targets. $Z$ does include emissions related to fuel pump sales in reports but is yet to include these in future targets (Z Energy, 2020c). Furthermore, as discovered when analysing reports and interviews, perceived responsibilities may not match either reporting or targets.

\subsection{Interviews}

Interviews were conducted September/October 2020, approximately a month after a regional (Auckland) outbreak of COVID-19. Interviewed corporates were a mix of those who took relatively early action, sometimes pre-dating 2010, right through to 
those who commenced late-2010s and included all CLCF industry sectors. The ten questions covered participant background (Q1), ER progress pre-COVID (Q2), approach changes over time (Q2a), areas of greatest progress and enabling factors (Q3), areas where more perhaps could have been achieved and hindering factors (Q4), impact of founding CLC on progress (Q4a), ER approach just before COVID (Q5), COVID impact on progress (Q6), target adjustments (Q6a) and likely progress within the next one to three years (Q7). (See Appendix 3 for the full questions). Accordingly included quotes are carefully selected to maintain participant anonymity, and the occasional word or target percent is redacted.

Interviews focus more on changes in approach to achieving ER progress and enabling/hindering factors than other aspects as these are less covered in other sources analysed. Within these more recent (post-Paris) progress and approach are explored in more depth as it is rare that sustainability staff tenure extends back to 2010. Whilst participants were typically experienced in sustainability (5+ years) none interviewed were executive level, and three of the six participants had less than two years' tenure in their current position, meaning that some participants did not experience older events, and witnessed rather than made strategic decisions. However they clearly signposted knowledge gaps and provided useful insight into how and why ER progress occurred or did not occur; an area less well-covered by secondary data sources. Analysis of responses is grouped by question relevancy; often answers to Q3 and Q4 brought out aspects relevant to Q2 and Q2a and vice versa, and many had commented on the impact of CLC and the approach prior to the nationwide March 2020 COVID outbreak before Q4a and Q5 were reached. Accordingly Q5 responses are combined with Q2 into section 6.2.1.

\subsubsection{ER progress pre-COVID and approach changes}

Participants saw progress as multi-faceted. Reporting, targets, actions, executive support, and changes in corporate policy, sustainability resource levels, supplier relationships and corporate decision-making processes and structures were all considered signs of progress. Rather than perceiving a definitive change in approach to ER the participants implied an evolving approach as external conditions change and the perceived importance of ER increases.

Page $\mid 58$ 
Progression of ER actions was described as going from 'low-hanging fruit' to more challenging behavioural and structural change. Several participants used the term 'low-hanging fruit' to describe waste reduction, LED lighting and other energy (electricity, fuel and GHG leakage) efficiency measures. Efficiency measures reduce carbon and save the corporate money. "Waste, although it represents a small aspect of the emissions it's something that's really important, not only just because it's the right thing to do, but it's ... visual as well." (Participant A). Whilst some of these 'lowhanging' changes, be it waste or others, had relatively minor impact upon emissions, their value in engaging employees and giving visibility (both internally and externally) to environmental issues was frequently mentioned (Participants $A, C, D, E)$. High visibility is seen to have multiple benefits: signalling to both internal (employees) and external stakeholders (mainly consumers, sometimes shareholders) their commitment to sustainability, including lowering emissions. Engaging employees and in some cases suppliers or downstream businesses in processes focussed on reducing environmental impact, with ER included amongst other environmental goals but gaining more prevalence (Participants $\mathrm{B}, \mathrm{C}, \mathrm{F}$ ). The more challenging changes to achieve ER for high emitting corporates were seen as emission sources that required capital investment; for lower emitters it was behavioural change, such as reducing employee transport emissions (business air travel, vehicle preference and commuting). (Specific corporate details are explored in more detail in section 6.3).

Reporting and targets were seen as key elements in defining and achieving progress by all participants, influencing action selection and rate of progress. For reporting emissions all CLCFs adhere to the GHG Protocol reporting standard as referenced in section 4.3.1. This guides corporates on forming emission ownership boundaries, akin (for some literally) to identifying financial liabilities ${ }^{15}$, and influences associated targets. As one participant reflects, current targets "cover scope 1 and scope 2, but our biggest emissions are scope $3 " 16$. Paying less attention to scope 3 emissions is a known tendency (Patchell, 2018) as they are indirect emissions (see Figure 1), which until the recent SBT initiative began (see Literature Review) could be excluded from targets.

\footnotetext{
${ }^{15}$ For some of the CLCFs emission inventories are realised as liabilities, due to requirements to pay for NZ ETS units based upon CO2e tonnes emissions of certain reporting boundaries that have not been offset.
}

${ }^{16}$ Participant E did also comment on how scope 3 was being included in future target.

Page $\mid 59$ 
All but one participant commented that reporting was improving in accuracy and coverage, and of the increasing willingness of executives to revise targets towards greater ER.

All participants saw targets as assisting ER, with Participant A commenting that "we're getting a lot of pressure from our board and our CEO to accelerate those [ER] projects" to ensure ER targets are met. All those who mentioned SBTs were supportive of them as an approach. Targets were found to be useful by participants for galvanising action and committing corporate resource. One CLCF amongst several had "committed ourselves to being carbon neutral, we're very determined to do that" (Participant B). The coverage of carbon neutrality targets varies - some cover scope 1 and 2 with others also including scope 3 emissions. There are no cases (interviewed or otherwise) for high emitting CLCFs where carbon neutrality covered associated emissions for the entire lifecycle for their products/services. So to identify as carbonneutral does not necessitate removing or neutralising through offsetting all associated emissions. None of the participants commented on how limiting ER efforts within defined boundaries could be problematic either in terms of causing stakeholder confusion or insufficient ER outcomes.

Boundaried ER efforts is anticipated (Walenta, 2018) and understandable as the remit of those interviewed is to reduce emissions the corporate has identified themselves as responsible for using the GHG Protocol. However a non-systemic approach of prioritising ER within reporting boundaries may not be the most effective way to reduce emissions overall. Two possible examples of this in effect involve outsourcing and insourcing of services. For instance in an outsourcing example travel related emissions (Scope 3) to establish the outsourced operation emissions were the focus (Participant D), however the new site's emissions (now outside reporting scope) were not mentioned. Conversely for another participant site emissions for a newly insourced service were of concern as associated emissions are now within the reporting boundary (Participant E). In both cases the services pre-existed before being outsourced/insourced. Also when explored the ER impact of outsourcing/insourcing did not seem present in the initial executive decision-making, raising a question around the ubiquity of ER consideration in executive decisions. 
This said, executive support was considered high throughout the participant CLCFs and had increased over time, thought to be primarily due to stakeholder expectations. Participant E described ER as being "something that the leadership team or the executive team agrees that they want to deliver on and then drive through the rest of the business." Stakeholders' influence in ER's importance was seen as an important factor in increased executive support. Corporate D's executives "really started to think about ... being in the shoe[s] of our customers, is that what they want? ... so much research now says that consumers want to consume from a sustainable business, or an ethical business". ER efforts are situated as influential in customer retention or loss. "Our emissions were growing quite substantially year on year, and so we knew that this was, an issue that was, very important, important to our customers, important to our people [i.e. employees]" (Participant A). As a result of asking public and staff corporate $\mathrm{C}$ became "much more focused on climate action rather than the smaller [emission impact] actions".

Executive support was not all that was required. "You've got your set resources to get your day-to-day stuff done, and recognising that this [reducing emissions] is a big undertaking. You need additional resource..." (Participant A). Corporate sustainability resource has evolved in some cases from being one person or one work area to sustainability roles integrated throughout different areas. In the earlier stages typically the sustainability team ${ }^{17}$ or person would be the internal resource who delivered an ER business case and sought approval, even if they were not the originator of the decarbonisation idea. In corporates more advanced in their decarbonisation efforts there was a greater number and spread of positions with dedicated roles or parts thereof relating to $\mathrm{ER} /$ sustainability within areas with higher associated emissions or the ability to influence external parties' emissions. Increasing sustainability awareness, resource and roles in different areas was seen as a major positive step towards decarbonisation (Participants $A, B, D, E$ ), and the absence a negative step (Participant F). A later evolution than explicit integration within some roles (Proactive stage - Table 2) is emission responsibility being inherent within all roles due to environmental concerns being part of the business purpose (Systemic Stage onwards). Whilst Participant $\mathrm{C}$ described sustainability as being inherent in everyone's

17 Sustainability team was the most used term, other terms being comparable variants. 
roles, from other comments it was evident the extent of decarbonising activity was still reliant on the sustainability advocacy level of individuals rather than universally guiding the business approach. (The financial resource aspect of decarbonisation is covered in section 6.5.2).

Corporate policy on ER was seen as essential to ensuring decision-making aligned with minimising emissions and setting the pace of progress. "It's very policy driven, within the corporate environment. So [corporate] policy is definitely a big lever to pull to make things happen" (Participant E). Having a policy meant that a decision was not as reliant upon the views of the decision-maker involved unless an exception to policy was deemed justifiable. "Changing policy and changing the procedures there, then it future proofs us and gives us a safety net... that also helps [hold] people to account, as well." (Participant A). Common policies mentioned include air travel, replacement fleet vehicle selection and supplier contracts/performance targets. "Suppliers have to comply with ... specific sustainability KPIs [Key Performance Indicators]" (Participant C). As with internal progress on ER, policy recognises suppliers also need to maintain ER. Corporate ER policy is an area that is still maturing, with "social and environmental policy soon to be a framework that sits over the top of everything" (Participant E). The degree to which policy supported a more expensive ER-achieving option varied. Some CLCFs expected ER to be cost-neutral or cheaper over the decision's lifetime, whereas others incorporated a carbon price or had allocated carbon funds.

In addition to corporate policy procurement and property management's relationships with suppliers were seen as very impactful upon ER progress. Participant B put it most succinctly: "procurement drives sustainability far faster than the internal sustainability person." For instance changing electricity or office paper supplier to being renewably sourced or already offset by the supplier respectively can reduce reported emissions for that item to zero (Participants D, E). Supplier relationships also gave greater ability to plan for reducing emissions. Participant A spoke of procurement staff gaining early sight for NZ availability of lower emission vehicles, and the ability to influence those plans. A change of supplier or an 'inherited' ER involves far less effort than internal change. This approach presumes the availability of a suitable supplier; suitable supplier options were not always present. Due to this demand though the size and 
availability of suppliers had increased, with waste avoidance options given as an example (Participant $\mathrm{C})$.

Becoming increasingly 'agile' was also seen as advantageous to identifying and advancing ER opportunities and the corresponding internal changes required for implementation. In this context agility can be seen as the ability and capacity to act within the workplace upon change in a beneficial way (Qin \& Nembhard, 2015). Having an 'agile mindset' (Participant A) or working within an 'agile format' (Participant D) highlighted the importance of being able to operationally change based upon previous outcomes, and to collaborate effectively across internal teams or suppliers on initiatives. "Anyone in the business can come up with an idea, ... we have a chat about it, and see whether there's legs, and then we throw together a business case" (Participant D). Another agile workplace characteristic is staff empowerment (Qin \& Nembhard, 2015). Employees feeling able to suggest initiatives regardless of role contributes to identifying more ER opportunities (Participants C, D).

An early approach and still prevalent is to instigate ER initiatives from the 'bottom-up'. Participants described the bottom-up process as a series of conversations, formal or informal agreement on objectives, determining priorities, the adoption approach of the ER initiative, formalise them into a business case outlining the impact and benefits of the initiative, and then to support or undertake actions towards desired outcomes whilst navigating multiple, potentially competing, corporate priorities, as proposed initiatives ascended through the layers of decision-making seniority. The recommended action(s) of the business case could vary widely in type and scope; an internal policy, target, change of operational process, feasibility investigation or other approaches may result. The 'bottom-up' approach was seen as effective as it facilitated support from the business area(s) involved in the initiative. Several limiting factors for the bottom-up process existed. Having adequate sustainability human resources to maintain conversations to pursue ER initiatives (Participant D), and implicitly there seemed to be a restriction to operational changes, rather than a strategic shift or alteration in business purpose. This did not preclude though some 'bottom-up' instigated changes e.g. departmental carbon budgets, having potentially far-reaching and strategic consequences. 
More recently 'top-down' engagement in ER strategy increased as well as the bottomup business case approach. Top-down involved greater executive engagement, with increasing executive sustainability exposure and involvement in forming ER initiatives. Several participants described strategic sessions held internally by the corporate, where external experts ${ }^{18}$ presented to the executive team on various environmental aspects, which were then used to aid executive decisions (Participants $A, B, D, E$ ). Participant A revealed that "in that forum ... there was a real understanding that climate change is a significant material issue and we as a business must do our part." The realisation that climate change has a direct impact upon the business as well as the environment is a key aspect in corporate support for ER, as then ER is recognised as having financial as well as reputational implications. Regardless of whether a top-down or bottom-up approach was discussed all participants indicated that ER decisions sat within the executive team, indicating they are seen as having strategic relevance.

The difficulty of achieving and sustaining ER was unanimously agreed, due to various factors. "It's been an interesting up and down journey for us, as opposed to just a straight down journey" (Participant E). ER progress amongst those interviewed more advanced in their progress was viewed as something that needed maintaining, rather than a set state. Emissions year on year fluctuated due to (variously mentioned) changes in business activity, such as volume of services/products sold, corporate air travel, or external factors such as the proportion of renewably sourced energy supply to the New Zealand electricity grid or demand for services.

\subsubsection{Areas of greatest progress and enabling factors}

Two common areas of greatest progress surfaced: energy use efficiencies and transport efficiencies. Energy efficiencies were predominantly through reduced electricity use and switching to renewable energy electricity suppliers. Transport efficiencies were achieved involving people (both customers and employees), products and services in a variety of ways. Product ER progress was through reducing product movement via improving logistics, distribution site choice and relocation to reduce product miles travelled and enable more modal shift from road to rail, air to ship, and steady driving where steady fuel-economic speeds are used to increase driving efficiency. For people and services office/branch relocation to increase public

\footnotetext{
${ }^{18}$ External experts may be invited or part of an existing sustainability panel/board.
} 
transport options or reduce average distance from home, a switch to EVs where possible, increasing online interactions/working from home options to lower the need to travel were referred to. Waste reduction or redirection was also cited by several as an area of greatest progress, more because of the high employee engagement and proportional drop in associated emissions for this source rather than its impact upon total absolute emissions.

Many of the internal enabling factors were also mentioned by participants in response to understanding approach and progress, such as reporting, targets, ER initiative creation and governance, corporate policy, internal sustainability resource, and supplier requirements. Therefore primarily external enabling factors are explored here. Customer demand for lower emission offerings was considered necessary to offer lower/zero emission alternatives to current products/services if costs to provide the alternative were higher. Whether the downstream offering recipient was a consumer or another business, their willingness to apply pressure to reduce emissions and if needed pay more were seen as necessary. "So you look at [redacted company names], [a] big chunk of our revenue ... have got some great targets themselves." (Participant B). This is a positive effect of the GHG Protocol approach, where one of the CLCFs is pressured as a supplier to reduce emissions.

For CLCFs with non-business customers public pressure combining with internally suggested change is seen as a powerful enabler of change. Participant D observed that "events do really help, or the negative press... when it's said externally [as well], then it really helps build our case. ...the whole Greta movement [the mass school strike for climate], that's been really helpful." The implication was that ER progress would have been slower without these external events. For Participant $C$ "it was the 2015 Paris agreement that ... spurred us into action in terms of we need to do more, that was definitely the driver".

Whether the event in 2018 of becoming a founding member of the Climate Leaders Coalition (CLC) enabled greater ER progress was neutral to positive. Participant C saw founding CLC as making little difference: "The company's been on its own journey for years before". Founding the CLC was positioned as a signifier of that progress rather than enabling further progress for the corporate. Another two participants $(B, F)$ emphasised it was more internal and company group decisions that impacted 
emissions with no knowledge of CLC enhancing progress. More positively three participants saw the initial (and subsequent) CLC pledge contributing: "having them [both pledges] act as targets ... really helped the business to commit and provide resources to help us achieve the targets. ... [but] it wasn't the only thing that was driving progress." (Participant D). Participant E saw the second (2019) pledge as more influential: "What the Climate Leaders Coalition gave us is we've got science-based targets now, we know what we need to get to, we've got a climate action plan, we just need to deliver on this.". The publicity of founding CLC helped with "the broader engagement piece with our supply chain and with our people." (Participant E). Corporate A also have agreed ER commitments within their industry: "we collectively as a group set targets and again, we are held accountable to that as well. And also, the Climate Leaders Coalition." (Participant A). So most saw founding CLC as helping progress but not decisively.

\subsubsection{Areas with more to achieve and hindering factors}

Current government policy was seen in many cases as a barrier or at best unsupportive of further progress. The need for government policy assistance is "right now massive, with the scale of change that needs to happen and the speed it needs to happen at." (Participant $\mathrm{C}$ ). The absence of policy certainty around future fuel energy direction was seen as a barrier to corporate heavy transport investment. The slowness of government action lead Corporate $\mathrm{C}$ to work "I mean directly [emphasis in original] with the Climate Change Commission at the moment to push for more targets on transport". In the absence of government transport emission targets Participant $C$ could not see their business achieving carbon neutrality.

All participants mentioned purchasing electric or hybrid company related vehicles as part of their ER activity. Multiple raised various government policy barriers present to wider EV adoption. In NZ when selecting an electric or hybrid company car there are additional upfront and tax costs incurred by the company. The cost of an electric or hybrid vehicle is still significantly higher than their ICE (internal combustion engine) counterpart unless in the luxury category (BloombergNEF, 2021; O'Carroll, 2021). Companies pay a fringe benefit tax if an employee can use a light passenger vehicle privately (Inland Revenue NZ, 2021). Fringe benefit tax has "definitely been a massive challenge for us." (Participant E). Since the interviews the NZ government introduced 
a rebate scheme however this does not cover the price difference and fringe benefit tax is still payable (NZTA, 2021). No CLCF has declared restricting employee choice of company vehicles to electric or hybrid only, so it relies upon employee preference. Selecting a more expensive car reduces the salary proportion of an employee's payment package. Several participants highlighted this is compounded by work safety requirements. NZ's workplace safety regulator requires a suitable charging station installed at the house if home-charging will occur (WorkSafe, 2019). This may further preclude electric vehicle selection and adds to company costs.

NZ government policy was not the only hindrance. Any EV had to also meet other corporate criteria. "There are some issues ... a two star NCAP rating, [or] ... it just doesn't have the capacity." (Participant A). Commercial low emission vehicle options are currently limited in NZ. Employee emission intensive behaviour, including flying between offices and opting to attend in person when other options were possible were also mentioned. Participant $\mathrm{E}$ spoke of the process to get ER initiatives agreed and in place not always being as fast as desirable. The need for more resource is often present. Participant F commented on they've been "pushing to - try and get more resources internally." Similarly Participant B observed that "we're a small team so we need to push out that work". Many spoke of the difficulty of getting employees to adopt greater modal shift (road to rail/bus, car to bike) or not to travel (working from home, video-conferencing). (NZ does not have a comprehensive nor high-speed rail network so the air to rail modal shift is not pursued by sustainability staff). Lower emitting corporates advanced in their ER efforts were starting to struggle to identify further significant reductions that did not challenge their business model. "Electricity ...we can't really tackle any more, ... we can look into solar panels, but aside from that we can't really see how we can reduce it other than literally closing [redacted], and that's not the right strategy." (Participant D). Getting beyond efficiencies into fundamental changes in the business offering, or limiting or reducing sales volumes or profits remained unexplored as viable options in responses.

\subsubsection{COVID impact}

COVID impact on product/service demand varied across the CLCFs interviewed. COVID restrictions forced temporary operational changes for some CLCFs including some whose product/service demand was unaffected, opening up consideration of 
longer-term changes for some of these CLCFs as a result. For two CLCFs interviewed COVID dramatically altered demand, and associated emissions ${ }^{19}$. One CLCF experienced little demand, another's skyrocketed. Both resulted in increased emissions per unit of offering. Operations were stretched in one case, causing normal operational process efficiencies to waver, and in the other fixed emission overheads became relatively larger due to reduced throughput ${ }^{20}$. Increased demand resulted in looking at alternative transport modes, and for the latter a slowing of delivery to maximise fuel efficiencies thereby reducing emissions for international shipping. For a third corporate demand was not immediately impacted, however the longer-term impact upon supply chains was yet to be known which could enforce reduced activity and associated emissions.

For the remaining three corporates interviewed demand for their offering was largely unaffected, however COVID travel restrictions proved business viability without travel, opening up new ER possibilities. Two highlighted future decarbonisation opportunities COVID presented by proving the viability of potential changes in employee policy and/or behaviour: a reduction in commuting and in company vehicle fleet size due to working from home, and a reduction in flights and driving due to videoconferencing more than previously (Participants D, E). Pre-COVID flying was seen as an essential business activity despite emissions: "the business didn't think that they could decrease their use of flights" (Participant D). It took COVID to introduce the realisation that "the business still runs, we can still continue ... without flying" (Participant D). Another hoped COVID had 'flipped' the default to "I can't travel for my job unless I have a really good reason" (Participant E). COVID opened up the possibility to "reduce the budgets ... for air travel, and reinvest that money that would have otherwise been spent on good remote working tools" (Participant A). No participant foresaw no corporate air travel. For one participant the concept of eliminating fleet cars arose. "Do we reduce the fleet, or do we just get rid of them?" (Participant E). Whether these temporary behaviours could be made to persist was seen variously to depend on effective communication, implementing internal carbon budgets, and relevant corporate policy.

\footnotetext{
${ }^{19}$ Participant letters are not provided here to protect anonymity.

${ }^{20}$ Lifecycle emissions would have dropped significantly for the latter because of much lower offering demand reducing downstream emissions, however this was not part of what was currently captured in their emission reporting.
}

Page $\mid 68$ 
COVID also highlighted changes in electricity use. Emission savings from temporarily vacated premises was described as 'minimal' (Participant E), due to the need to maintain basic building services and occasional staff presence. An opportunity was identified for electricity efficiencies if a similar 'lockdown' scenario reoccurred. COVID also shifted where the electricity was being used. The absence of a standard to calculate emissions by employees working from home became apparent, highlighting future complexities in calculating employees' emissions when home. "We actually need to work out a way of capturing what are we responsible for, ... it's going to be really, really hefty challenge for us and many others." (Participant E). This highlights some of the complexities of defining emission responsibility, let alone calculating it, and potentially raises some moral dilemmas, such as 'reasonable' home electricity use whilst working at home potentially coming within the domain of an employer.

Participant $D$ felt more confident in achieving their ER target post-COVID: "Prior to COVID we were wondering how we would achieve our [redacted]\% reduction, because it is quite aspirational given that we have done so much already in the past... Now we're thinking OK the target's probably achievable." Half of those interviewed were reassessing targets as it was scheduled; none mentioned adjusting targets specifically due to COVID.

\subsubsection{Target Adjustments and future}

Four of the six interviewed CLCFs expressed concerns over how to meet their future emissions targets, with three (two high emitters and one lower emitter) placing them as 'aspirational', and another indicating it was unrealistic without major policy and funding assistance from the government ${ }^{21}$. All four mentioned in some manner the increased difficulties of reducing remaining emissions, though none hinted at business transformation. The two lower emitters indicated they had exhausted all major scope 1 and 2 ER opportunities and that whilst incremental improvements could be made they were uncertain how to achieve further substantive ER. Three of the six thought SBTs (Science-Based Targets initiative, 2020), will further improve ER progress. Target specificity and coverage is still maturing amongst CLCFs; SBTs are gradually being adopted by the CLCFs and have the target characteristics Dahlmann et al.

\footnotetext{
${ }^{21}$ Participant reference omitted to aid anonymity.
} 
(2019) found are more likely to achieve ER. Whether Dahlmann's (2019) findings hold if a corporate has reached saturation point (corporate ER progress stage 5) as the lower emitters have is unclear, as to reduce ER when 'saturated' requires more fundamental changes in business approach. Most participants saw SBTs as important and necessary, but still aspirational due to external dependencies, long-term government policy decisions related to decarbonisation, followed by consumer behaviour needed to drive demand for low emission policies and products/services, being the most consistently mentioned. Despite Stakeholder theory helping illuminate influences on corporate activity interviewees made it clear that stakeholder influences were not seen as a decisive factor.

All higher-emission corporates interviewed indicated that targets were becoming increasingly harder to obtain: "...we've just scraped through [meeting the last target], it wasn't an easy thing to do". (Participant $\mathrm{X}^{22}$ ) The same participant was similarly dubious about further ER to meet future targets: "if there was an easy solution then we would have already done it", a common sentiment amongst four of the participants. Two participants provided a stark contrast. Participant A was confident that "we'll keep warming within 1.5 degrees as our contribution... And we've set up a road map ...that tells us how we will get there". No other businesses interviewed had this confidence of aligning their ER with $1.5^{\circ} \mathrm{C}$ over the next 9 years to 2030 . Corporate $\mathrm{D}$, carbonneutral due to ER and offsetting, was looking to become 'climate positive': "the operational side is definitely moving beyond carbon neutral, because we're already doing that. So we're thinking about what's next. And for us is moving into the whole climate positive space, and trying to understand what our role is in that." Climate positive was described as assisting other businesses to reduce their emissions, even though it did not impact upon Corporate D's reported emissions.

Regardless of progress stage of the interviewed CLCF, decarbonising initiatives needed to be considered compatible with 'being a business'. One participant describes the process as "trying very much to combine both the business and environmental benefits so that it's not me pushing my agenda, it's very much taken on board as a something of interest to the wider company" (Participant F). Whilst finding common

\footnotetext{
${ }^{22}$ Participant " $X$ ", rather than the letter is given as this quote in conjunction with other quotes may undermine anonymity.
}

Page $\mid 70$ 
ground is a part of negotiation, it highlights the gap between environmental and business interest, that environmental activities such as ER still require internal advocacy, rather than being intrinsically aligned to business decision-making. Participant $\mathrm{C}$ described the dilemma as "how do we take a leadership position in this role to encourage the transition at the same time as being a business". The context was clear in that the need to decarbonise does not alter the need to be profitable. Participant $\mathrm{X}^{22}$ indicated it was unclear how the recognised need and corporate willingness to move demand away from their current carbon-intensive offering - how these two objectives would be reconciled. Profitability places a clear limitation on the acceptable approaches to progress decarbonisation and limits a business from evolving past the Systemic stage (Table 2). Profit may further limit them to the preceding Saturated stage if a transition path to an alternative decarbonised product/service whilst maintaining profit is not seen as potentially viable. "We've got to still keep posting profits, healthy business, ... all three [business, people, environment] have to be chugging along really well, for business needs the other two" (Participant B). Whilst recognition was unanimous that decarbonisation must occur and in business reliance on a 'healthy' environment is recognised, mention of a potential need to eventually rethink the profit purpose of business was absent. 


\subsection{Progress by Corporate}

A brief description of each CLCF is provided and salient details on their ER progress. The order of corporates is to aid readability and has no other significance.

\subsubsection{Spark NZ}

Spark NZ's (Spark's) 'birth' was on 8 August 2014, when it was rebranded and refocussed from being a state-run nationwide telecommunications utility company (Telecom New Zealand) to "Spark NZ", a 'digital services provider', owner of the national fibre network (Spark, 2021). Spark (then Telecom NZ) commenced emission reporting prior to 2010 and has throughout that decade focussed on win-win situations - reducing (purchased) electricity use whilst improving network efficiencies, capabilities and robustness, reducing relative emissions and costs markedly. Concurrently digital growth in NZ has been rapid; a $700 \%$ increase in data traffic has occurred since 2016 (Spark, 2020b), with data centres currently their largest energy usage (Spark, 2020a).

Spark's predecessor Telecom New Zealand had a theme of 'world-class carbon performance' (Telecom NZ, 2011, 2012, 2014) focussed on their performance relative to other telecommunication corporates globally. Until recently Spark had not given decarbonisation initiatives a broader context and they were not widely publicised. Carbon emissions were treated as a reporting item, reflected by the high use of carbon related words ${ }^{23}$ pre-Paris and post-Paris/pre-CLC, but negligible use of the word climate across this entire period. A general theme of technological innovation to meet customer needs was present both pre-CLC and post-CLC, with perhaps more emphasis on customer-driven post-CLC ${ }^{24}$. Post-CLC emissions were more broadly contextualised, with 'climate' being fourth most frequent.

Recently Spark re-positioned itself to being NZ's "high-productivity low-carbon economy" enabler (Spark, 2020a). Whilst collaboration is an existing theme an enabler - a company who enables others to reduce their emissions, is a new theme. This places Spark as fulfilling a wider role of aiding decarbonisation. Growth is seen as a positive attribute, as growth implies more carbon reductions are enabled elsewhere.

\footnotetext{
${ }^{23}$ Carbon, 'greenhouse gas', 'greenhouse gases', and ghg

${ }^{24}$ Reuse of sentences across annual reports means determining a change is inconclusive.
}

Page $\mid 72$ 
The increased use of remote digital tools such as video-conferencing and cloud-based software during COVID restrictions in early 2020 appears to be the catalyst for this repositioning. Media release timings support this assertion. Since the 2014 rebrand there were 515 media releases ${ }^{25}$. Only ten of these referenced climate change, emissions, or energy efficiency, despite the subject matter of many more articles being relevant to decarbonisation. Five of these ten were after 1 March 2020. Spark in 2010 had many of same initiatives as they continue currently; travel and waste reduction, energy efficiencies, reduce use of refrigerants (Telecom NZ, 2010). Main target is $25 \%$ reduction by 2025 based upon base year 2016 levels. Seen as compatible with SBT but has not been certified as such CDP 2020. On the positive side Spark from 2016 have had an increasing internal price on carbon (CDP, 2020b). ER initiatives are called "no-regrets measures with zero marginal financial impact" (CDP, 2020b, C4.3b), illustrating Spark's current ER scope is strictly limited to 'win-wins', as described in section 6.5.1.

\subsubsection{New Zealand Post Group}

New Zealand Post Group (NZPost) has a similar history, from being a former staterun utility to operating as a commercial concern. NZPost delivers parcels and envelopes, both of which are now open to competitors (NZ Post, 2018). For NZPost business outcomes comparable to a commercial business but is legally required to provide a "universal" delivery service (NZ Post, 2018), meaning that NZPost must offer deliveries to every address in New Zealand.

Again similarly, NZPost was pursuing ER in 2010 within the 'win-win' scope: "There is a clear link between our investment in reducing environmental impacts and reducing the operating costs of our business." (NZ Post, 2010, p. 51). NZPost though was already using absolute ER targets, and provided greater transparency of emissions composition and causes of increases and decreases compared to Spark and many other CLCFs. Continual growth in NZ online shopping (NZ Post, 2014), aided by NZPost's 2012 launch of the international postal redirect service 'YouShop' for delivery from overseas businesses not delivering to NZ (NZ Post, 2013), lead to ensuring

\footnotetext{
${ }^{25}$ Communications by Telecom NZ are not included due to the rebrand, and Telecom NZ related articles held at Telecoms.com suggest that their relevance is low.
}

Page $\mid 73$ 
NZPost could meet demand-driven growth as the main theme for the 2014 annual report (NZ Post, 2014).

Increasing emissions due to increasing delivery and handling volumes despite decarbonising programmes to reduce emissions resulted in NZPost outlining the merits of relative versus absolute emission measures (NZ Post, 2014). 'Intensitybased reporting' (NZ Post, 2015)) was then formalised as being 'per parcel' and 'per letter' (NZ Post, 2016), completing a shift to relative targets. Emission reporting evolved in 2019 to having both relative and absolute components, with relative emissions being used to help inform rather than define progress. These shifts appeared unrelated to external events such as the Paris Agreement and the founding of the CLC.

Growth again became a central focus in 2017, attributed to the increasing export market due to online sales by NZ businesses as well as inbound parcel growth (NZ Post, 2017, p. 16). NZPost's tone is supportive of growth in demand and aligns it with NZ's success as well as its own, though growth as a driver of emissions is acknowledged (NZ Post, 2017). Growth is also recognised as an opportunity: the increased revenue can be invested in change. The Paxster (urban electric postal delivery vehicles) rollout also occurred; the result of a collaborative development between the supplier and NZPost (NZ Post, 2017). Just before CLC was publicly founded the decarbonisation fund was established and an absolute emission target introduced (NZ Post, 2019).

NZPost's evolution from targeted efficiency programmes to a more general transition was reflected in the annual (integrated) reports26. Post-Paris/pre-CLC the terms consumption and programme dropped outside the top ten. Post-CLC carbon/CO2, emission/emissions and sustainable/sustainability claimed the top three spots, forcing reduce (and variants) from second to fourth. Electric jumped up from 18th to fifth, with waste dropping from fifth to sixteenth, and perhaps most importantly efficiency (and variants) from seventh to fourteenth.

\footnotetext{
${ }^{26}$ NZPost media release availability and relevance is sparse - the first available article is $23 \mathrm{Feb}$ 2018, with only two relevant articles since, despite also searching archived versions of the NZPost website.
} 
COVID increased parcel demand whenever public movement was restricted, with the largest spike post-March 2020 lockdown due to a parcel deliveries backlog (Sadler, 2020). As there was already a strong upward trend in NZ online sales pre-COVID (Shaw, 2019), the scale of longer term COVID impact on parcel delivery volumes above what it may have grown to regardless is yet to be identified. Decarbonising international deliveries remains largely undiscussed.

\subsubsection{Air New Zealand}

Air New Zealand (AirNZ) is the main domestic (and international) airline for passenger transport and air freight, 52\% government owned (Air NZ, n.d.), and covers over $80 \%$ of the domestic air-travel market (Forsyth Barr, 2021). Over 99\% of AirNZ's carbon emissions are from jet fuel (Air NZ, 2020b). Comprehensive action has been undertaken to minimise ground emissions and fleet efficiency, however a renewable jet fuel source has yet to be secured. Before COVID, predictions were for annual global passenger growth of $4.6 \%$ (Mazareanu, 2020). Current 2021 predictions are 57\% lower passenger traffic than 2019 levels (IATA, 2021); whether global passenger flights will remain for some time at a level substantially lower than before COVID is unknown.

Whilst available media releases covered the full eleven years, relevant content commenced with the September 2015 sustainability launch, despite previous subject material relevant to ER. In 2008 (then) CEO Rob Fyfe stated "our goal is to be the [emphasis added] world's most environmentally sustainable airline" (Air NZ, 2008, p. 14). Media releases prior to 2015 did not reflect this aspiration and sustainability language was not used in an ER context. For instance in 2011 receipt of new more fuel-efficient airplanes focussed on the improved aspects of customer experience and operational efficiencies, with no mention of carbon emissions, e.g. (Air NZ, 2011). The 2015 Sustainability launch goal, "becoming one of the [emphasis added] world's most sustainable airlines" (Air NZ, 2015c, para. 9), was slightly weaker. However surrounding actions, such as increased governance through an independent Sustainability Advisory Panel established in 2014, instigating annual sustainability reports, and placing sustainability more central strategically, were more comprehensive. 
Post-Paris/pre-CLC the long-term growth strategy is treated as unequivocally successful in subsequent years despite increasing emissions. "Over the past five years, the airline has successfully executed a strategy focused on expanding ... [to] a network that is 30 percent larger" (Air NZ, 2017a, p. 7). AirNZ avoid the conflict of growth and ER by presenting sustainability and ER as separate concerns. The Tourism section in the 2015 sustainability report is headlined with: "Our role [in growing New Zealand's tourism to $\$ 41$ billion by 2025] is to generate demand ..., invest in the development of new markets, and provide a network and connectivity to enable growth" (Air NZ, 2015b, p. 26). AirNZ reconcile growth in tourism flights (And associated emissions) with sustainability by only looking at immediate environmental impacts of tourists. Existing and longer-term climate change effects on the tourist locations and the conflict of growth and ER is absent. In 2015 the Carbon and Tourism sections are on the same Annual report page but communicated without reflection on each other, the Tourism section stating that "Generating demand for travel to New Zealand is integral to all our marketing" (Air NZ, 2015a, p. 13). A similar strategy exists domestically, as evidenced by off-seasonal regional event sponsorship and surrounding commentary. Conjointly Air NZ have tried to obtain an ongoing reliable high-volume source of biofuel to reduce their emissions (New Zealand Government, 2016).

AirNZ's most frequent relevant words changed the most from pre-CLC to post-CLC of any of the CLCF's media releases, reflecting the change in ER initiatives from groundbased efficiencies and biofuel investigations to aircraft-related efficiencies. Pre-CLC $\mathrm{EVs}$ /electric vehicles was the second most frequent term; post-CLC there were no mentions. (AirNZ reached the target of having 100\% electric light vehicle fleet (76 cars) in 2017 (Air NZ, 2017b) ). Biofuel, ground-based energy use, such as plane tugs, baggage tugs and belt loaders onto planes, are mentioned post-CLC in sustainability reports e.g. (Air NZ, 2018a) but not in media releases, perhaps as progress in these areas is stalled (biofuel) or gradual (ground-based) and therefore less newsworthy.

Post-CLC media releases focus on aircraft related efficiencies and offsetting. Aircraft related efficiencies vary between relating to the model of aircraft, to aircraft modifications. Most offset mentions relate to AirNZ's FlyNeutral, an offset tool facilitating travellers to offset their flight's emissions, rather than AirNZ offsetting. The implication is that carbon offsetting is seen as the traveller's responsibility. Then Chief Page $\mid 76$ 
Executive Officer Christopher Luxon states that "we [AirNZ] risk losing our social license to operate if we do not genuinely address climate change" (Air NZ, 2019a, p. 2), however there was no evidence of recognition of the conflict between growth and reducing emissions by AirNZ. This is only voiced thus far by the independent Sustainability Advisory Panel (Air NZ, 2018a), so whilst changes in other areas to reduce emissions are commendable, they are not a significant part of AirNZ's overall emissions. Air NZ (like Fonterra) use the "better option" argument, indicating that their fleet is amongst the most emission efficient globally.

In 2020 government-imposed international travel restrictions due to COVID resulted in vastly reduced long-haul passenger travel routes (Air NZ, 2020a). AirNZ air cargo flights increased during the same period, but by less than the corresponding decrease in passenger flights, resulting in a $19 \%$ overall emissions decrease. AirNZ also released new carbon targets and strategy. Foran also states that "further significant decarbonisation will be required, especially because family connections, business, tourism and New Zealand's key export industries rely on international air transport" (Air NZ, 2020c, p. 3), emphasising the role of air travel as essential for NZ's social and economic wellbeing. This is not unfounded given NZ government engaging AirNZ to aid in international cargo as an essential service during COVID and beyond (Minstry of Transport, 2020). Electric planes for domestic routes are described as almost a decade away (Anthony, 2021), and biofuels cannot be sourced reliably at the scale needed (NZ Herald, 2017). Mention of future financial risks due to climate change such as the increase in extreme weather events causing flight cancellations, and how ER helps reduce these, remain absent. AirNZ's growth strategy remains (Air NZ, 2020a).

\subsubsection{Ports of Auckland Limited}

Ports of Auckland Limited (PoAL) operates one of the busiest Australasian ports, are a key NZ port for cruise ships, and are the port immediately adjacent to NZ's largest city, Auckland (iCOntainers, 2020). PoAL is owned by Auckland City Council and its purpose is "to operate as a successful business [stipulated by the Port Companies Act 1988, section 5]; i.e. to be as profitable and efficient as comparable businesses that are privately owned, and sustainable over the long term" (PoAL, 2020b, p. 4). What sustainable means is not elaborated upon. 
PoAL position themselves as pioneers rather than technologically advanced enablers. As with Spark, PoAL's first carbon inventory was completed circa 2007 (PoAL, 2010). Pre-Paris decarbonising was framed as being "lean and green" (PoAL, 2013, p. 38), emphasising the dual benefits of reduced costs and emissions through energy (fuel and electricity) efficiencies. Post-Paris/pre-CLC the use of 'pioneer' was headlined in both 2016 and 2017: "It is our ambition to be the most sustainable port in New Zealand and to be a pioneer in sustainability within the industry" (PoAL, 2016, p. 8). Pioneer positioning specific to decarbonisation was initiated post-CLC, with the consistent use and mentions of "first", be it in relation to Auckland (onsite hydrogen production and refuelling) (PoAL, 2019a), or New Zealand more generally (automated straddle carrier operation) (PoAL, 2018), or globally (full-size electric tug) (PoAL, 2020a). Another part of this pioneering narrative within annual reports is the goal to be NZ's first zero emissions port (PoAL, 2020a), the word zero being the third ranked word post-CLC 27 .

PoAL's pioneer stance covers port operations only: the quandary of increases in international freight (and associated rise in absolute emissions) is portrayed positively and inevitable. A zero-emissions port means, for PoAL, zero operational PoAL emissions. Emissions associated with freight and cruise ships are only mentioned obliquely in terms of providing shore power whilst ships are docked to avoid air pollution, or lower emissions per container due to dredging to ensure larger ships can dock. Freight volume increasing is presented as a necessity of Auckland's increasing population. PoAL is supportive of the transition to a low-carbon NZ, with increasing vehicle shipments predicted due to rising electric vehicle demand (NZ has no local car manufacturing), mentioned across several reports. Previous and recent moves to better integrate rail and port freight to lower domestic freight emissions are present (PoAL, 2017, 2019b, 2020a), capacity will decrease ER. PoAL rightly identify Auckland port as the lowest carbon port for fulfilling the import demands of Auckland's growing population. Whilst everything said is accurate and the efforts to reduce operational emissions are impressive, the limitations of the portrayal are concerning. The wider emissions implications of growth in cruise ship, import and export activity are not addressed. This gap extends to PoAL's 30 year plan (PoAL, 2020c), which recognises

\footnotetext{
${ }^{27}$ Media articles post-CLC similarly frequently use 'first', surpassed only by emission(s), hydrogen, automation, and hub. Whilst the word zero is also present it is relatively less frequent than in the annual reports, as determined by the articles' subject matter.
}

Page $\mid 78$ 
only port operations and potential relocation emissions, sees substantial future increases in port activity as inevitable.

\subsubsection{Z Energy}

Transport related emissions are a major source (47\% in 2018) and increasing contributor to NZ's carbon emissions, having doubled since 1990 (MfE, 2020). Z Energy (Z) is NZ's largest fuel distributor, with circa $400 \mathrm{NZ}$ sites through its three distribution outlets: Z 200+ (Z Energy, n.d.-b), Caltex 140+ (Z Energy, n.d.-a), and Pak'NSave - 53 (Newsroom, 2018), supplying 45\% of NZ's transport fuel (MfE, 2020).

Z's emissions-related portrayal has evolved from 'waste warriors' to future-focused energy distributors. For media releases the top words evolved from waste (pre-Paris), renewable energy - charging and biodiesel (post-Paris/pre-CLC), to carbon (postCLC). Annual reports mirrored this evolution, with the added insight that offsetting was first mentioned in an emissions context post-CLC. These findings also match Z's declared shift in focus from waste to renewable energy sources (Z Energy, 2017) and changes in transportation needs. A key ingredient in this shift to future energy is convincing the audience of energy agnosticism - that $Z$ is not wedded to fossil fuels so that they can be 'part of the solution' despite being self-admittedly currently part of the problem (MfE, 2019a). As a fuel distributor showing willingness and the capability to change energy supply sources is essential for ER plausibility. Post-Paris/pre-CLC media releases emphasised renewable fuel sources, however these mentions dropped markedly post-CLC. In practice this switch to renewables has proven problematic for Z Energy, which has cited barriers to cost-competitive tallow supplies resulting in suspending a biofuel plant (Gibson, 2020), and extremely low electric vehicle ownership in NZ (Motor Industry Association, 2020a). Accordingly emphasis post-CLC has shifted to advocating renewable energy policy and certainty, including a carbon price, together with offsetting.

As with PoAL the picture for ER is less congruent when the focus is broadened. $Z$ emphasise concern and action regarding carbon emissions sustainability on their flagship Z Energy website (‥co.nz). However there is no presence under the Caltex branded website (caltex.co.nz) in regard to climate change or ER (Z Energy, n.d.-a). The loyalty scheme 'Pumped' across both Z and Caltex brands provides fuel discounts with incentives based upon the volume of fuel in a certain time period. There is no Page | 79 
associated mention on these 'Pumped' pages of the adverse impact of greater petrol consumption on emissions and the climate. Also Z-Energy's price-led component of its distribution network has dramatically expanded with supplying Pak'NSave - a nation-wide budget supermarket with self-service petrol outlets, commencing in 2020 (Newsroom, 2018).

Amongst this, COVID restrictions dramatically reduced fuel demand during the first half of 2020, with a substantial financial impact (Z Energy, 2020c). Z Energy's primary focus in early 2020 was on "remaining competitive" (Z Energy, 2020c), to maintain their profitability. By contrast Z's most recent submissions to government can be considered a stronger, more rapid statement for decarbonisation than through other communication channels. Z advocate for carbon prices, ER and greater central government intervention through policy to accelerate decarbonisation in their most recent submission within the study ( $Z$ Energy, 2019b). The urgent need of policy that supports and accelerates recognising climate change costs is emphasised. This was unexpected and contrary to the anticipated role of corporate submissions as a way to slow or reduce policy change. However a quicker, more policy driven approach to decarbonisation may be favourable to this corporate. (See section 6.4.4). And submissions are perhaps a better communication channel for this message than other channels, where the target stakeholders are investors and public members, neither of whom may be immediately convinced that requesting (in effect) higher fuel prices is desirable. Z notably stop short of asking for aggressive policy on reducing ICE vehicles or policy support in a change of business model to being an alternative energy distributor. $Z$ are appropriately wary of government talks of hydrogen as an energy source, as current intentions are it to be sold internationally, opening up price to fluctuations due to international demand (Z Energy, 2019a).

\subsubsection{Toyota New Zealand}

For several decades Toyota New Zealand (ToyotaNZ) are the largest seller of passenger vehicles, having sold over $20 \%$ of New Zealand's new light vehicles (Motor Industry Association, 2020b). Toyota Motors Corporation (TMC) - ToyotaNZ's parent company, position themselves as visionaries and a mass consumer conveyor towards a sustainable future, and ToyotaNZ aligns with this. ToyotaNZ's CEO states that "CO2 reductions are a journey for Toyota and our customers. This is why hybrids help us 
achieve reductions as we transition to alternatives when supply, infrastructure, and demand is ready" (Toyota NZ, 2020c, para. 8). A clear transitional 'journey' of fuelefficient cars to hybrids, then plug-in hybrids, then zero emission (battery or hydrogen) with ultimately Mobility as a Service (MaaS), where the vehicle type is suited to the context, is framed as the only sensible approach. The implied assumption is that steps cannot be skipped. In fact TMC's CEO explicitly warns of transitioning too quickly (Cao, 2020). Multiple interpretations are possible. The path can be seen as portrayed as a robust approach ensuring palatability to consumers and supporting a measured consumer, energy infrastructure and supply transition. Alternatively, it can be seen as a delay tactic that slows decarbonisation (Lamb et al., 2020), to ensure hybrid sales are maximised whilst they develop mass market fully electric vehicles (Farrer, 2021). Both could be true. Regardless of strategic motivation, their NZ 2019 new vehicle emission average of $167.5 \mathrm{CO} 2 \mathrm{~g} / \mathrm{km}$ is $4.8 \%$ below the NZ industry average (Toyota $\mathrm{NZ}, 2020 \mathrm{c}$ ), but both averages are still well above those in Europe, at 122.4 and $158.4 \mathrm{~g} / \mathrm{km}$ for new passenger cars and vans respectively (EEA, 2020b).

In contrast to Z, ToyotaNZ's media portrayal has not evolved over 2010-2020 inclusive, though the number of relevant media releases per period was small. On average only four relevant media release articles per year were published over the 11 years. To place this in context, there were over 80 ToyotaNZ media releases in 2020 alone (Toyota NZ, n.d.). This small number was surprising given the prominence of the Toyota sustainability ethos on the website, the hybrid Toyota Prius' global prominence, and TMC being recognised by CDP as a leader in ER (CDP, 2021; Toyota, 2017). Less surprising was hybrid being the most frequent (relevant) word across all periods, followed by emission(s), Enviro-Mark (now Toitū EnviroCare, the company used for carbon reporting certification), and environmental. Other words anticipated such as efficient/efficiency and economical were present within the top 20 but outside the top 5, which may be due to the subject material, writing style, or that hybrid electric vehicles (HEVs) - in this case predominantly non-plugin that create stored energy from engine breaking - have potentially considerably higher emissions per mile when compared with PHEVs (plug-in hybrid electric vehicles) or BEVs (battery-only electric vehicles) when used in a country with over $80 \%$ renewablysourced electricity such as NZ (MBIE, 2018). 
As with Z the move towards a new business model is stated. ToyotaNZ's future business model also involves a change in vehicle use and ownership. The term Mobility as a Service (MaaS) first appeared in media releases in 2020 (Toyota NZ, 2020a). This concept encompasses shared vehicle use rather than exclusive use or ownership, and multi-modal transport that is coordinated across transport types. There is currently no evidence in annual reports or media releases by ToyotaNZ of encouraging shared ownership. ToyotaNZ do have targets to increase the proportion of non-ICE vehicles sold (Toyota NZ, 2020d).

\subsubsection{Vector Limited}

Vector Limited (Vector) manages the electricity network lines and distribution within the Auckland region of New Zealand, controlling New Zealand's largest (by household volume) electricity network (Vector, n.d.-b). Vector positions itself as a future-thinking energy technology company, operating to a global standard. This is a stable positioning: pre-CLC and post-CLC media releases shared four of the top six most prevalent terms; technology, chargerlchargerslcharging, future and worldiglobal respectively ${ }^{28}$. The terms that moved into the top five are also informative. Post-CLC 'electric' moved from eleventh to second, and carbon from sixteenth to sixth. A year prior to CLC's launch Vector first began speaking of electric vehicles' potential as a 'V2G' (vehicle to grid) electricity source (Vector, 2017), then several electrification projects (charger stations and buses) occurred post-CLC. The term 'climate change' was first used in January 2017, and first included in an annual report that same year. 2017 was also the first year emissions were reported. Therefore it appears little understanding is lost by not having earlier media releases.

The reasoning Vector give for being a future-thinking energy technology company is consumer-led, which also means the use of this portrayal can be adjusted to suit the perceived situation. Using the latest technology is to minimise costs to the consumer, and more recently, network resilience. This positioning is perhaps inevitable given Vector's dividend structure. Profits are distributed as dividends to qualifying Auckland households, therefore the electricity consumers are also shareholders in the company

\footnotetext{
28 These rankings ignore words used in a broad range of contexts whose prevalence could not be usefully interpreted, such as energy and electricity. As only one media release was publicly available pre-Paris, this period is not included.
}

Page | 82 
(Vector, n.d.-a). The implication, as with some of the other CLCFs, is that the appropriate pace of change is set by the consumer, not an ER target.

\subsubsection{Ngāi Tahu Holdings Corporation}

Ngāi Tahu Holdings Corporation (NTHC) is a diverse corporate owned by the Ngāi Tahu iwi (a Māori tribe) with multiple business areas including tourism, forestry, property, farming and seafood, amongst others. NTHC's purpose is that it "generates revenue to support tribal aspirations and provide for future generations" (Te Rūnanga o Ngāi Tahu, 2020b, p. 71), in alignment with Ngāi Tahu's values.

NTHC started measuring carbon emissions in 2017, though unlike Vector an environmentally centred strategy precedes then. However of 187 media releases across the eleven years only four contained material relating to carbon emissions and three were from October 2018 onwards. Therefore no word frequency analysis was conducted. Similarly, in their annual reports it is only from 2017 onwards that NTHC refers to carbon directly. Prior to and continuing past 2017, more general environmental strategies are present including kaitiakitanga - a Māori word that simply translated in this context is environmental guardianship for all generations. This strategy has resulted in actions prior to 2017 that have incidentally reduced emissions. Tree-planting and regenerative farming practises, to improve water quality, and support biodiversity, are examples (Te Rūnanga o Ngāi Tahu, 2016).

Whilst NTHC is structured as a corporation, cultural differences do apply, especially regarding strategy formation and communication. For NTHC to communicate a strategic position on climate change beyond reporting required first forming tribal agreement that involves many huis (meetings) with Ngāi Tahu hapū (sub-tribal groups). So whilst the process can take longer than for other corporates and is not communicated till agreed, the strategy formation is more deliberative and inclusive than other CLCFs' strategy formations.

NTHC's climate strategy encompasses ER and adaptation. "Amidst change and loss there is also hope and opportunity" (Te Rūnanga o Ngāi Tahu, 2019b, From the Kaiwhakahaere section, para. 16). He Rautaki mō Te Huringa o Te Āhuarangi (Ngāi Tahu's climate change strategy) was formalised by Te Rūnanga o Ngāi Tahu - the tribal council (Te Rūnanga o Ngāi Tahu, 2018). As the climate change strategy 
document indicates, NTHC's decision-making needs to consider both climate mitigation and adaptation effects, which is unusual amongst the thirteen corporates. All others had less emphasis in initial climate related strategies on adaptation, with this appearing later, or in some cases, yet to. Due to the lack of publicly available information on NTHC little is known about their progress or specifics of the actions taken.

\subsubsection{The Warehouse Group}

The Warehouse Group (TWG) is New Zealand's largest general retail group with approximately 247 retail outlets (Toitū Envirocare, 2019). In contrast to Vector and NTHC, TWG started reporting their operating emissions before 2010 (TWG, 2008), reflecting their longer-term focus on ER. TWG's flagship chain "The Warehouse" - NZ's largest retail chain and still the source of over half the group's revenue (TWG, 2020a, p. 56), occupies a high-volume and low-budget retail market position, perhaps not an obvious location to find an early adopter of ER. However The Warehouse's origins are Sir Stephen Tindall, former CEO and founder, who also helped form and chaired the NZ Sustainable Business Council (CLC, 2019b).

Media releases available on the TWG website were few, despite companies within TWG regularly appearing in relevant mainstream news articles. Of the available 20182020 media releases and corresponding annual reports were compared and found relatively consistent in positioning. Three of the top five terms appeared in both sources and in the same order. So it was taken as reasonable that the absence of media releases available prior to 2018 did not hamper analysis, and annual reports could be taken as representative for all eleven years. Pre-Paris the term emissions was the most prevalent term, followed by recycle, waste and reduce (including their stem variants). Operating strategies and actions that simultaneously reduce cost overheads and emissions have obvious appeal.

Post-CLC TWG placed ER and sustainability as being parallel strategy initiatives (TWG, 2020a), listed and measured separately. Whilst this is an understandable way to rationalise complexity, the parallel approach allows 'carbon neutral' and 'sustainable and affordable' products positioning to seem congruent, though sustainable products' evaluation does not yet include the emissions during the product's lifecycle. Though TWG now have a Chief Sustainability Officer, and are more vigorously pursuing waste Page | 84 
reduction and wish to increase product 'take-back' (Dunn, 2019). This was followed in 2020 by The Warehouse launching "sustainable \& affordable"; the concept that cheap products does not necessarily mean unsustainable, explicitly resolving one potential reason for greenwash cynicism. (TWG, 2020b). (Other brands within the group share in carbon ER measures, but sustainability has not become part of their marketing identity.) Reflecting this shift, in post-CLC annual reports sustainability/sustainable became the most frequent relevant term, with emissions down to second and carbon climbing from mid-tens previously to third. Sustainability and emissions post-CLC were not mentioned within thirty words of each-other unless listed as separate strategic items, emphasising the current strategic separation. Of concern too is that their Scope 3 emissions increased $16 \%$ compared to the baseline year, largely due to emissions growth in sea freight (Casey, 2020), and that "we will be looking to increase our percentage of growth capital spend as we start to execute our growth aspirations" (TWG, 2019, p. 38).

Their future intentions for carbon ER are substantive if realised. There is an intent to remove suppliers who use carbon intensive sea freight (Harris, 2020), and to also looking at including production carbon emissions in the future (Casey, 2020).

\subsubsection{KiwiRail Holdings Limited}

The corporate purpose of KiwiRail Holdings Limited (KiwiRail) has tried to serve both ER and commercial since being established in 2008. "The Crown, as the shareholder, delivered a clear message to KiwiRail. Future investment support in KiwiRail would only be forthcoming on the basis of strong commercial principles." (KiwiRail, 2010, p. 3). KiwiRail's current positions itself as the low carbon alternative to road. KiwiRail's media releases relied heavily upon the fact that rail is a lower carbon freight transport alternative than trucking. Though relevant media releases were relatively sparse with 17 , or $19 \%$ of all media releases, and only covered from late 2017 through to end of 2020, a definite picture for this period emerged. The top five most frequent words both pre-CLC and post-CLC were rail, freight, emission/emissions, reduce (or variants) and road. As the frequency attests, the fact that moving freight by rail results in an estimated "66\% fewer carbon emissions than heavy road freight per tonne of freight carried" e.g. (KiwiRail, 2019, para. 8), updated to 70\% (KiwiRail, 2020b, p. 9) was often cited. Their other operational aspects - inter-island ferrying and passenger services, 
were not emphasised. KiwiRail's main position is they help other corporates reduce their carbon through freight.

KiwiRail centring on the low carbon alternative to road theme appeared post-Paris and solidified post-CLC, replacing a diligence theme. To get an understanding of positioning shift across all eleven years their annual (integrated) reports were studied. Whilst emissions and reduction related words consistently featured in the top four relevant terms across all periods, rail went from eighth (pre-Paris) to second (pre-CLC) to first (post-CLC). This reflected the 'steel wheels' strategy of identifying and then refining the estimate for carbon savings when switching from road to rail. Prior to this the narrative was centred on diligence, where energy reduction equals cost reduction and ER. Accordingly the terms fuel/fuels and energy went from first and fourth (preParis) to sixth and ninth (post-CLC) respectively, as the shift solidified. As the theme of reducing/reduction fits with both narratives, this remained constantly high throughout all three periods. This consistent narrative may be partially a reflection of little options for change, as government funding till recently for rail and ferry has been minimal for over a decade (KiwiRail, 2020a).

Government investment in KiwiRail for both rail and ferry increased dramatically in 2019 and 2020 as the government sees rail and ferry as routes to decarbonisation (KiwiRail, 2020a). As a result KiwiRail have been able to commission construction of ferries that can potentially use alternative fuel sources and be electricity powered when docked (KiwiRail, 2020c). There are also plans to increase rail's capacity for freight movement. Whilst this will lower total domestic freighting emissions if road-freight tonnes/mile decrease, especially if electric locomotives are involved, there has been no discussion of limiting road freight tonne miles. Despite mention of absolute targets as part of their 2020 Annual integrated report (KiwiRail, 2020b) the measures included in the report are emissions per Net Tonne Kilometres (NTK), a relative emission measure which avoids the issue of growing freight volumes.

A key difficulty, as with PoAL, is that KiwiRail see themselves as providing a service which is destined to grow, and do not question the systemic issues surrounding this, or what they are freighting, which includes coal and Fonterra milk powder for international shipment amongst the top freight items by volume (KiwiRail, 2020b). Whilst it is unreasonable to presume they solely take responsibility for such large 
issues, there is no acknowledgement of the continual increase in freight, regardless of transport mode, being an issue in itself.

\subsubsection{Fonterra Co-operative Group Limited}

Fonterra Co-operative Group Limited (Fonterra) has evolved its identity from shareholder-lead, with 'inherited' green credentials, to stakeholder-lead, with sustainability as a strategic differentiator. The evolution is reflected in their media releases, annual reports, and the recent (2017-2020) sustainability reports. Fonterra had 357 available media release items covering November 2012 till 31 December 2020 (Fonterra, n.d.). Media releases with relevant content have dramatically changed from proportionally low ( $3 \%$ of releases pre-Paris), to moderate (7\% post-Paris/PreCLC), to high (57\% post-CLC). Fonterra's portrayal of a shareholder-lead vision was ensuring (as it is a cooperative every farmer contributing milk becomes a shareholder) dividends through competing on a collective scale internationally - a volume approach. Fonterra's focus until then was on its inherited 'green credentials', through NZ milk suppliers to Fonterra being from year-round grass-fed dairy-farming, combined with NZ's green image internationally (Kaefer, 2016; Khan \& Lockhart, 2019; Underhill, 2016). The shift is declared in the opening letter from the Board Chair and CEO in Fonterra's (2019) sustainability report:

Eighteen months ago, we may have said we're a global dairy giant here to make a difference in the lives of two billion people through a volume ambition of [reaching] 30 billion litres of milk by 2020 . Today, we stand for value. We're a

New Zealand dairy farmers' co-op, doing smart, innovative things with New

Zealand milk to create value for our owners, customers, and communities. (p. 4) The 'value' spoken of is explicitly defined in the environmental context as reducing manufacturing greenhouse gas emissions, water use and landfilled waste (Fonterra, 2020e). The topic of emissions is now appearing in interim report media releases (Fonterra, 2020a), previously a financial-only communications stronghold. Fonterra's current self-described role is to "to create goodness for generations for our farmer owners, employees, unit holders, customers, consumers and communities." (Fonterra, 2020 c, p. 1). Fonterra are using intergenerational stakeholder themes common to climate change mitigation, thus implying an alignment and support of climate change mitigation regardless of whether there is a match in strategy or actions. 
Possible causes for the shift are numerous and co-existent, so causality is unclear. Stakeholders including the NZ public and overseas businesses (e.g. Nestlè) have voiced concerns about emissions to Fonterra with emissions and other sustainability concerns being part of their central strategy (Fonterra, 2020c). Reports e.g. (Deloitte, 2017) have indicated the need to change the dairy approach to a 'quality-add' rather than volume based approach. Competitors outperform Fonterra due to their high value focus (Fonterra, 2020c). NZ and international media coverage of methane emissions and NZ waterway pollution by farm effluent continue e.g.(ABC News, 2021), and there are fixed deadlines for inclusion of agricultural emissions in the NZ ETS (MfE, 2021b). Fonterra's introduction of an independent sustainability advisory panel (Fonterra, 2019d). Lastly, but definitely not least, financial pressures indicated the existing high volume approach was not working (Fonterra, 2018b).

Fonterra in reports and media releases frames support for substantial ER in a carefully boundaried manner. Boundaries include the need for technological advancement, clear responsibility separation from farm-based emissions, and ruling out dairy alternatives. Increasing productivity per cow and increasing dairy demand due to changing dietary demands, increasing population and increased competition to dairy are mentioned, but no stated limits to dairy production (until after the study). Fonterra during and slightly after the study was solely a dairy advocate, with numerous articles supporting milk's superiority to alternative products e.g. (Fonterra, 2021). (After this study concluded Fonterra declared a milk peak and that they were looking at plant based milks to maintain revenues (Gray, 2021; Hancock, 2021)).

Methane is obvious in its complete absence from all annual reports from 2010 to 2020 inclusive, excluding one mention in 2017: "our science community has confidence in new and emerging technologies to manage ruminant emissions further" (Fonterra, 2017 , p. 7). Annual reports' narrower emission communication focus than media release, website or sustainability reports implies Fonterra wishes to frame its responsibilities to financial stakeholders as limited to operational emissions whilst trying to maintain a broader frame to other external stakeholders thereby not having to reconcile methane ER difficulties with future financial viability. This separation from methane is further reinforced by the new "Fonterra difference" programme, which allows Fonterra to set collection standards for milk, excluding farms who do not meet the criteria (Fonterra, 2019b). Whilst having collection standards can assist lowering Page | 88 
associated emissions, consistently Fonterra are communicating that they will aid ER but do not consider themselves responsible for methane emissions. (This mirrors Z's ambivalence as an energy distributor rather than a fossil fuel reseller.) Technology is framed as enabling methane reductions but then also is implicitly the pace-setter and limiter to reductions if that is the governing path. As identified by Lamb et al. (2020), both the technology solution and shifting of responsibility are commonly used to refocus the reader from the immediate need to reduce emissions.

\subsubsection{IAG New Zealand Limited}

IAG New Zealand Limited (IAG) is owned by Insurance Australia Group Limited (IAG Group). IAG is perhaps the least publicly known amongst the CLCFs. They are NZ's largest general insurance services provider, with NZI, and business division brands State Insurance, AMI, Lumley, Swann Insurance, NAC insurance and Lantern Insurance 29 (IAG, n.d.). approximating $46 \%$ of NZ's general insurance market (Tibshraeny, 2017). IAG also have brokerage and partnership services so that other businesses can offer their insurance products, and underwrite insurance for three of New Zealand's five main banks, including fellow CLCF WestpacNZ.

Few media releases were on IAG's website and of those relevant many related to their consumer poll or adaptation. Of 63 IAG media releases spanning December 2015 2020 inclusive, eleven were relevant. It was thought perhaps more relevant communications might be made through their brand websites, but this is not the case. The websites of their three largest brands - AMI, NZI, and State Insurance, https://www.ami.co.nz/, https://www.nzi.co.nz/ and https://www.state.co.nz/ - make no direct mention of climate change mitigation measures being taken by IAG ${ }^{30}$. As with other CLCF members annual reviews were explored to understand positioning and progress. More is visible in the IAG group site, with IAG Group actions making IAG the earliest CLCF to aim and achieve for 'carbon-neutral'. IAG Group declared in 2006 carbon-neutrality by 2012 , achieved by offsetting remaining operational emissions, but

\footnotetext{
${ }^{29}$ Additional brands Mike Henry Travel Insurance and DriveRight are still controlled by IAG but not currently active.

30 There are mentions of sustainability and climate change risk on IAG's insurance provider websites but nothing as of 30 June 2021 specifically relating to climate change mitigation or emissions.
}

Page | 89 
ignores investment-related emissions (Insurance Australia Group Limited, 2006, 2017).

Annual reviews understandably framed IAG Group's role as a risk reducer and climate change expert. "The risk of extreme and destructive weather events will increase if we don't succeed in reducing our global greenhouse gas emissions. This is particularly relevant to our business" (Insurance Australia Group Limited, 2019, p. 13). The insurance sector is one of the few sectors where the link between business purpose and climate change is inherent, given the need to assess the risk of more frequent climate change related events such as extreme weather for predicting future insurance claim amounts and setting insurance policy premiums accordingly. IAG Group selfdeclare themselves as "experts in assessing climate change" (Insurance Australia Group Limited, 2020, p. 6), with regional knowledge, however there is not enough specific content to form a distinct positioning for IAG New Zealand. IAG Group's primary communication focus is climate change risk and resilience - the chance of events and the ability to withstand them through lessening the impact and/or asset insurance. IAG's ER activity is framed as another way of reducing climate change related risks. This logic is not applied externally - there is no mention of adjusting insurance premiums for higher-emitting companies due to them increasing climate change related risks.

\subsubsection{Westpac New Zealand Limited}

Westpac New Zealand Limited (WestpacNZ) is one of New Zealand's five major banks (KPMG, 2021), and is part of an Australian-lead corporate group (Westpac Group, n.d.). In contrast to IAG the expert status is a two-pronged claim, due to the financial implications of climate change, both as a risk, and as an opportunity. Within the climate change context WestpacNZ describes itself as a specialist in "minimising financial risks and maximising opportunities" (Westpac NZ, 2018, para. 25). This is achieved through helping "our customers manage the transition", and ensuring "capital investment flows to the parts of the economy where it is needed." (Westpac NZ, 2018, para. 25). As with IAG climate impact modelling identified financial incentives for climate risk reduction strategies, and increased costs if not pursued (Westpac NZ, 2018). Pursuing these opportunities is framed as WestpacNZ fulfilling their role as a leader in their industry sector, as it was for IAG. In WestpacNZ's case they additionally 
reinforce their expert status by citing experience in trading NZ ETS units, commissioning stakeholder (business, customer and consumer) opinion surveys, supplying carbon measurement tools, and providing various partnerships and offerings to facilitate decarbonisation (Westpac NZ, 2018). Their government policy advocacy position in Australia and NZ of having a carbon price and policy certainty has remained consistent throughout (Westpac Group, 2017). Thus WestpacNZ place themselves as transition managers/enablers, as well as sharing IAG's claims of climate change expert and leader status.

WestpacNZ have been reporting carbon via Westpac Group since 2008 but had little relevant in media releases or annual review and sustainability reports ${ }^{31}$ pre-CLC, a full decade later. Post-CLC a lot more relevant content was present in reports and media releases. There were only 16 media releases with relevant content and of those only two pre-Paris and only four post-Paris/pre-CLC, leaving ten post-CLC. Due to the sparsity little analysis could be conducted. However word frequencies were consistent with the annual reports. Emissions was ranked first pre-Paris, with climate, sometimes accompanied by change, being the most frequent relevant word post-Paris/pre-CLC and post-CLC, yet ranking tenth pre-Paris. This reflects the change in focus from primarily ER to a wider advocacy stance, and focussing on decarbonisation in lending and investment away from coal mining and towards renewable projects.

From a focus on operational ER Westpac Group and within that WestpacNZ was early to recognise its broader role through lending and investing, however their climate change policies are far from leading the NZ banking sector. The strategic realisation that lending and investment are influential tools for ER pre-dates the Paris Agreement. In 2014 Westpac Group committed to "develop financial solutions for customers that address environmental challenges, and to grow its lending and investment in the CleanTech sector" (Westpac NZ, 2014). The focus initially was on policy encouraging companies involved in mitigation rather than any avoidance or penalty to high emitters. In 2017 an action plan began looking more at the lending and investment exclusions, with lending criteria defined for existing and new thermal coal mine activity (Westpac Group, 2017). Also targets increased for facilitating (via bonds) investment in 'climate

\footnotetext{
${ }^{31}$ Westpac produced annual reports entitled annual review and sustainability report. These, until the 2020 report, covered Westpac Group, with Westpac New Zealand information within parts of the report. The first New Zealand specific Annual review and sustainability report was in 2020.
}

Page | 91 
change solution companies', and advocacy for (government) policies supporting this type of investment was declared. However compared to another major NZ bank's policy of no lending to companies involved in the manufacturing, production or extraction of coal, oil or gas (KiwiBank, 2020), WestpacNZ's policy is weak. 


\subsection{Shared path}

A sufficient number of ER strategy and action elements occurred of similar types, in a similar order, to constitute what can be considered a shared path across the CLCFs. A shared path involves an approach to ER using comparable strategies and prioritisation of actions. Whilst a corporate's main sources of emissions could vary due to their being in different industry sectors, the approach is common. The shared path finding echoes the more general studies of Garcés-Ayerbe et al. (2016) and Gunarathne and Lee (2019) which found corporates follow a shared route to becoming environmentally proactive. The identified elements of a shared path are:

- Reporting

- Strategic declaration

- Quick 'win-wins' - reductions in energy use and waste that save operational costs and require little to no capital investment, simple supplier changes, or offsetting

- Spread/systematisation - the growth of carbon management resources within and across departments, with increasingly senior support, and additional governance and strategic decision-making exposure

- Slower 'win-wins' - reductions in energy use and waste that save operational (or reputational) costs and require capital investment and/or interrelate to more operational processes, altering existing supplier procurement agreements

- Shared limitations.

\subsubsection{Reporting as the foundation for carbon governance}

Reporting has been the foundation underpinning the strategy and action of the CLCFs. The first step is to form an initial inventory of operational emission sources, quantify emissions associated with significant items, report those within reporting boundaries, and then seek operational efficiencies. A carbon management system to support reporting or extend existing environmental management systems to cover carbon emissions was evident in all CLCFs, though they varied in their extent and complexity. 
None of the CLCFs declared engagement with reducing emissions without first reporting on them ${ }^{32}$.

For many corporates, especially high emitters, as is the case with the CLCFs, the dominant emission source that needs addressing is known: Fonterra's are heat process energy and methane from cows; Z's are fuel distribution and use; and AirNZ's is jet fuel use. Prior quantification of other emission sources for that corporate is not a pre-requisite. Resources required to accurately form an extensive inventory and report emissions are not trivial (Participants $A, F)$. This raises the question whether in some cases they may be better initially deployed on ER action instead. Also a change in reported emissions does not necessarily represent a corresponding change in the underlying corporate emissions. Changes in reporting boundaries, base years, and calculations make comparison problematic within and across corporates (Dragomir, 2012; Wegener et al., 2019). These issues aside, even if reported emissions were taken at face value a causal relationship between reporting and absolute ER is unproven (Damert et al., 2017; Tang \& Demeritt, 2018).

\subsubsection{ER as a strategic item}

Whilst the importance of ER was increasingly emphasised over the studied period, ER in the annual reports initially appeared as and continues to be listed as a strategic item amongst others. ER is not an overarching business philosophy or approach that forces alignment of other strategic items. It is clear from the interviews, prior annual reports, submissions and corporate media releases that consideration of ER can still struggle for parity amongst other business concerns. For instance carbon management personnel was always initially in one department or person across the CLCFs, and at the outset met with resistance when trying to engage in other areas prior to 2018. To progress ER they needed to engage with other business areas. Several interview participants commented on how internal engagement had become much easier, with people wanting or actively seeking engagement on $E R$, rather than requiring them to knock on the door in a position of asking a favour. "There's been a huge shift within the business and I think that's really been helped by the external environment [climate

\footnotetext{
32 This does not preclude incidental or unpublicised actions that reduced emissions occurring before reporting.
} 
protests and media coverage]." Participant D was emphatic that the corporate executive team is "very supportive" of sustainability, while noting that it took strong signals from external stakeholders to escalate ER activity amongst competing corporate priorities.

Perhaps tellingly, financial incentives for staff related to ER came later and are only present in two of the six interviewed CLCFs. Whether financial incentives are directly linked to ER is either absent or ambiguous at the remaining seven CLCFs. Use of social incentives including positive feedback, and gamification; for instance turning waste reduction into a competition e.g.(Z Energy, 2020b), appear to remain the most frequent approach. Placing ER as a socially positive activity reaffirms ER as something desirable. The implications of individual financial rewards and ER are mixed. Placing an action in purely a social context avoids any moral ambiguity, as a person cannot be accused of ensuring ER for monetary gain; and financial reward can be a disincentive for those motivated by moral reasons (Kasser, 2016).

\subsubsection{Shared limitations}

Initial limitations on pursuing implementation of ER actions were internal and pronounced, with the absence of a dedicated budget initially (and in most cases still absent - see 6.6.2), no mandate for substantive change, combined with ER staffing residing in one department, less reporting coverage, less access to senior decisionmakers and less supportive surrounding staff than now. But, as also revealed in the interviews, in most CLCFs there has been progress in all these areas.

Interviewees cited fiscal responsibilities, remaining competitive, government policy uncertainty and systemic dependencies as limiting external factors (see section 6.2.3). Being fiscally responsible on behalf of stakeholders - be they shareholders expecting dividends, retaining employees, continuing to grow so that growth can enable subsequent ER, were variously used as arguments to limit more often than to extend ER action, despite the anticipated economic costs of unmitigated climate change (World Economic Forum, 2020).

\subsubsection{Submissions}

Submissions by the CLCFs for the period from 1 Jan 2010 to 28 February 2020 to relevant requests for responses by the parliament or government bodies were Page $\mid 95$ 
analysed, covering 75 direct submissions across 18 submission requests (see Appendix $4^{33}$. The spread of requests was four pre-Paris, seven post-Paris/Pre-CLC and seven post-CLC. The topics to respond to ranged from specific energy topics such as hydrogen and process heat to NZ ETS (Emissions Trading Scheme) amendments, to broad legislation intended to introduce a carbon emissions reduction legislative framework. Indirect submissions by an industry collective such as an association that included a CLCF were excluded from analysis, (see section 5.3.2 for the reasoning). There was also a change of the ruling party in government from October 2017 onwards from National to a Labour-lead coalition (Electoral Commission, 2017), whose campaign positioning had put emphasis on greater ER action, including notably agricultural (methane) emissions (Trevett, 2017). Therefore comparison of submissions within and across requests had to be carefully considered based upon context of the item being responded to, the questions asked, and any industry specific aspects, so a word frequency analysis was not appropriate.

The number of submissions made by the CLCFs varied, with 70 of the 75 submissions by seven of the CLCFs. Submission frequency generally corresponded with those potentially most impacted by legislation, with Fonterra (16 of 18), Vector and $\mathrm{Te}$ Rūnanga o Ngāi Tahu (NTHC's tribal council) at 12, Z with 11, and then AirNZ and KiwiRail at 7 . WestpacNZ was relatively highly engaged, given that most requests did not directly impact their business, at 5 submissions. Spark and NZPost had no responses, and IAG, PoAL, Toyota and TWG had 2 or less. Prompting the most submissions ( 8 out of the 13 CLCFS) were the July 2018 and 2019 requests regarding the 'Zero Carbon Bill' and subsequent amendments (Climate Change Response (Zero Carbon) Amendment Act (No 61), 2019), which was unsurprising given the Bill determines the structure for NZ's long-term approach to setting emission targets, including establishing an independent body to advise the government: the New Zealand Climate Change Commission. It is the July 2019 request as the last submission made by many of those who did submit and is used to aid comparison across the CLCFs.

Across the CLCFs submissions there was unanimous support for the need to reduce emissions, greater policy certainty and emission targets being apolitical. Reasons

\footnotetext{
${ }^{33}$ Responses1 March 2020 - 31 December 2020 were not included due to response sparsity.
} 
given for needing policy certainty were long-term asset investment decisions, the general ability for policy to provide, anticipate, and incorporate carbon prices in general business decision-making processes e.g. (KiwiRail, 2018; Z Energy, 2019b). Underlying this is the more specific need to have more predictable NZ ETS unit pricing through various mechanisms including capping the number of units and setting price ranges, and greater certainty around when ETS changes affecting unit prices will happen e.g. (Westpac NZ, 2016). Support did vary on the treatment of methane emissions (Fonterra, 2018a; Z Energy, 2018b).

Pre-Paris submissions were less likely to include reference to the submitting corporate's own ER efforts than post-Paris. It is possible that the visibility of submissions to other stakeholders and the media post-Paris was consciously realised and influenced this. In some cases submissions contained noticeably more information as time progressed about the submitting corporate, their activities and how they contributed to New Zealand positively. Vector's submissions for instance also became more formatted, and visually appealing (Vector, 2016, 2019c). It is suggested the submissions were realised to be a communication vehicle to the public as well as the government and treated accordingly; more research would be needed to confirm this.

Fonterra's position throughout all submissions is that the pace of change and therefore the rate of ER should be determined by technology and economic viability. The main reasons given are that methane is a short-lived gas and therefore less urgent than other greenhouse gases (GHGs) to reduce, the current absence of adequate methane-suppressing technology, and the necessity to avoid 'emissions leakage', where more emission-intensive competitors increase their market portion due to carbon-related costs increasing Fonterra supplied milk product prices relative to theirs. A recent independent peer reviewed report found NZ dairy milk fat per $\mathrm{kg}$ had one of the lowest emissions globally (Mazzetto et al., 2020). So Fonterra's narrative of unintended consequences is potentially valid but only to an extent, and fits a known ER stalling strategy (Lamb et al., 2020). The unspoken assumptions that global dairy product demand is purely price driven is in doubt as Fonterra's relationship with Nestlé would belie (Fonterra, 2020b), the size of the market is not a static entity where a straight swap of suppliers necessarily occurs as Fonterra's marketing budget and activity would attest (Fonterra, 2020c). Also customer demand is already moving 
towards alternative milks, hence Fonterra diversifying into non-dairy milks (Gray, 2021).

The government approach has aligned with Fonterra's position. In summarising the 2018 Zero Carbon Bill responses, the government also indicated that it recognises "DACC [Dairy Action for Climate Change 2017-2018] aims to address on-farm dairy greenhouse gas emissions in the context of a profitable and sustainable dairy industry" (MfE, 2018c, p. 12). DACC is lead by DairyNZ and Fonterra, both advocates for the dairy industry, and two government departments. Whether the speed of transition is faster or slower than an alternative approach is difficult to know. A government lead solution may be more ambitious but met with greater industry resistance; alternatively the current pace is industry lead, albeit with external emission targets and stakeholder pressure.

$Z$ in contrast advocated for accelerated policy action and less consultation post-CLC, and are supportive of a direct carbon tax on fuel (Z Energy, 2019b). Z's consumer base is domestic; therefore any national policy applies equally to competitors, so no potential competitive disadvantage is experienced. In terms of domestic price impact, initially the required price rise to include carbon tax based upon NZD $\$ 50$ per tCO2e is $6 \%$ if petrol is priced at NZD\$2.00/litre (Wannan, 2021). Based upon historic petrol pricing fluctuations the initial impact on demand would be minor; but the carbon price is modelled to escalate as ER needs increase (Wannan, 2021). Z also calls for a government-funded fuel purchase subsidy mechanism to assist in a just transition by buffering the impact of the price increase on those struggling to pay for fuel (Z Energy, 2019b). Whilst maybe altruistic, advocating an equity price buffer is astute as it supports an ER policy while ensuring the transitional impact on fuel demand is minimised.

Te Rūnanga o Ngāi Tahu's wished to change some of the wording of the Zero Carbon bill to ensure ER occurs to the level advised by the NZ Climate Change Commission by the "Minister [of Climate Change] must [rather than may] "take into account" Commission advice when setting emissions reduction plans." (Te Rūnanga o Ngāi Tahu, 2019a, p. 4) as well as ensure rapid ER. Like $Z$ they sought a fair transition but discussed it in a much broader context, including a more collaborative approach 
involving iwi to the formation and consideration of Pacific Island nations. Their submissions wished ER ambition throughout the study.

Vector placed themselves as wishing to be advisory to government on the energy transition as well as agreeing with Te Rūnanga o Ngāi Tahu on the need for NZ Climate Change Commission targets to be adhered to by the Minister for Climate Change (Vector, 2019c). They also wished a 'fair transition' but in a narrower sense, implying but not specifying this related to electricity not being too expensive for consumers.

WestpacNZ also wished to be advisory, emphasising the importance of the financial sector in aiding a transition to a lower emissions economy (Westpac NZ, 2019). They also highlighted their role in aligning investments to a lower carbon economy, their already active role in the carbon market, and raised the issue of protesting the Climate Change Commission's funding.

\subsection{Navigating ER and the growth paradigm}

\subsubsection{Corporate objectives remain centred around the growth paradigm}

Recent CLCF examples of misalignment between profit and growth strategies and ER are not hard to find. TWG in 2019 launched TheMarket, an online location for consumers to buy products that are then fulfilled using TWG's infrastructure. TheMarket CEO, Justus Wilde describes the company as being "for new products they may not even know that they wanted." (The Warehouse Group, 2019). TWG are consciously driving greater consumption, which will inevitably increase emissions. Z are the supplier to PAK'nSAVE, a NZ supermarket chain whose strategy is based upon low price increasing sales volume (PAK'nSAVE, n.d.), although some relative emission efficiencies due to their cost savings approach extending to reduced use of bags and packaging. As COVID has proven NZ's tourism industry need international travellers to be viable at their pre-COVID scale, so much so that NTHC have indefinitely suspended some of their tourism companies (Te Rūnanga o Ngāi Tahu, 2020b). IAG currently insures companies regardless of their emissions profile. Whilst NZPost has to deliver the parcels and letters received, it has also driven demand by offering international redirect addresses to facilitate delivery of goods that do not deliver to New Zealand addresses (NZ Post, n.d.). Vector have invested in battery 
storage and vehicle-to-grid charging technology for the home, whilst their bottled gas home supply industry continues to grow, broader gas supply issues aside (Vector, 2019a, 2020). Vector also sold off their Kapuni gas treatment plant to see "the Kapuni field developed further" (Vector, 2020, p. 18). Some, such as Spark, are in an enviable position by others since their service of facilitating travel-free communication can be considered to reduce emissions. But even they have had to invest in ER to upgrade and rationalise legacy systems and improve data centre efficiencies as service increased, accentuated by COVID-driven demand (Spark, 2020a). Both KiwiRail and PoAL contribute to lowering Fonterra's milk powder transport footprint through their lower emissions than alternatives associated with handling and domestic transportation, and Fonterra are working to lower their operational emissions; however the more fundamental systemic questions remain about the viability of the dairy industry and the global distribution of dairy products at current scales. And Fonterra, like many corporates, continue to generate milk product demand through marketing. Declaring that growth is no longer a viable long-term option, or certain revenue opportunities will not be pursued, or a shift in products or services offered is required, is a fundamental corporate adjustment. ('Peak' milk and diversification have both been announced since the study's conclusion, see section 6.3.11). Stakeholder involvement and support beyond the boundaries of the corporation would be required, as explored later in this Discussion under 'government assisted change' and 'broader stakeholder governance'. Until then the misalignment creates a tension which corporates still seek to resolve through their narrative, limited business adjustment, and declaring the need for external assistance.

Some of the CLCFs' corporate narratives have evolved past what has been previously documented. Familiar narratives to resolve the tension of climate change with unaligned corporate behaviour were detected in all of the CLCFs' communications; the win-win narrative and its sub-variants such as efficiency, growth as aiding ER through relative ER per unit; the lesser evil where a CLCF providing the product means a higher emitter isn't; the servant of the customer will; the need for government intervention; climate change absenteeism in contexts not congruent with $\mathrm{ER}$, or stating a future resolution to resolve this tension, to name a few. Multiple narratives were used within the same corporate. Through all this the carbon positioning of the corporates was an area that on the surface varied the most but where common themes appeared, 
supporting the profit growth narrative. An extreme example of attempting to align growth and ER includes AirNZ's justification of larger domestic planes on the basis that emissions per passenger reduce, despite absolute emissions increasing (Air NZ, 2018b).

The perceived benefit of ensuring stakeholders know of ER activities was evident in the present study for almost all CLCFs, with standard practice being re-presenting ER activities within and across the different media: reports, media releases and submissions. NTHC and TWG were unusual in that they did not publicise their ER activity, and in NTHC's case are still not doing so.

The ability for corporations to call themselves 'carbon neutral' despite being far from achieving the necessary reductions to neutralise their emissions may give a false impression of adequate progress (Koteyko, 2012). However there are concerns with carbon neutrality for several reasons. Carbon neutrality is synonymous with offsetting in this study and more widely (Koteyko, 2012); many see it as an inadequate response to preventing further climate change (Lovell et al., 2009). Whilst offsetting is preferable to corporates ignoring emissions, offsets' incremental impact on emissions is in doubt (see section 4.3.3). Offsetting does not reduce the corporate's ongoing emissions, and a corporate being declared carbon-neutral may mislead the consumer into thinking the product/service they have purchased is carbon-neutral.

ToyotaNZ, TWG, IAG and WestpacNZ as examples have been certified as carbon neutral. ToyotaNZ indicate that "freight logistics is the greatest contributor to our carbon footprint" (Toyota NZ, 2020d). ToyotaNZ's carbon-neutrality and reporting exclude vehicle-use emissions, as is correct under the reporting rules. IAG and WestpacNZ similarly exclude emissions associated with investments. TWG exclude manufacturing emissions for goods not manufactured by them. TWG's responsibility on emissions beyond their reporting boundaries is made very clear: "Consumers wrongly attribute emissions generated by manufacturing the products we sell to the Group's footprint" (TWG, 2020a, p. 45). Corporates by proxy placing themselves as merely conduits for supplied products or services seems incongruent with for instance TWG's current marketing stance as a sustainability-centred organisation. This highlights the gap between emission responsibility as defined by carbon-neutrality or reporting boundaries and as defined by consumers. 


\subsubsection{Funding emission reduction}

Having a decarbonisation fund has facilitated change in domestic emissions within NZPost. NZPost set up a dedicated fund based upon the emissions associated with parcel and envelope delivery. NZPost's Head of Sustainability explains: "The fund has a value set against the cost of being carbon neutral now, similar to buying carbon credits to offset emissions" (NZ Post, 2019, p. 6). The decarbonisation fund aids ER initiatives by changing the parameters surrounding the decision-making process as it is ER-dedicated financial resource. As CLCFs interviewed attested, a common approval process for corporate ER projects is a business case submission, decisionmakers ensuring the ER business case satisfies a cost-benefit analysis criterion, prioritisation criteria, and an adequate budget for implementation. Each of these steps is traditionally a potential barrier to ER project implementation. For instance, in the context of process heat, which is responsible for $8 \%$ of NZ's emissions, a users' report found that cost-benefit and prioritisation tests were the reasons for non-selection when corporate decision-makers chose between process heat projects and non-energy capital projects (PwC, 2018). A cost-benefit ratio test typically helps decision-makers compare the associated costs and benefits of proceeding or not ("cost-benefit analysis," 2016). Criteria are used to compare an ER business case against competing business cases. Cost-benefit analysis may encompass environmental and social considerations but will invariably be expressed in financial terms, perhaps with nonfinancial provisos. NZPost's dedicated decarbonisation fund eliminates the need for NZPost ER projects to compete against non-ER projects, guaranteeing ER project spend.

A decarbonisation fund can also positively impact the daily decision-making process. NZPost has in place a policy of 'EV-first' for any replacement vehicle. This policy is not unique amongst the CLCFs; however the decarbonisation fund is used in NZPost's case to neutralise the cost difference (NZ Post, 2019). This means managerial decision-makers can compare vehicles on suitability and reliability rather than weighing up price-based decisions affecting departmental budget. This funding strategy reduces the cognitive workload of non-executive decision-makers and ensures pro-ER choices do not involve more complicated decision-making than non- 
ER choices, known to be a potential failure point for ER supportive decision-making (Hahn et al., 2014). However the very effective decarbonisation fund approach cannot be described as transformative, as there was an absence of evidence that any wider deviation from use of the traditional cost-based business case for decision-making occurred.

PoAL, Air NZ, Z, Spark, Vector, and Fonterra have all funded multi-million ER projects without the presence of internal decarbonisation funds. Factors that aided their approval can be reasonably inferred, even though the reasons are not known publicly. PoAL's electric tug, AirNZ's air-fleet modernisation, and Spark and Vector's infrastructure investments fall within the 'energy efficiency' category, actions that mutually benefit ER and create financial savings. Therefore these projects require do not conflict with traditional business objectives.

Both $Z$ and Fonterra have made carbon-reducing investments which required specific capital expenditure: biodiesel plant and coal-fired boiler conversions respectively e.g. (Fonterra, 2020e; Z Energy, 2020a). Whether the catalyst to act was reducing emissions, signalled government policy (NZ Government, 2007), or other factors is unclear. The biodiesel plant has now been mothballed as "without Government support for renewable transport fuels, the economics of local manufacturing are too challenging" (Z Energy, 2020a, p. 5). (Since then consultation is now taking place on a biofuels mandate (MBIE, 2021) ). WestpacNZ and IAG use a carbon price incorporated in decision-making but have not used this to allocate decarbonisation funds. Both corporates have lighter operational emissions, but their potential impact on emissions through investment and insurance choices is arguably very significant; hence their strategy is an important policy matter, rather than a funding matter. How much ER financing approaches reflect the different ER contexts and whether greater ER achievements would have been achieved by other corporates if they had established an internal decarbonisation fund requires further exploration.

\subsubsection{COVID created opportunities, not transformation}

There are numerous contemplations hoping that temporarily enforced COVID changes helps businesses (and others) envisage a path to zero emissions (e.g. Prideaux et al., 2020; Rosenbloom \& Markard, 2020). Corporate ER opportunities as a result of COVID did occur, however none were fundamental changes and there is no evidence Page | 103 
yet that COVID caused CLCFs to revisit their growth strategy, perhaps due to no evident alternative narrative. COVID did open up ER opportunities not previously available, namely reducing commuting, business travel, fleet vehicle and office use, increasing online activity and capabilities, and for some CLCFs slower international shipping. Whilst all of the CLCFs showed a humanitarian oriented response to COVID there was as at the study end of December 2020 an absence of wider changes or narratives, such as substantial changes to the product/service offering or of a new business approach to achieve decarbonisation (Crockford, 2020; Fonterra, 2020d; IAG, 2020c; Keall, 2020; Ministry of Health, 2020; NZ Government, 2020b; NZ Herald, 2020b; Te Rūnanga o Ngāi Tahu, 2020a; The Warehouse Group, 2020; Toyota NZ, 2020b; Westpac NZ, 2020). 


\subsection{Progress Summary}

Not all corporates were at the same stage of progress, nor all parts within a corporate. The possible range of progress is from Stage 1: Compliant, (only activity as required by law), to Stage 8: Coevolutionary, (a complete shift in products or services and their up and downstream dependencies away from offerings that cannot be decarbonised) (Table 2). CLCFs' progress pre-Paris initially spanned stages 2: Active to 4: Integrated. By the study's end progress had reached variously stages 3: Proactive to almost reach 5: Saturated. Reported emission trends and scope of business changes did not give confidence in achieving future reductions in line with limiting global warming to $2^{\circ} \mathrm{C}$.

\begin{tabular}{|c|c|c|c|c|c|c|c|c|}
\hline Corporate & Compliant & Active & Proactive & Integrated & Saturated & Systemic & Regenerative & Coevolutionary \\
\hline Air New Zealand & & $\bigcirc$ & O & 0 & ? & & & \\
\hline Fonterra & & 0 & O & & & ? & & \\
\hline IAG & & & 00 & O & $?$ & & & \\
\hline KiwiRail & & 00 & & O & ? ? & & & \\
\hline Ngāi Tahu Holdings & 0 & O & & O & & & ? & \\
\hline NZ Post & & & O & O & & ? & & \\
\hline Ports of Auckland & & & 00 & 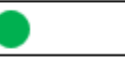 & ? & & & \\
\hline Spark & & O & O & O & ? & & & \\
\hline The Warehouse Group & & O & 0 & \multicolumn{2}{|c|}{$?$} & & & \\
\hline Toyota New Zealand & & 00 & O & \multicolumn{2}{|c|}{ ? } & & & \\
\hline Vector & O & O & O & & ? & & & \\
\hline Westpac New Zealand & & & $\bigcirc$ & & $?$ & & & \\
\hline \multirow[t]{6}{*}{ Z Energy } & & O & O & & & ? & & \\
\hline & \multicolumn{8}{|l|}{ Legend } \\
\hline & Pre-Paris & & & & & & & \\
\hline & Post-Paris/Pre-CLC & & & & & & & \\
\hline & Post-CLC & & & & & & & \\
\hline & Future & & & & & & & \\
\hline
\end{tabular}

Figure 5: Corporate emission reduction stages reached by the CLCFs

Despite differences in progress it was discernible that the ER approaches could be considered a shared path of least corporate financial resistance. Lower emitting CLCFs may achieve the required reductions however high emitters looked unlikely to due to systemic barriers and absence of urgency to reduce volume or transform products/services. For all CLCFs changes were observed in narratives or behaviour over time, though for some they were minor. Changes were sometimes linked to the Page | 105 
Paris Agreement, founding CLC or COVID. Changes did not extend to growth, which remained framed as a necessary assumption, and sometimes placed as an enabler of ER, rather than a barrier or challenge. Conflict between the corporate purposes of growth and profit and some ER options was evident. Whilst the portrayed identity evolved for some corporates, and several envisaged future changes to their fundamental business away from a carbon emission related offering, as of the study end there were no actions that directly drove a change in business purpose to align with decarbonisation.

Existing narratives of efficiency solutions and for high emitters technological advancements predominated as being the solution to decouple carbon. Reporting reinforced responsibility boundaries to be less than total emissions, though a recent switch by some to SBTs has extended the responsibility range into including scope 3 emissions in targets. Submissions unanimously supported long-term consistency and predictability in policy for emissions reductions. Z pushed for accelerated policy implementation, however unlike Fonterra this would did not potentially disadvantage them competitively, as they had domestic sales only. COVID opened up possibilities for longer term ER through business disruption but also reinforced companies' role of businesses and economic importance, making it potentially harder to challenge the corporate growth and profit purpose. Whilst future targets were generally well defined, uncertainty was expressed in four of the six interviewed as to how these new targets will be achieved. Many saw their targets as aspirational rather than feasible, unless government intervention in the shape of policy and financial support occurred.

A brief summary of each CLCF's ER progress is now provided. The order of corporates is to aid readability and has no other significance. Greater detail on each corporate is provided in section 6.3.

\subsubsection{Toyota New Zealand}

Toyota New Zealand's (ToyotaNZ) progress as with others depends upon the scope of consideration. New Zealand based operation emissions have been minimised and certified and could potentially be considered reaching the Saturation progress point. However this would be ignoring the emissions associated with what ToyotaNZ sells, 
and the TMC business narrative of hybrids bridging the transition to full electric-only vehicles as being a necessary path.

\subsubsection{The Warehouse Group}

The Warehouse Group (TWG) are advanced in their ER efforts for a general retailer, with energy efficiencies achieved across all outlets. They are unusual in that a Sustainability specific executive has been employed. However a distancing from supplier manufacturing emissions and the business model being still firmly based upon increasing volume and the types of product sold sourced predominantly from overseas mean that unless some dramatic changes to the offered product range occur the furthest they will ever progress is at the lower reaches of the Integrated stage.

\subsubsection{Air New Zealand}

Air New Zealand (AirNZ) is the clearest example of the 'paradox' in action. AirNZ are technologically advanced, thorough in ER efforts, and early adopters of loweremission aircraft, with plans for domestic planes to be electric or hybrid. Yet throughout the period a growth strategy remained, even after the sharp contraction caused by COVID.

\subsubsection{Westpac New Zealand Limited}

A very early starter on ER. For Westpac New Zealand Limited (WestpacNZ) to progress into Saturated their investment and lending policies would need to be strengthened further to exclude high emission and greater lending advantages given to low-emission businesses, business flying would need to substantially reduce, and other aspects like the footprint of branches may need to be considered more substantively.

\subsubsection{IAG New Zealand Limited}

IAG New Zealand Limited (IAG) are similar to WestpacNZ in that they were early to engage with ER and to reach neutrality through carbon offsetting. Again as with WestpacNZ ER is stated as a central strategy but a realised strategy to ER across all business facets is yet to occur. 


\subsubsection{New Zealand Post Group}

New Zealand Post Group (NZPost) have dramatically reduced their reported emissions over the period and rolled out a fleet of electric delivery vehicles nationwide, uniquely have a dedicated decarbonisation fund and staff focused solely on ER, and a clear roadmap to achieving their targets. The 'elephants in the room' remaining to be addressed are international parcel shipping and parcel volumes growing indefinitely, which are thus far being planned for as inevitable rather than something to be actively engaged with reducing.

\subsubsection{KiwiRail Holdings Limited}

KiwiRail Holdings Limited (KiwiRail) have achieved ER through sizable efficiency gains that have plateaued post-CLC. As highlighted by KiwiRail shifting freight by rail has $70 \%$ lower emissions by tonne and kilometre travelled than by trucking. Some of their asset purchases during the study were not the lowest emission option available. Major government investments in rail infrastructure are anticipated to result in further relative ER. The underlying question of indefinitely growing export and import freight is unquestioned.

\subsubsection{Ports of Auckland Limited}

Ports of Auckland Limited (PoAL), like KiwiRail, have made efficiency gains, and they are the lowest emission port for handling Auckland's imported goods as domestic freighting is minimised. However their overall strategy is not congruent with ER due to plans to increase cruise berth size, and like KiwiRail, do not express concern over indefinite growth except to highlight the emissions associated with site relocation.

\subsubsection{Fonterra Co-operative Group Limited}

Fonterra Co-operative Group Limited (Fonterra) supplied milk arguably has the lowest associated emissions per kg milk fat globally, however the large emission impact of dairy remains. Fonterra post-study have mentioned peak milk and started to diversify into plant-based milks, which like Z, perhaps indicates they know transformation away from their current product is required, though this has yet to be declared by Fonterra. 


\subsubsection{Z Energy}

Z Energy (Z) pushed the most for governmental ER policy depth and acceleration and have positioned themselves as energy agnostic and have built a biofuel plant. However their emissions have increased, due to increasing their market share. They have invested in an electricity retailer but not indicated whether that is the new energy source they intend to provide. Meanwhile brand and marketing incongruencies with supporting a reduction in petrol demand continue.

\subsubsection{Ngāi Tahu Holdings Corporation}

The business entity Ngāi Tahu Holdings Corporation (NTHC) have done little to no known action despite the philosophy of Te Rūnanga o Ngāi Tahu being the most aligned of all CLCFs to advanced stages of the Corporate ER progress framework. Being heavily involved in primary business industries, tourism and property development means there is plenty of scope for reductions.

\subsubsection{Spark NZ}

Spark NZ (Spark) under the guise of Telecom NZ was an early adopter but then there was a pause in progress under the new business brand, Spark. The 'win-wins' for Spark have arguably been of a scale larger than for any other business proportional to their total emissions. Legacy communication systems, modernisation of data centres and a general focus on energy efficiencies has reduced ER as well as operating costs even with business growth. As with KiwiRail being a greener option to road freight, Spark assists other companies in their emissions through online services arguably replacing the need to travel. Again, as with KiwiRail, whether there is a growth ceiling is not conceptualised.

\subsubsection{Vector Limited}

The electricity distributor Vector Limited (Vector) for the Auckland region are late 'participants', having done nothing discernible prior to 2017, the year before the CLC founding pledge. Since then efficiencies and resilience, including battery storage have been targeted. Flattening electricity peaks rather than reducing usage appears to be the primary focus. As with PoAL they position themselves as lead by the needs of consumers. 


\section{Discussion}

This discussion explores findings under the following areas:

- The merits and weaknesses of the corporate ER stages framework at determining progress,

- the impact of the corporate growth imperative,

- the corporate and social well-being,

- the government,

- study specific considerations and the global context, and

- COVID-19 and implications for the future

The findings allow reflection on the future of corporate ER given recent NZ policy and the progress made thus far by the CLCFs. The shared path predominantly covers strategy and action findings, the duality within both corporate public communications and Parliamentary submissions, and COVID -19's impact on all these aspects and possible future implications. The limitations of the findings are also discussed, with suggestions as to further research.

\subsection{Determining ER progress}

The corporate ER stages framework (Table 2) and the underpinning ER strategy and action classification (Figure 4) were both found to be important in this study for their role in identifying and maintaining a wider view and analytical stance than is typically present in studies where the corporate entity is the unit of analysis. Previously relevant progress models were created within the corporate context (Landrum, 2018). As a result, progress was defined and measured in terms of what corporations had done, rather than what is necessary to decarbonise. Thus the limiting factors arising from the corporate-centred purpose of profit and growth in prior models remained implicit, as did the surrounding views and assumptions (Landrum, 2018). The corporate ER stages ('ER stages') framework bases analysis on the broader consideration of what is necessary to achieve decarbonisation, beyond the range of strategies and actions consistent with the growth assumption (Bjørn et al., 2018; Dyllick \& Muff, 2016). A broader model also aligns with corporate responsibilities now stretching beyond those bound by profit and growth in NZ and elsewhere (Gartenberg \& Serafeim, 2019; Khan 
\& Lockhart, 2019). The ER stages framework also avoids the tendency for progress at the corporate entity level to be considered only in quantitative terms. Whilst emissions quantification is useful in comparing a larger numbers of corporations, as discussed in the literature review reported emissions can be problematic in giving a picture of emissions both temporally and across corporates. Hale et al. (2021) also identified the need for a framework to measure the ER progress of corporates that looked at progress in the broader sense of the word. The resulting framework has many useful attributes including clarity and replicability, and introduces an important concept, robustness, defined around a corporate's ability to reach their targets. Given the low confidence amongst interviewed CLCFs in attaining future targets this would be a useful addition to the corporate ER stages framework used. Conversely an advantage of this framework over Hale et al.'s (2021) is that it gives consideration to limiting business approaches such as the growth paradigm that may counteract any ER progress.

The results in this study suggest the framework used is coherent and representative. For low emitters it is potentially possible for sufficient ER to occur to initially meet ER requirements but systemic issues such as transport will remain. The value of this framework being based upon a broad view of progress became apparent, as a shared path was apparent across strategies, actions, and communications. This bodes well for this progress framework being considered useful to other studies wishing to understand current and likely future corporate ER progress.

The detection of a shared path raises questions around other corporates less advanced in their ER efforts. It may be possible progression along the shared path is more rapid for corporates commencing ER actions now, given the more favourable government policy and social impetus. Or alternative paths may emerge. The Head of Sustainability for NZPost (Baggaley, 2019) revealed that they had tried to focus on the solution to packaging with the lowest carbon footprint, which was plastic not plantbased wrapping, due to the likelihood of the plant-based wrapping recipients having access to a compost being too low. However this decision had not been received well by customers. This suggests that the path of quick, high visibility wins that meet public and employee favour may be needed to signal progress to stakeholders, and that selecting more subtle paths with higher ER but less stakeholder appeal could prove problematic. There is little known yet about alternative paths for traditional profit-base Page | 111 
corporates. Regardless of path there is little yet to suggest that corporates would not all rapidly slow at the saturated stage of progress, as a shift in the growth purpose of a corporate is not apparent. A growing body see continued financial growth and rapid decarbonisation as incompatible given the lack of evidence otherwise (e.g. Hickel \& Kallis, 2020; Klein, 2014; Patel \& Moore, 2018).

\subsection{Growth}

The role of the corporate in society and associated environmental responsibilities has increased over time with the growing tension between the growth path of corporates and economic activity on the one hand and environmental sustainability on the other (Lawrence et al., 2013; Rahman, 2011); however the primary purpose of profit and growth did not alter amongst CLCFs, despite acknowledging climate change and acting on that knowledge. The CLCFs recognised and incorporated reducing emissions as part of the set of responsibilities in their governance. Systems were put in place to identify opportunities to reduce emissions, with staff dedicated to reducing or encouraged to reduce emissions as part of their role. However after initiatives compatible with growth or profit purpose are exhausted no transformative progress has occurred within the CLCFs, despite rhetoric based around the 'shared value' theory driving sustainability innovation suggesting otherwise (e.g. Business Roundtable, 2019; Loorbach \& Wijsman, 2013; Porter \& Kramer, 2011).

'Shared value' is defined as a business "creating economic value in a way that also creates value for society by addressing its needs and challenges" (Porter \& Kramer, 2011, p 4). The vision is that through focussing on addressing critical societal issues, which includes environmental factors such as a stable climate, the business will innovate and transform to align with these needs and prosper financially. (Transformation and innovation in this context result in carbon decoupling and systemic change, as per stage 6 of the framework.) Whilst Porter and Kramer's innovation and transformation are theoretical possibilities, findings within this study, within de los Reyes and Scholz (2019), and more generally the global pattern of increasing corporate emissions, suggest that the required decarbonising transformation is elusive. ER actions as identified here and by de los Reyes and Scholz (2019) constitute two types of shared value: efficiencies, where a reduction in business costs occurs due to a reduction in (typically) energy or physical resource use; 
or changes that are believed to protect or increase profit either directly through increased desirability, or indirectly through enhancing company reputation (de los Reyes \& Scholz, 2019; de los Reyes et al., 2017). So far the evidence suggests that a corporate operating under the traditional business purpose (profit and growth) does not result in a 'reinvention of capitalism' despite efforts to reduce emissions; corporates are confined to actions that fit within the existing business purpose: profit and growth.

Numerous reasons were provided by the corporates as to why growth is necessary, which had four main variants: external factors necessitate growth, reducing emissions is a lower priority than growth, growth helps reduce emissions, consumers are responsible. These variants were used individually or in combination. All aimed to reconcile corporate intent to reduce emissions and continued corporate growth. The importance of these different narratives is that they set constraints on strategies and actions for reducing emissions and the associated achievable levels of reduction.

The argument that growth helps us reduce emissions may point to relative or absolute emissions. The better option/lesser evil argument has two variations: lower than competitors (Fonterra, Air NZ, Toyota, Spark), and lower than substitutes (KiwiRail). A new 'enablement' theme, where growth in one company (Spark) helps others reduce emissions, was also present (see section 6.3.1).

\subsection{The corporate's social role}

Over time multiple factors have reinforced certain corporations' products or services as contributing to social well-being, raising the prospect that any ER strategy that confronts the growth of these products or services may be seen as compromising basic products or services and therefore social well-being. The broadening of corporate responsibilities (see section 4.2), the blending of corporates and utilities, the GFC, and COVID have all reinforced certain corporates' association with well-being. Nine of the thirteen CLCFs can be considered to provide or support providing basic products or services. Basic products or services are "the ingredients of well-being [emphasis in original] in that they allow human beings to be secure, healthy, literate, and able to participate effectively in their societies" (Reinert, 2018, p. 1). Some stateowned utilities, providing basic services such as electricity, have been 'corporatised', 
where central or local government retains ownership but determines that the given area is to function as a commercial enterprise e.g. (MBIE, 2015). KiwiRail, PoAL, NZPost and Vector are all a result of similar processes (KiwiRail, 2010; NZ Post, 2018; PoAL, n.d.; Vector, n.d.-a). Avoiding fuel or food shortages and delivery of mail (i.e. Z, PoAL, KiwiRail and NZPost respectively) have long been considered basic services, as COVID media coverage and legislation attests ("Deed of Amendment and Restatement", 2013; Mitchell, 2021). Vector provides the electricity distribution infrastructure for Auckland (Vector, n.d.-a). Another essential service, telecommunications is now provided by Spark, formerly part of NZ's former stateowned telecommunications provider is now Spark (Spark, 2021). The GFC reinforced banks such as WestpacNZ as intrinsic to NZ society (Hepburn et al., 2020), and with multiple physical disasters occurring the concept of being uninsurable (Cuming, 2019) has emphasised the importance of insurance providers such as IAG. During COVID AirNZ was commissioned by the government to aid with repatriation of NZ citizens and time-sensitive deliveries such as COVID vaccine (NZ Government, 2020b). This means 9 of the 13 CLCFs can reasonably be considered to provide a basic product or service.

A basic product or service must be ubiquitous - restrictions on provision implies reducing well-being (Reinert, 2018). It is unclear where the cut-off is though - for instance NZPosts' deliveries are a mix of essential and non-essential items due to the burgeoning online delivery business (Shaw, 2019). If the product/service or its provision is unable to be decarbonised, then finding an alternative or applying restrictions arguably becomes a broader social issue, extending beyond corporate social responsibility. The extent to which decarbonising of corporations who provide or aid provision of basic goods/services is seen as a government responsibility is an emerging area that requires further study.

\subsection{The New Zealand and global context}

NZ's economic and business profile has some distinct characteristics compared to other Annex 1 countries, with each sector its own context and history within the New Zealand setting needing consideration. Notable characteristics include access to predominantly $(80 \%+)$ renewable electricity (MBIE, 2020), a relatively intimate business community due to the country's small economy, relatively few large or energy 
intensive businesses, and a lightly regulated business marketplace (Khan \& Lockhart, 2019). New Zealand's tourism, dairy and meat industries all emphasise NZ as an unpolluted environment in their marketing, thus utilising NZ's positive international environmental reputation to aid international product and tourism revenue (Hopkins et al., 2015). This 'clean and green' image is also seen as an important reason to look after the environment by the majority of the NZ public (Colmar Brunton, 2018), with $71 \%$ of New Zealanders stating action on climate change needs to be taken by businesses (Ipsos-IAG, 2021). However, NZ's environmental 'credentials' have been repeatedly called into question on the international stage e.g. BBC (2011); Roy (2019). NZ's average GHG emissions per person are among the highest globally (MfE, 2020), with transport (industry and private), and dairy-related emissions (especially biogenic methane and nitrous oxide from farming, and carbon dioxide from coal powered processing operations) being major contributors. Industries, especially the dairy and tourism sectors, have been under NZ media and public pressure to reduce their environmental impact, including their emissions (Hughey et al., 2019; Khan \& Lockhart, 2019; Roy, 2019). This may mean corporates' perceived reputational risk and the ability for stakeholders to influence may be higher than in some other OECD countries. In the EU, excluding heavy industry, road transportation, and commercial and institutional sectors' emissions have increased, but not to the same extent as NZ's (EEA, 2020a; MfE, 2020). In NZ, this is attributed to various policy factors including a low price on carbon until recently, and the absence until after the study's conclusion of vehicle carbon emission standards (Ministry of Transport, 2021).

BusinessNZ is by GDP, turnover and emissions NZ's largest corporate business interest group (BusinessNZ, n.d.). BusinessNZ includes various groups, including the Major Companies Group (MCG). MCG includes amongst its members 10 of the 13 CLCFs; KiwiRail, NZPost and NTHC are not members. MCG released an "Economic Guidance Plan" post-COVID March/April 202 peak which informs the government they should "focus on emissions intensity rather than quantum of emissions" (BusinessNZ Major Companies Group, 2020, p. 7). This is not in line with SBTs which were developed for the very reason that intensity, or relative targets, could be fulfilled whilst emission volumes, or quantum still increased (Science-Based Targets initiative, 2020).

NZ's large businesses have several formal channels to influence the government, set up for NZ business both by the government and by associations. In late 2018 the NZ Page | 115 
government established the Prime Minister's Business Advisory Council, in effect from 2018 to 2020 to ensure NZ's economy has "the investment, innovation and skills required to ensure we can all share in prosperity and opportunity in a sustainable way" by having a council that will "inform government policy" (NZ Government, 2018b, p. 1). PMBAC was initially chaired by then Chief Executive Officer of AirNZ Christopher Luxon (NZ Government, 2018a), before he resigned to successfully stand to be a member of parliament (New Zealand Parliament, n.d.), and was then replaced by Fonterra's Chief Operating Officer Fraser Whineray (Fonterra, 2019a), illustrating the high exposure CLCF members have to parliament.

Conversely, the power of government legislation and policy to impact future corporate behaviour is recognised as substantial. The NZ Emission Trading Scheme (NZETS) is seen as the NZ government's main mechanism for managing national GHG emissions, including those by corporations (Leining \& Kerr, 2018). In 2020 it was updated to have a limited number of units, a deadline for including agricultural emissions, predictable NZETS unit pricing, and phasing out of the free allocated units to heavy-emission industry sectors (Environmental Protection Authority, 2020). These changes were seen as necessary for the NZETS to start driving corporate behaviour to lower emissions (Shaw, 2020b; Silver et al., 2017), as previously it had not (MfE, 2016). For high-emitting businesses (excluding the agricultural sector till 2022) it is mandatory to hold units equivalent to the associated carbon equivalent tonnes of relevant emissions. With future limited supply of units it appears likely that the price per unit will increase, which is hoped to motivate decarbonisation due to the increasing cost of emissions. (The NZ government recently increased the NZETS unit purchase price from NZD\$25 to NZD\$35 per tonne $\mathrm{CO}_{2}$ ("Climate Change Response Act 2002 No 40 (15 March 2021),")).

Legislation also plays a subtler hand in corporate governance of ER, which can aid or hinder ER efforts. Until recently Fonterra, as a dairy-processing co-operative existent due to legislation, had to accept milk regardless of farming source or practises. In 2020 dairy legislation was changed so that Fonterra "may, in its discretion, accept or decline an application made in an application period by a new entrant to supply milk to new co-op", taking into consideration the "land-use opportunities available to the applicant" (Dairy Industry Restructuring Amendment Act 2020, s. 73). Additionally, section 106 now allows for Fonterra to differentiate price offered for milk to supplying farms based Page | 116 
upon sustainability practises, including climate change. PoAL, another entity existent due to legislation, must "operate as a successful business" (Port Companies Act 1988, s. 6), defined by PoAL's current statement of corporate intent as being "as profitable and efficient as comparable businesses that are privately owned, and sustainable over the long term" (PoAL, 2020b, p. 4). (What sustainable means is left undefined.) NZPost has to provide delivery to every delivery point in New Zealand with certain service frequencies ("Deed of Amendment and Restatement", 2013), again highlighting a possible conflict between trying to reduce emissions and binding obligations. These are just several examples of the need for the New Zealand and local government and the corporate governance bodies they own to revisit legislation, understandings, intents and policies to ensure they do not hamper efforts to reduce emissions, whilst not compromising other areas, such as social equity.

Whether the corporates can be considered internationally advanced in their ER efforts depends upon the CLCF and industry, and the answer to the question of what emissions they are seen as responsible for. As explored there are some world-leading aspects, for instance PoAL's electric tug, and the ruminant methane suppression research commissioned in part by Fonterra. However some of Fonterra's boilers are also still coal-fired and PoAL is increasing cruise ship berthing. Unilever as an overseas example has restorative practise goals for its agricultural supply chains to ensure superior carbon soil storage (Unilever, 2020), though like many other companies sources and sells product globally and incurs the carbon emissions that entails. What can be said is that corporate norms are shifting is evident, both in New Zealand and internationally, towards greater acceptance by corporates for the need to lower emissions (see section 4.3.1), and CLCF positioning through communications has echoed this shift. This fits with interview comments and previous findings that external stakeholders are able to drive change across corporates that are directly visible to consumers (see section 6.2).

\subsection{Systemic barriers}

Systemic barriers to ER also exist, that cannot be reasonably resolved by a corporate without government and in some cases international assistance. Transportation, and its associated emissions is a shared issue across all corporates. Employee commuting, client visits, business meeting travel, goods supply and equipment 
movement are common across all the CLCFs and to varying degrees across all corporations. Product logistics can be improved to minimise miles travelled, site use optimised and consolidated where possible to reduce energy use; but employees' home locations are much less controllable, many job roles cannot be performed remotely, and goods may not be locally supplied. Employee travel emissions, for example, are influenced by many factors that help determine home location, including but not limited to housing locations and affordability, and the availability of public transport infrastructure (Climate Change Commission, 2021). As briefly mentioned previously another example of a shared functional need across corporations is the international transportation of goods, an increasingly evident issue due to the globalisation of supply chains and consumer purchasing (Stiglitz, 2017), an international emissions management issue and of particular concern for NZ due to our geographical remoteness, considerable import and export industry development, and the absence of a sizeable domestic manufacturing industry, as is the case in the EU and USA (Stiglitz, 2017). Systemic change is needed in both international transportation and supply chain reconfiguration to achieve the scale and speed of ER needed (Köhler et al., 2019); this will require change by all stakeholders: governments, corporates and consumers.

Energy needs cannot be met in all circumstances by the electricity grid. A high-density energy source short-listed by the current NZ government is hydrogen, which is winning favour for longer-haul road freight (MBIE, 2019). Renewable aviation energy for longhaul flights remains problematic (Bailis et al., 2016; Baker, 2020; NZ Herald, 2017), though electric or hybrids are being pursued for domestic flights (NZ Herald, 2018; RNZ, 2020). Fuelling infrastructure and social barriers exist for aircraft adoption of hydrogen due to negative risk perceptions (Baker, 2020). Z's position on hydrogen for land-transport use is cautious, mainly due to concern that the government is mentioning hydrogen as a potential export earner, meaning that domestic prices volatility could be created by international fluctuations (Z Energy, 2019a). This is not surprising given Z's biofuel plant experience with fluctuating tallow prices and the multi-decade lifespan of infrastructure investment. Industrial process heat use by Fonterra and other agricultural companies has typically involved coal to date, ascribed by Fonterra as being due to the scale of energy needs and remoteness from the electricity grid. Fonterra have converted some coal boilers to biofuels, but indicate the 
speed of decarbonising remaining boilers is restricted by cost and profit considerations (Fonterra, 2019c). As with other corporates, they indicate that government funding would accelerate the transition process (Fonterra, 2019c). Why the transition costs should be funded publicly is unclear, given that Synlait has demonstrated the costeffectiveness of a large-scale electrode boiler at its Dunsandel plant (Transpower, 2021), and Fonterra's existing successes with boiler conversions to biofuel (Fonterra, 2019d).

\subsection{Financing ER choices}

The CLCFs had various approaches to funding, with varying incorporations of a 'price' on carbon, ranging from cost-saving or cost-neutral projects through to NZPosts dedicated decarbonisation fund (see section 6.5.2). Progress was achieved through all funding approaches though progress appeared faster, and extended further into supplier relationships, in terms of a dedicated fund that could be used to subsidise ER choices so that they could be compared on an equal investment cost-basis with other options. More research on the effect of these different approaches is needed. The implications of corporates instead providing financial rewards for ER achievement to individual employees are ambiguous. Value, as well as the frequently used monetary definition, is "the importance or worth of something for someone" (Cambridge Dictionary, n.d.), and is therefore inherently subjective. Placing emissions within a financial framework perpetuates a financially based framing of value, which reduces how important environmental issues are perceived (Kasser, 2016). So giving an employee financial reward for ER achievements may have adverse consequences not yet fully understood. Conversely, as finance is the underpinning system of establishing value within a corporate environment, the absence of a financial reward may lessen ER's perceived worth. A financial reward may also help remind decision-makers too of the financial implications of climate change, a link which is gaining more corporate visibility, especially due to the (in New Zealand) now mandatory assessments of future corporate risk (NZ Government, 2021).

\subsection{Covid and the future}

There is a hope that the disruption COVID-19 caused, and continues to cause around the globe, will provide an opportunity for businesses to reflect on their role in an 
environmental and social context, reducing or adjusting activities associated with emissions as a consequence ( $\mathrm{He} \&$ Harris, 2020; Hepburn et al., 2020). The opportunity due to COVID to invest in transformative infrastructure change is seen as larger than in 2009, due to the greater scale of government financial intervention, and renewable energy options being cost-competitive if not cheaper than non-renewable energy (Agrawala et al., 2020). Both the NZ Climate Change Commission and the climate change minister Hon. James Shaw also saw COVID economic stimulus spend as a chance to invest in moving towards a lower-emissions economy (Climate Change Commission, 2020; Shaw, 2020a).

As discussed in section 4.5 the NZ government's financial stimulus response to COVID's NZ peak in March/April 2020 did not prioritise ER. However prior to and after this COVID peak the government committed support for numerous initiatives to achieve ER (NZ Government, 2019). the government has made various changes to the NZETS scheme to try and increase its effectiveness in causing corporate ER, the legislated dairy co-op scheme that Fonterra manages can now exclude high-emitting farms from milk collection, and climate change financial risk reporting is now compulsory for corporations (Dairy Industry Restructuring Amendment Act 2020; Shaw, 2020b, 2020c).. Given the recency of these changes it is too early to know their impact, however relevant submissions from CLCFs have largely been supportive of the policy framework and increased certainty of the NZETS unit pricing framework.

Current confidence whether future ER targets will be achieved was not high amongst interviewees. Limiting external or internal factors such as government policy and corporate growth and profit requirements were cited. If mentions of transformative business approaches were present they were conceptual and not time-bound, unless they were technology-based, which could involve speculative timeframes. Also a growing complication in the future use of targets is that corporates more advanced in ER may reach saturation point (corporate ER progress stage 5) where reducing emissions takes a are systemic will require external assistance with systemic emission sources or a fundamental change in business approach. More study is needed of the interplay between SBTs and corporate intent for corporations at different ER progress stages to understand how reliable an indicator of future ER a declared target is and the conditions a corporate places on reaching that target. 


\subsection{Transferability of findings}

Basing research on the progress of the Climate Leaders Coalition founding corporations (CLCFs) has potential disadvantages as well as the numerous advantages already mentioned. A Forsyth Barr report identified a disproportionate number of the CLCFs (AirNZ, Z and Fonterra) as being companies exposed to carbon risk due to growth limitation implications (Boley et al., 2019). This is not unusual in studies, in fact many studies are just on these 'high-emitters'. Also the shared path identified echoes other studies' findings (see section 6.4). Still, caution must be taken when applying results from a study that has distinct characteristics.

Something unforeseen at the time of research is how distinct globally aspects of NZ's COVID experience would be, due to the tightly maintained borders and lack of community cases relative to many other countries. Whether impacts upon corporates' ER role in other nations varies widely because of this remains to be seen. Given though the illustrated usefulness of the corporate ER stages framework (Table 2) and the shared progress path exhibited by all the CLCFs, and the internationally present primacy of growth aiding profit in developed countries, it is believed findings will prove transferable and a stepping stone to further insight. It is not expected that corporate behaviour will be comparable in countries where most of the general populace is not supportive or unaware of the need for climate change mitigation, nor where capitalism is not the dominant marketplace mechanism.

Determining the ER stage of each corporate represented is by necessity subjective, with numerous factors to consider. How progress is interpreted in mapping to a corporate ER stage depends upon whether the emission responsibilities are identified using the broader stakeholders' perspective on responsibilities versus the tighter boundaries defined by the reporting standard. Given the framework has been constructed based upon the evidence that the broader view of emissions responsibility is needed to address the systemic nature of many emissions sources, it is not appropriate to use the corporate emission progress framework in the narrower context of emission responsibilities as defined by the GHG Protocol reporting standard (see section 4.3.1). 


\section{Conclusion}

To determine the greenhouse gas ER progress of the founding members of the Climate Leaders Coalition (CLCFs) a corporate emissions stages framework was constructed. This framework was based upon a range of sustainability stages beyond those known to exist within current corporates and included multiple facets, including emission strategies, actions, communications, and reports. The reasoning was identifying each corporation's progress using this framework would provide a wider context for understanding progress than one facet alone.

In this study the corporate emissions stages framework was deemed useful. CLCFs' progress pre-Paris initially spanned stages 2: Active to 4: Integrated. By the study's end progress had reached variously stages 3: Proactive to 5: Saturated. Reported emission trends and scope of business changes did not give confidence in achieving reductions in line with limiting global warming to $2^{\circ} \mathrm{C}$.

Using the framework identified a shared path to reducing emissions amongst the CLCFs, despite differences in industry sector, scale of emissions, and recency of first reporting emissions. The key elements present in the shared path are: reporting as the starting point and orientation for ER, strategic declaration, short-term 'win-wins' involving cost savings as well as ER, the gradual spread and increase in systems and people seniority and exposure related to sustainability, and slower 'win-wins' that require greater planning and investment. Visibility and employee engagement, as well as cost and ER, also appeared to be important characteristics. The shared path is also defined by what is absent. Key elements absent from the CLCFS progress and therefore the shared path are challenging the corporate growth assumption, and business transformation away from emission-intensive products/services to enable greater ER.

Communications echoed the shared path progression with most corporates changing the language used in media releases and reports from prior to the Paris Agreement, with an increased focus on ER related activity that had a larger ER impact but may be less visual than earlier ER initiatives such as waste reduction and LED lighting. Many increased the proportion of communications relevant to climate change mitigation 
post-Paris and ensure ER was more prominent in Annual reports and mentioned not just in the dedicated report section as previously.

Corporate positioning in submissions to government as time progressed became more homogenous with other content such as annual reports and more polished. All CLCFs were supportive of however some wished to An exception was $Z$ where their

COVID-19 opened up further possibilities for ER with one corporation interviewed indicating they now believed a future target achievable. These new ER possibilities were isolated aspects though, generated predominantly due to government-enforced travel restrictions, and did not seem to indicate a wider shift in thinking or approach to ER. However, New Zealand has been unusual globally in the relatively short length of time COVID-related restrictions were in place, so greater future ER possibilities may have been experienced in other countries.

Being a founding member of the CLC did appear to influence behaviour, though this was attributed more to the pledged target than being a foundational member. Interviewees were more likely to view founding CLC as indicative of their intent to progress ER rather than causal of further progress. Post-CLC the corporate communications, be they media releases, submissions or reports, voiced support of ER, however this voiced support was not always congruent with other communicated aspects, such as new branches or increased capacity.

Efforts by all CLCFs to reduce emissions were not trivial, with some low emitters struggling to identify further ER, highlighting systemic difficulties such as transport and international freight movement. Accordingly two thirds of those interviewed saw future targets as aspirational, so the shared path and associated strategies thus far does not extend far enough. Given the advent of SBT adoption by more CLCFs and the frequent announcements during 2020 and 2021 of future intentions, an updated study in several years is likely to be informative. 


\section{Appendices}

\section{Appendix 1: Corporate environmental progress frameworks}

\begin{tabular}{|c|c|c|c|}
\hline Type & Category names & Categories & Source \\
\hline $\begin{array}{l}\text { Corporate social } \\
\text { performance }\end{array}$ & Reactive, Defensive, Accomodative, Proactive & 4 & Carroll, 1979 \\
\hline Carbon strategy & $\begin{array}{l}\text { Cautious planners, emerging planners, internal } \\
\text { explorers, vertical explorers, horizontal explorers, } \\
\text { emissions traders }\end{array}$ & 6 & Kolk and Pinkse, 2005 \\
\hline Carbon strategy & Indifferent, beginner, emerging, active & 4 & Jeswani et al., 2008 \\
\hline Carbon strategy & $\begin{array}{l}\text { Carbon compensation, carbon reduction, carbon } \\
\text { independence }\end{array}$ & 3 & $\begin{array}{l}\text { Weinhofer \& Hoffmann, } \\
2010\end{array}$ \\
\hline Carbon strategy & $\begin{array}{l}\text { Minimalists, regulation shapers, pressure } \\
\text { managers, emissions avoiders }\end{array}$ & 4 & Sprengel \& Busch, 2011 \\
\hline Carbon strategy & $\begin{array}{l}\text { Wait and see observers, cautious reducers, } \\
\text { product enhancers, all-round enhancers, } \\
\text { emergent explorers, all-round explorers }\end{array}$ & 6 & Lee, 2012 \\
\hline $\begin{array}{l}\text { Env'tal behaviour } \\
\text { strategy }\end{array}$ & Laggard, Initiated, Proactive, Eco-innovators & 4 & Garcés-Ayerbe et al., 2016 \\
\hline $\begin{array}{l}\text { Env'tal behaviour } \\
\text { strategy }\end{array}$ & $\begin{array}{l}\text { Legislation fulfillment, training, systematization, } \\
\text { eco2, eco-innovative, leading green company }\end{array}$ & & $\begin{array}{l}\text { Ormazabal and Sarriegi, } \\
\text { 2012; Ormazabal et al., } \\
2015,2017\end{array}$ \\
\hline $\begin{array}{l}\text { Env'tal behaviour } \\
\text { strategy }\end{array}$ & Reactors, defenders, analyzers, prospectors & 4 & Primc and Čater, 2016 \\
\hline $\begin{array}{l}\text { Env'tal behaviour } \\
\text { strategy }\end{array}$ & Regulatory, gross emissions, efficiency, life cycle & 4 & Rothenberg et al., 2005 \\
\hline $\begin{array}{l}\text { Env'tal behaviour } \\
\text { strategy }\end{array}$ & $\begin{array}{l}\text { Functional specialization, internal integration, } \\
\text { external integration (Reactive, preventive and } \\
\text { proactive) }\end{array}$ & 3 & Jabbour et al., 2010 \\
\hline $\begin{array}{l}\text { Env'tal behaviour } \\
\text { strategy }\end{array}$ & $\begin{array}{l}\text { Passive, attention to legislation, attention to } \\
\text { stakeholder, total environmental quality }\end{array}$ & 4 & Murillo-Luna et al., 2011 \\
\hline $\begin{array}{l}\text { Env'tal managem't } \\
\text { progress }\end{array}$ & $\begin{array}{l}\text { Elementary, engaged, innovative, integrated, } \\
\text { transforming }\end{array}$ & 5 & Mirvis and Googins, 2006 \\
\hline $\begin{array}{l}\text { Env'tal managem't } \\
\text { progress }\end{array}$ & $\begin{array}{l}\text { Rejection, nonresponsiveness, compliance, } \\
\text { efficiency, strategic proactivity, the sustaining } \\
\text { corporation }\end{array}$ & & $\begin{array}{l}\text { Benn, Dunphy, and } \\
\text { Griffiths, } 2014\end{array}$ \\
\hline $\begin{array}{l}\text { Sustainability } \\
\text { strategy }\end{array}$ & $\begin{array}{l}\text { Nonparticipatory, Compliance, Business-centered, } \\
\text { Systemic, Regenerative, Coevolutionary }\end{array}$ & 6 & Landrum, 2018 \\
\hline
\end{tabular}




\section{Appendix 2: Corporate Emission Reduction Activity Descriptions}

\begin{tabular}{|c|c|c|c|c|}
\hline $\begin{array}{l}\text { Strategic } \\
\text { objective }\end{array}$ & Type & Strategic area & Activity area & Description \\
\hline $\begin{array}{l}\text { Carbon } \\
\text { governance }\end{array}$ & Indirect & $\begin{array}{l}\text { External } \\
\text { activities }\end{array}$ & $\begin{array}{l}\text { Engagement } \\
\text { with other } \\
\text { corporations }\end{array}$ & $\begin{array}{l}\text { Collaborative engagement with other } \\
\text { corporations who may or may not be part of } \\
\text { the supply chain. This captures broader } \\
\text { strategies or activity aimed at emission } \\
\text { reduction beyond those directly reducing } \\
\text { the corporation's reported emissions. }\end{array}$ \\
\hline $\begin{array}{l}\text { Carbon } \\
\text { governance }\end{array}$ & Indirect & $\begin{array}{l}\text { External } \\
\text { activities }\end{array}$ & $\begin{array}{l}\text { Engagements } \\
\text { with } \\
\text { environmental } \\
\text { NGOs }\end{array}$ & $\begin{array}{l}\text { Collaborative engagement with } \\
\text { environmental non-governmental } \\
\text { organisations. }\end{array}$ \\
\hline $\begin{array}{l}\text { Carbon } \\
\text { governance }\end{array}$ & Indirect & $\begin{array}{l}\text { External } \\
\text { activities }\end{array}$ & $\begin{array}{l}\text { Engagement } \\
\text { with other } \\
\text { entities }\end{array}$ & $\begin{array}{l}\text { Collaborative engagement with other (non- } \\
\text { corporate nor NGO) bodies such as } \\
\text { associations, communities, local or central } \\
\text { government, and smaller businesses. } \\
\text { Excludes formal government } \\
\text { communications such as submissions. }\end{array}$ \\
\hline $\begin{array}{l}\text { Carbon } \\
\text { governance }\end{array}$ & Indirect & $\begin{array}{l}\text { Organisational } \\
\text { involvement }\end{array}$ & $\begin{array}{l}\text { Carbon } \\
\text { management } \\
\text { resource } \\
\text { allocation }\end{array}$ & $\begin{array}{l}\text { The corporation's internal financial and } \\
\text { human resource allocated to carbon } \\
\text { management. }\end{array}$ \\
\hline $\begin{array}{l}\text { Carbon } \\
\text { governance }\end{array}$ & Indirect & $\begin{array}{l}\text { Organisational } \\
\text { involvement }\end{array}$ & $\begin{array}{l}\text { Carbon } \\
\text { decision- } \\
\text { making }\end{array}$ & $\begin{array}{l}\text { The way in which carbon decision-making is } \\
\text { managed, including seniority, composition } \\
\text { and regularity of carbon decision-making. } \\
\text { Seniority is considered not only in how } \\
\text { senior those making emission related } \\
\text { decisions are, but also as the level and } \\
\text { frequency of exposure at a senior level of } \\
\text { carbon information. }\end{array}$ \\
\hline $\begin{array}{l}\text { Carbon } \\
\text { governance }\end{array}$ & Indirect & $\begin{array}{l}\text { Organisational } \\
\text { involvement }\end{array}$ & $\begin{array}{l}\text { Internal } \\
\text { engagement } \\
\text { and incentives }\end{array}$ & $\begin{array}{l}\text { Corporate staff engagement, culture and } \\
\text { financial and non-financial incentives. }\end{array}$ \\
\hline $\begin{array}{l}\text { Carbon } \\
\text { governance }\end{array}$ & Indirect & $\begin{array}{l}\text { Organisational } \\
\text { involvement }\end{array}$ & $\begin{array}{l}\text { Carbon } \\
\text { management } \\
\text { systems }\end{array}$ & $\begin{array}{l}\text { Governance mechanisms for supporting } \\
\text { management and staff to align actions with } \\
\text { decarbonisation. }\end{array}$ \\
\hline $\begin{array}{l}\text { Carbon } \\
\text { governance }\end{array}$ & Indirect & $\begin{array}{l}\text { Risk } \\
\text { management }\end{array}$ & $\begin{array}{l}\text { Anticipated } \\
\text { regulation, } \\
\text { market } \\
\text { adjustments }\end{array}$ & $\begin{array}{l}\text { Awareness and incorporation of financial } \\
\text { and non-financial risks associated with not } \\
\text { reducing carbon, either through local or } \\
\text { central regulators or market conditions. }\end{array}$ \\
\hline $\begin{array}{l}\text { Carbon } \\
\text { governance }\end{array}$ & Indirect & $\begin{array}{l}\text { Risk } \\
\text { management }\end{array}$ & $\begin{array}{l}\text { Opportunity } \\
\text { identification }\end{array}$ & $\begin{array}{l}\text { Assessment of new/different products or } \\
\text { services that have comparatively much } \\
\text { lower|or no associate carbon or advantages } \\
\text { gained by producing relatively less carbon } \\
\text { than competitors. }\end{array}$ \\
\hline
\end{tabular}




\begin{tabular}{|c|c|c|c|c|}
\hline $\begin{array}{l}\text { Strategic } \\
\text { objective }\end{array}$ & Type & Strategic area & Activity area & Description \\
\hline $\begin{array}{l}\text { Carbon } \\
\text { governance }\end{array}$ & Indirect & $\begin{array}{l}\text { Carbon policy } \\
\text { and } \\
\text { measurement }\end{array}$ & $\begin{array}{l}\text { Carbon target } \\
\text { setting and } \\
\text { adjustment }\end{array}$ & $\begin{array}{l}\text { Reduction target setting approach, scope, } \\
\text { and adjustment. }\end{array}$ \\
\hline $\begin{array}{l}\text { Carbon } \\
\text { governance }\end{array}$ & Indirect & $\begin{array}{l}\text { Carbon policy } \\
\text { and } \\
\text { measurement }\end{array}$ & $\begin{array}{l}\text { Reporting } \\
\text { scope, } \\
\text { robustness and } \\
\text { completeness }\end{array}$ & $\begin{array}{l}\text { Reporting comprehensiveness as indicated } \\
\text { by scope of reporting boundaries, } \\
\text { robustness of reporting method and ease of } \\
\text { interpretation, and completeness in terms of } \\
\text { emission inventory items and associated } \\
\text { emission consideration. }\end{array}$ \\
\hline $\begin{array}{l}\text { Carbon reduction } \\
\text { / elimination }\end{array}$ & Direct & $\begin{array}{l}\text { Product/service } \\
\text { alterations }\end{array}$ & $\begin{array}{l}\text { Altered } \\
\text { product/service } \\
\text { portfolio or } \\
\text { volume }\end{array}$ & $\begin{array}{l}\text { Changes to product and/or services offered, } \\
\text { either in the product/service or range or } \\
\text { associated focus and volumes. }\end{array}$ \\
\hline $\begin{array}{l}\text { Carbon reduction } \\
\text { / elimination }\end{array}$ & Direct & $\begin{array}{l}\text { Product/service } \\
\text { alterations }\end{array}$ & $\begin{array}{l}\text { Product/service } \\
\text { outsourcing }\end{array}$ & $\begin{array}{l}\text { Movement of operational boundaries } \\
\text { through outsourcing - business activities } \\
\text { become produced/service by an } \\
\text { independent company, or brought inhouse - } \\
\text { formerly external production/service } \\
\text { activities become part of the corporate } \\
\text { operations. }\end{array}$ \\
\hline $\begin{array}{l}\text { Carbon reduction } \\
\text { / elimination }\end{array}$ & Direct & $\begin{array}{l}\text { Internal process } \\
\text { alterations }\end{array}$ & $\begin{array}{l}\text { Product/service } \\
\text { distribution }\end{array}$ & $\begin{array}{l}\text { Emissions associated with the process of } \\
\text { distributing goods/services to consumers or } \\
\text { other downstream destinations. }\end{array}$ \\
\hline $\begin{array}{l}\text { Carbon reduction } \\
\text { / elimination }\end{array}$ & Direct & $\begin{array}{l}\text { Internal process } \\
\text { alterations }\end{array}$ & $\begin{array}{l}\text { Other } \\
\text { operational } \\
\text { improvements }\end{array}$ & $\begin{array}{l}\text { Reducing administrative and other } \\
\text { infrastructure emissions. }\end{array}$ \\
\hline $\begin{array}{l}\text { Carbon reduction } \\
\text { / elimination }\end{array}$ & Direct & $\begin{array}{l}\text { Supply chain } \\
\text { alterations }\end{array}$ & $\begin{array}{l}\text { Upstream } \\
\text { supply chain } \\
\text { changes }\end{array}$ & $\begin{array}{l}\text { Changes to reduce emissions associated with } \\
\text { suppliers of goods/services used by the } \\
\text { corporation. }\end{array}$ \\
\hline $\begin{array}{l}\text { Carbon reduction } \\
\text { / elimination }\end{array}$ & Direct & $\begin{array}{l}\text { Supply chain } \\
\text { alterations }\end{array}$ & $\begin{array}{l}\text { Downstream } \\
\text { supply chain } \\
\text { changes }\end{array}$ & $\begin{array}{l}\text { Changes to reduce emissions associated with } \\
\text { recipients of the goods/services provided by } \\
\text { the corporation. }\end{array}$ \\
\hline $\begin{array}{l}\text { Carbon } \\
\text { compensation }\end{array}$ & Direct & $\begin{array}{l}\text { Carbon } \\
\text { offsetting and } \\
\text { balancing }\end{array}$ & $\begin{array}{l}\text { Internal } \\
\text { offsetting/ } \\
\text { balancing }\end{array}$ & $\begin{array}{l}\text { Offsetting or counteraction of emissions by } \\
\text { ensuring absorption of emissions happens } \\
\text { within the corporation unrelated to } \\
\text { operational processes. }\end{array}$ \\
\hline $\begin{array}{l}\text { Carbon } \\
\text { compensation }\end{array}$ & Direct & $\begin{array}{l}\text { Carbon } \\
\text { offsetting and } \\
\text { balancing }\end{array}$ & $\begin{array}{l}\text { External } \\
\text { offsetting/ } \\
\text { balancing }\end{array}$ & $\begin{array}{l}\text { Investment in offsetting or recognised } \\
\text { technology development projects to aid } \\
\text { future offsetting. }\end{array}$ \\
\hline $\begin{array}{l}\text { Carbon } \\
\text { positioning }\end{array}$ & Indirect & Corporate role & $\begin{array}{l}\text { Declaring } \\
\text { responsibilities }\end{array}$ & $\begin{array}{l}\text { High profile declarative statements involving } \\
\text { business purpose, strategy or intent } \\
\text { regarding reducing carbon emissions. }\end{array}$ \\
\hline
\end{tabular}




\begin{tabular}{|l|l|l|l|l|}
\hline $\begin{array}{l}\text { Strategic } \\
\text { objective }\end{array}$ & Type & Strategic area & Activity area & Description \\
\hline $\begin{array}{l}\text { Carbon } \\
\text { positioning }\end{array}$ & Indirect & $\begin{array}{l}\text { Public } \\
\text { communications }\end{array}$ & Reports & $\begin{array}{l}\text { Placement, sharing and transmission of } \\
\text { reports to stakeholders. }\end{array}$ \\
\hline $\begin{array}{l}\text { Carbon } \\
\text { positioning }\end{array}$ & Indirect & $\begin{array}{l}\text { Public } \\
\text { communications }\end{array}$ & Media releases & $\begin{array}{l}\text { Communication of emission reduction } \\
\text { activities and strategies via media releases. }\end{array}$ \\
\hline $\begin{array}{l}\text { Carbon } \\
\text { positioning }\end{array}$ & Indirect & $\begin{array}{l}\text { Public } \\
\text { communications }\end{array}$ & $\begin{array}{l}\text { Mitigation } \\
\text { related } \\
\text { submissions }\end{array}$ & $\begin{array}{l}\text { Responses to invited climate mitigation } \\
\text { related submissions by the NZ government. }\end{array}$ \\
\hline
\end{tabular}




\section{Appendix 3: Interview Questions}

Q1: Please describe briefly any climate related positions you've had in the company and how long you have worked with the company in these roles? And, if longer, your total time with the company?

Q2: Looking back before COVID-19, in your own words can you please describe the progress since 2010 to reduce your company's current or future greenhouse gas emissions?

Q2a: (If not already answered) Has the approach changed over time? If so how?

Q3: What do you think are areas where the greatest progress has been made to reduce emissions or to help achieve future emission reductions? What internal or external circumstances or factors enabled this progress?

Q4: What are areas where there could perhaps have been more achieved? What internal or external circumstances or factors most hindered this progress? What might have enabled these changes?

Q4a: (If not already answered) Did founding or launching the original Climate Leaders Coalition statement and the updated statement have any effect on progress? If so, in what way?

Q5: Immediately before COVID-19, how would you describe your company's approach to emissions reduction?

Q6: Since COVID-19, what has been the impact of the COVID-19 disruption on progress?

Q6a: (If not already answered) Have targets been adjusted or is there an intent to adjust targets? Will this adjustment/non-adjustment affect your company's approach?

Q7: If you are able, can you please comment on your company's likely progress within the next one - three years? 
Appendix 4: Relevant corporate submissions to government

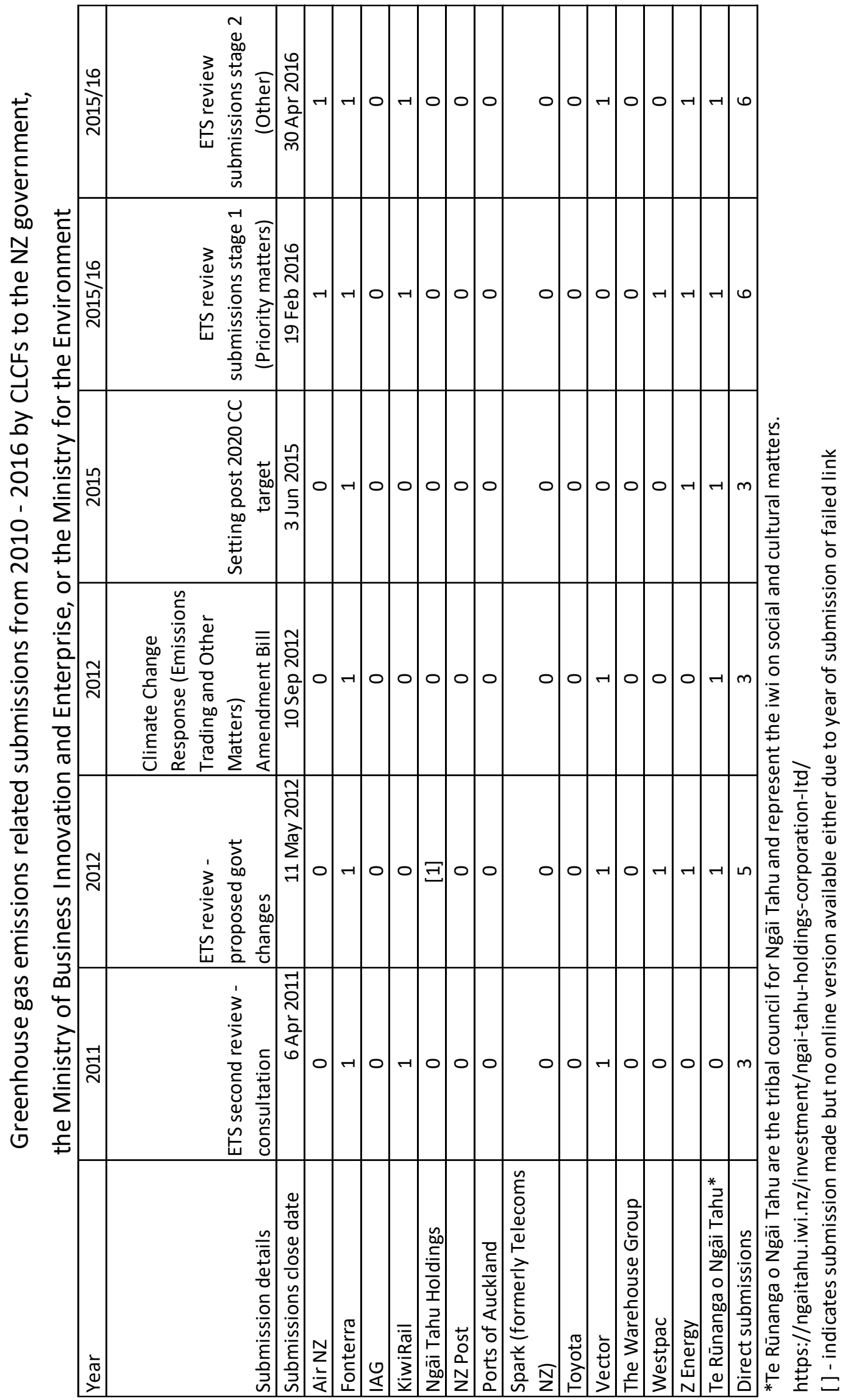

Page | 129 


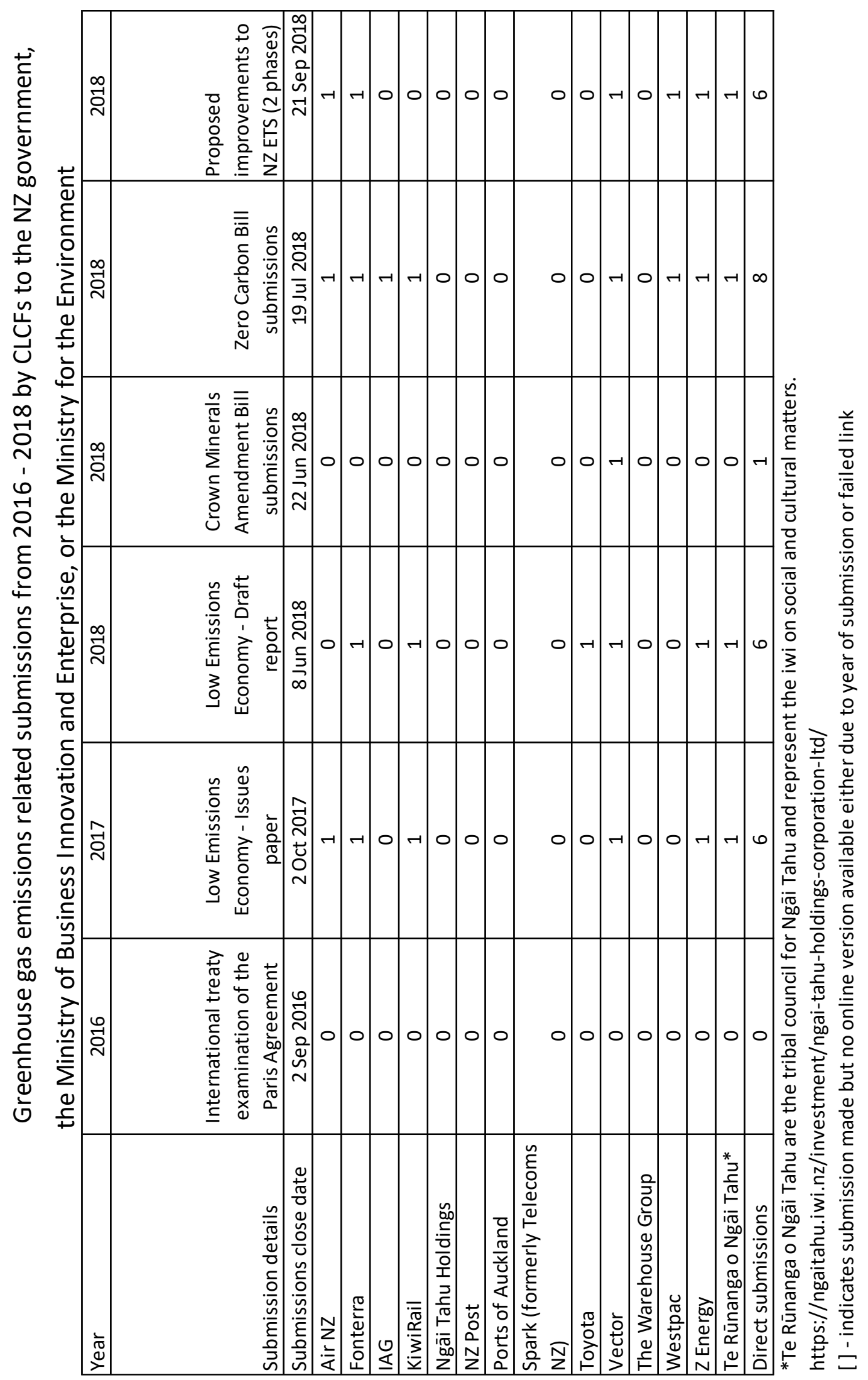




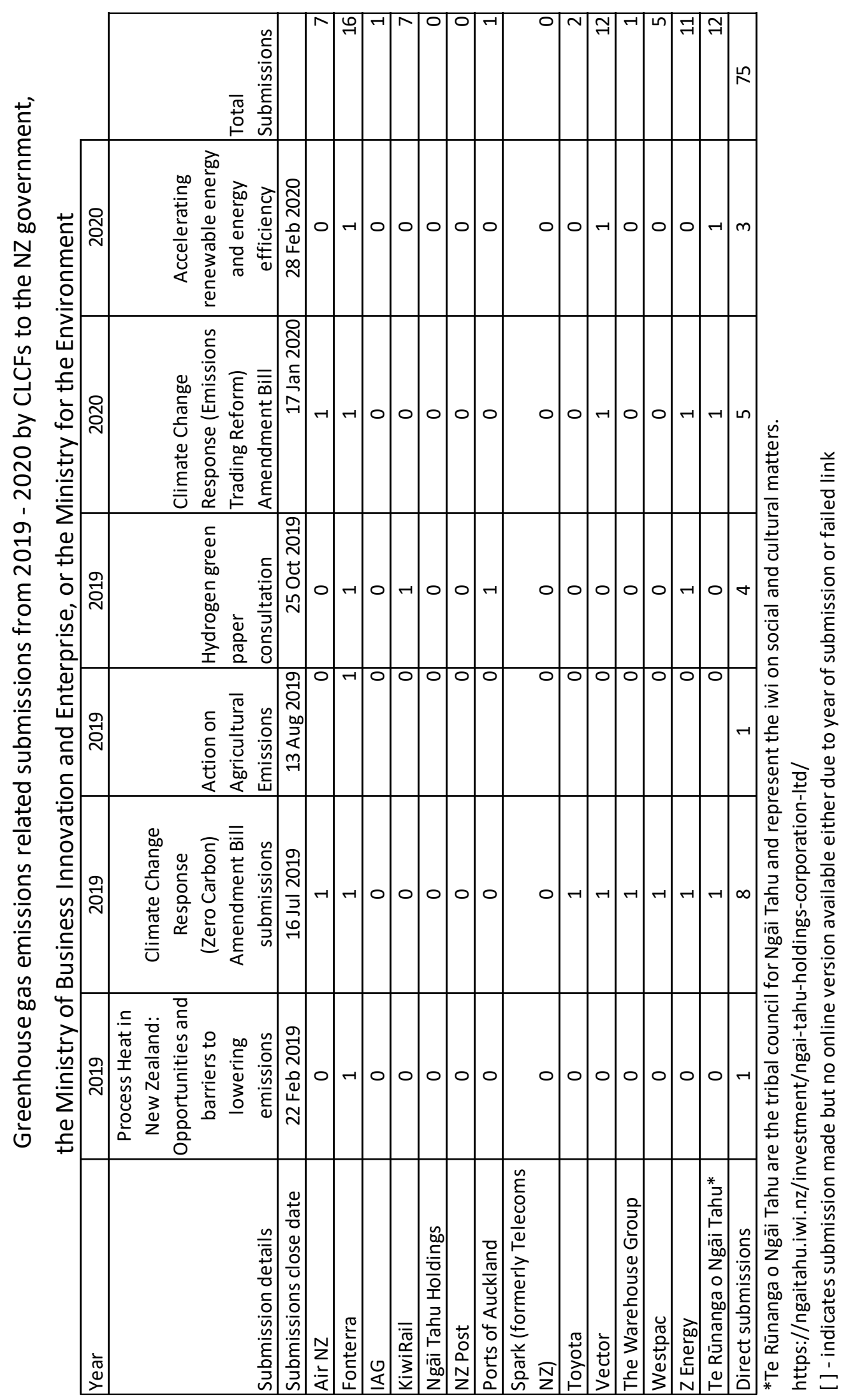




\section{Appendix 5: Corporate emissions figure coverage}

The table below indicates emission figures publicly available via corporate annual/environmental/integrated/sustainability reporting or CDP responses.

\begin{tabular}{|l|c|c|c|c|c|c|c|c|c|c|r|r|}
\hline CLC Founder & 2010 & 2011 & 2012 & 2013 & 2014 & 2015 & 2016 & 2017 & 2018 & 2019 & 2020 & Toral \\
\hline Air New Zealand & 1 & 1 & 1 & 1 & 1 & 1 & 1 & 1 & 1 & 1 & 1 & 11 \\
\hline Fonterra & $\mathrm{N}$ & $\mathrm{N}$ & 1 & 1 & 1 & 1 & 1 & 1 & 1 & 1 & 1 & 9 \\
\hline IAG & 1 & 1 & 1 & 1 & 1 & 1 & 1 & 1 & 1 & 1 & 1 & 11 \\
\hline KiwiRail & 1 & 1 & 1 & 1 & 1 & 1 & 1 & 1 & 1 & 1 & 1 & 11 \\
\hline Ngāi Tahu Holdings & - & - & - & - & - & - & 1 & 1 & 1 & $?$ & $?$ & 3 \\
\hline NZ Post & 1 & 1 & 1 & 1 & 1 & 1 & 1 & 1 & 1 & 1 & 1 & 11 \\
\hline Ports of Auckland & - & - & - & - & - & - & - & 1 & 1 & 1 & 1 & 4 \\
\hline Spark & 1 & $\mathrm{~N}$ & $\mathrm{~N}$ & 1 & 1 & 1 & 1 & 1 & 1 & 1 & 1 & 9 \\
\hline The Warehouse Group & $\mathrm{N}$ & $\mathrm{N}$ & 1 & 1 & 1 & 1 & 1 & 1 & 1 & 1 & $\mathrm{~W}$ & 8 \\
\hline Toyota New Zealand & 1 & 1 & 1 & 1 & 1 & 1 & 1 & 1 & 1 & 1 & 1 & 11 \\
\hline Vector & - & - & - & - & - & - & - & 1 & 1 & 1 & 1 & 4 \\
\hline Westpac New Zealand & 1 & 1 & 1 & 1 & 1 & 1 & 1 & 1 & 1 & 1 & 1 & 11 \\
\hline Z Energy & - & - & 1 & 1 & 1 & 1 & 1 & 1 & 1 & 1 & 1 & 9 \\
\hline Total & 7 & 6 & 9 & 10 & 10 & 10 & 11 & 13 & 13 & 12 & 11 & 112 \\
\hline
\end{tabular}

\section{Notes:}

Years indicated are the year in which the reporting period ends. Most periods end 30 June.

"1" - emission figures were publicly available and located

" $\mathrm{N}$ " - the corporation was quantifying emissions but information was not in the public domain

"W" - the corporation had quantifed emissions but the results are yet to be released

"-" - the corporation did not report or no evidence could be found of emissions reporting

"?" - it is uncertain whether the corporation has calculated their emissions for that year 


\section{Appendix 6: CLCF Reported emissions at key points throughout 2010-2020, by Scope}

\begin{tabular}{|c|c|c|c|c|c|c|c|c|c|c|c|}
\hline $\begin{array}{l}\text { Climate Leaders Coalition } \\
\text { Foundational member }\end{array}$ & Scope & Early 2010s & FY & pre-Paris & $\mathrm{FY}$ & $\begin{array}{c}\text { pre-CLC } \\
\text { founding }\end{array}$ & FY & pre-COVID & FY & Current & FY \\
\hline Air NZ & 1 & $2,959,402$ & 2011 & $3,073,455$ & 2015 & $3,730,246$ & 2018 & $3,925,650$ & 2019 & $3,176,634$ & 2020 \\
\hline Air NZ & 2 & 7,246 & 2011 & 5,543 & 2015 & 3,044 & 2018 & 3,098 & 2019 & 2,832 & 2020 \\
\hline Air NZ & 3 & - & 2011 & - & 2015 & - & 2018 & & 2019 & - & 2020 \\
\hline Air NZ & Total & $2,966,648$ & 2011 & $3,078,998$ & 2015 & $3,733,290$ & 2018 & $3,928,748$ & 2019 & $3,179,466$ & 2020 \\
\hline Fonterra Co-operative Group Limited & 1 & $1,392,940$ & 2012 & $1,433,175$ & 2015 & $1,716,000$ & 2018 & $1,690,000$ & 2019 & $1,696,000$ & 2020 \\
\hline Fonterra Co-operative Group Limited & 2 & 656,399 & 2012 & 618,609 & 2015 & 692,000 & 2018 & 659,000 & 2019 & 628,000 & 2020 \\
\hline Fonterra Co-operative Group Limited & 3 & Unknown & 2012 & $20,383,445$ & 2015 & $22,398,000$ & 2018 & $21,459,000$ & 2019 & $21,240,000$ & 2020 \\
\hline Fonterra Co-operative Group Limited & Total & Unknown & 2012 & $22,435,229$ & 2015 & $24,806,000$ & 2018 & $23,808,000$ & 2019 & $23,564,000$ & 2020 \\
\hline IAG & 1 & $985^{*}$ & 2010 & 1,879 & 2015 & 1,329 & 2018 & 1,236 & 2019 & 1,030 & 2020 \\
\hline IAG & 2 & $1,355^{*}$ & 2010 & 1,657 & 2015 & 816 & 2018 & 702 & 2019 & 537 & 2020 \\
\hline IAG & 3 & $1,601 *$ & 2010 & 3,064 & 2015 & 4,039 & 2018 & 4,036 & 2019 & 3,175 & 2020 \\
\hline IAG & Total & 3,941 & 2010 & 6,600 & 2015 & 6,184 & 2018 & 5,975 & 2019 & 4,743 & 2020 \\
\hline KiwiRail & 1 & $293,000^{*}$ & 2011 & Unknown & 2016 & Unknown & 2018 & Unknown & 2019 & Unknown & 2020 \\
\hline KiwiRail & 2 & $13,000^{*}$ & 2011 & Unknown & 2016 & Unknown & 2018 & Unknown & 2019 & Unknown & 2020 \\
\hline KiwiRail & 3 & not available & 2011 & Unknown & 2016 & Unknown & 2018 & Unknown & 2019 & Unknown & 2020 \\
\hline KiwiRail & Total & $306,000^{*}$ & 2011 & 272,345 & 2016 & 227,116 & 2018 & 240,094 & 2019 & 230,046 & 2020 \\
\hline KiwiRail GHG emissions measure & CO2ge per NTK & 34 & 2010 & 32 & 2015 & 28 & 2018 & 27 & 2019 & 28 & 2020 \\
\hline Ngāi Tahu Holdings Corporation & 1 & - & 2010 & 40,813 & 2016 & 106,128 & 2017 & 115,217 & 2018 & - & 2020 \\
\hline Ngāi Tahu Holdings Corporation & 2 & - & 2010 & 965 & 2016 & 1,558 & 2017 & 1,236 & 2018 & - & 2020 \\
\hline Ngāi Tahu Holdings Corporation & 3 & - & 2010 & 14,258 & 2016 & 10,543 & 2017 & 9,469 & 2018 & - & 2020 \\
\hline Ngāi Tahu Holdings Corporation & Total & - & 2010 & 56,035 & 2016 & 118,229 & 2017 & 125,921 & 2018 & - & 2020 \\
\hline NZ Postal Group Limited & 1 & $19537 \mid 16455$ & $2010 \mid 2012$ & 15,650 & 2015 & 3,849 & 2018 & 3,744 & 2019 & 4,113 & 2020 \\
\hline NZ Postal Group Limited & 2 & 6509 | 5007 & $2010 \mid 2012$ & 4,664 & 2015 & 2,788 & 2018 & 2,123 & 2019 & 2,042 & 2020 \\
\hline NZ Postal Group Limited & 3 & 49852 | 10335 & $2010 \mid 2012$ & 93,400 & 2015 & 122,871 & 2018 & 105,341 & 2019 & 100,460 & 2020 \\
\hline NZ Postal Group Limited & Total & $75898 \mid 12590$ & $2010 \mid 2012$ & 113,714 & 2015 & 129,509 & 2018 & 111,208 & 2019 & 106,615 & 2020 \\
\hline Ports of Auckland Limited & 1 & - & 2010 & 12,254 & 2017 & 12,799 & 2018 & 12,353 & 2019 & 12,056 & 2020 \\
\hline Ports of Auckland Limited & 2 & - & 2010 & 1,867 & 2017 & 2,023 & 2018 & 1,523 & 2019 & 1,368 & 2020 \\
\hline Ports of Auckland Limited & 3 (mandatory) & - & 2010 & 620 & 2017 & 465 & 2018 & 574 & 2019 & 293 & 2020 \\
\hline Ports of Auckland Limited & 3 (optional) & - & 2010 & 1,467 & 2017 & 1,513 & 2018 & 2,253 & 2019 & 2,166 & 2020 \\
\hline Ports of Auckland Limited & Total & - & 2010 & 16,208 & 2017 & 16,799 & 2018 & 16,702 & 2019 & 15,882 & 2020 \\
\hline Spark NZ & 1 & 5,543 & 2009 & 1,843 & 2015 & 3,643 & 2018 & 3,538 & 2019 & 3,632 & 2020 \\
\hline Spark NZ & 2 & 42,241 & 2009 & 19,302 & 2015 & 16,169 & 2018 & 16,802 & 2019 & 17,501 & 2020 \\
\hline Spark NZ & 3 & 11,695 & 2009 & 7,534 & 2015 & 8,675 & 2018 & 9,168 & 2019 & 7,076 & 2020 \\
\hline Spark NZ & Total & 59,479 & 2009 & 28,679 & 2015 & 28,487 & 2018 & 29,508 & 2019 & 28,209 & 2020 \\
\hline The Warehouse Group & 1 & 1,207 & 2012 & 4,434 & 2015 & 2,963 & 2018 & 2,932 & 2019 & not yet & 2020 \\
\hline The Warehouse Group & 2 & 13,399 & 2012 & 13,972 & 2015 & 11,921 & 2018 & 9,703 & 2019 & & 2020 \\
\hline The Warehouse Group & 3 & 12,538 & 2012 & 21,581 & 2015 & 25,969 & 2018 & 26,564 & 2019 & & 2020 \\
\hline The Warehouse Group & Total & 27,144 & 2012 & 39,988 & 2015 & 40,852 & 2018 & 39,199 & 2019 & - & 2020 \\
\hline Toyota New Zealand Limited (TNZ) & 1 & 942 & 2011 & 1,553 & 2015 & 1,492 & 2018 & 1,447 & 2019 & 1,367 & 2020 \\
\hline Toyota New Zealand Limited (TNZ) & 2 & 299 & 2011 & 317 & 2015 & 245 & 2018 & 281 & 2019 & 274 & 2020 \\
\hline Toyota New Zealand Limited (TNZ) & 3 & 7,076 & 2011 & 20,612 & 2015 & 28,453 & 2018 & 25,570 & 2019 & 24,444 & 2020 \\
\hline Toyota New Zealand Limited (TNZ) & Total & 8,317 & 2011 & 22,482 & 2015 & 30,190 & 2018 & 27,298 & 2019 & 26,091 & 2020 \\
\hline Vector Limited & 1 & - & 2010 & 341,964 & 2017 & 371,084 & 2018 & 402,575 & 2019 & 300,315 & 2020 \\
\hline Vector Limited & 2 & - & 2010 & 31,599 & 2017 & 29,070 & 2018 & 23,768 & 2019 & 22,863 & 2020 \\
\hline Vector Limited & 3 & - & 2010 & - & 2017 & 5,869 & 2018 & 11,009 & 2019 & 11,180 & 2020 \\
\hline Vector Limited & Total & - & 2010 & 373,563 & 2017 & 406,023 & 2018 & 437,352 & 2019 & 334,358 & 2020 \\
\hline Westpac NZ Limited & 1 & 2,029 & 2010 & 2,263 & 2015 & 1,987 & 2018 & 1,691 & 2019 & 1,420 & 2020 \\
\hline Westpac NZ Limited & 2 & 3,951 & 2010 & 3,162 & 2015 & 2,222 & 2018 & 1,901 & 2019 & 1,764 & 2020 \\
\hline Westpac NZ Limited & 3 (mandatory) & not available & 2010 & 2,966 & 2015 & 1,458 & 2018 & 2,633 & 2019 & 1,828 & 2020 \\
\hline Westpac NZ Limited & 3 (optional) & not available & 2010 & - & 2015 & 665 & 2018 & 1,122 & 2019 & 1,003 & 2020 \\
\hline Westpac NZ Limited & Total (incl optional) & $\begin{array}{r}5,980 \\
\end{array}$ & 2010 & 8,391 & 2015 & 6,332 & 2018 & 7,347 & 2019 & 6,015 & 2020 \\
\hline Z Energy & 1 & 797 & 2012 & 2,250 & 2015 & 3,853 & 2018 & 3,837 & 2019 & 4,127 & 2020 \\
\hline Z Energy & 2 & 5,984 & 2012 & 5,323 & 2015 & 4,223 & 2018 & 4,195 & 2019 & 3,371 & 2020 \\
\hline Z Energy & 3 (operational) & 26,307 & 2012 & 23,213 & 2015 & 34,916 & 2018 & 33,025 & 2019 & 33,291 & 2020 \\
\hline Z Energy & 3 (refinery, supply) & $1,155,501$ & 2012 & 952,707 & 2015 & $1,602,422$ & 2018 & $1,458,107$ & 2019 & $1,552,017$ & 2020 \\
\hline Z Energy & 3 (fuel use) & $6,101,736$ & 2012 & $5,649,743$ & 2015 & $10,330,585$ & 2018 & $10,459,104$ & 2019 & $10,531,782$ & 2020 \\
\hline Z Energy & Total & $7,290,325$ & 2012 & $6,635,699$ & 2015 & $11,975,999$ & 2018 & $11,958,268$ & 2019 & $12,124,589$ & 2020 \\
\hline
\end{tabular}




\section{Appendix 7: Annual/Sustainability/Environmental Reports coverage}

\begin{tabular}{|c|c|c|c|c|c|c|c|c|c|c|c|}
\hline Corporation & 2010 & 2011 & 2012 & 2013 & 2014 & 2015 & 2016 & 2017 & 2018 & 2019 & 2020 \\
\hline Air New Zealand & 1 & 1 & 1 & 1 & 1 & 1 & 1 & 1 & 1 & 1 & 1 \\
\hline Fonterra & 1 & 1 & 1 & 1 & 1 & 1 & 1 & 1 & 1 & 1 & 1 \\
\hline IAG & 1 & 1 & 1 & 1 & 1 & 1 & 1 & 1 & 1 & 1 & 1 \\
\hline KiwiRail & 1 & 1 & 1 & 1 & 1 & 1 & 1 & 1 & 1 & 1 & 1 \\
\hline Ngāi Tahu Holdings & 1 & 1 & 1 & 1 & 1 & 1 & 1 & 1 & 1 & 1 & 1 \\
\hline NZ Post & 1 & 1 & 1 & 1 & 1 & 1 & 1 & 1 & 1 & 1 & 1 \\
\hline Ports of Auckland & 1 & 1 & 1 & 1 & 1 & 1 & 1 & 1 & 1 & 1 & 1 \\
\hline Spark^^ & $\mathrm{N} / \mathrm{A}$ & $\mathrm{N} / \mathrm{A}$ & $\mathrm{N} / \mathrm{A}$ & $\mathrm{N} / \mathrm{A}$ & 1 & 1 & 1 & 1 & 1 & 1 & 1 \\
\hline The Warehouse Group & 1 & 1 & 1 & 1 & 1 & 1 & 1 & 1 & 1 & 1 & 1 \\
\hline Toyota New Zealand* & $\mathrm{N} / \mathrm{A}$ & 1 & $\mathrm{~N} / \mathrm{A}$ & 1 & $\mathrm{~N} / \mathrm{A}$ & 1 & 1 & 1 & 1 & 1 & 1 \\
\hline Vector & 1 & 1 & 1 & 1 & 1 & 1 & 1 & 1 & 1 & 1 & 1 \\
\hline Westpac New Zealand & 1 & 1 & 1 & 1 & 1 & 1 & 1 & 1 & 1 & 1 & 1 \\
\hline Z Energy** & $\mathrm{N} / \mathrm{A}$ & 1 & 1 & 1 & 1 & 1 & 1 & 1 & 1 & 1 & 1 \\
\hline Total & 10 & 12 & 11 & 12 & 12 & 13 & 13 & 13 & 13 & 13 & 13 \\
\hline
\end{tabular}

^Telecom New Zealand became Spark in 2014, which was a distinctly new strategic direction, therefore the earlier reports are not relevant *Toyota New Zealand sustainability reports were only produced bienially before 2015

**Greenstone Energy became Z Energy in 2011, which was a distinctly new strategic direction, therefore the 2010 reports are not relevant 


\section{Appendix 8: Press release coverage}

\begin{tabular}{|c|c|c|c|c|c|c|c|c|c|c|c|}
\hline Corporation & 2010 & 2011 & 2012 & 2013 & 2014 & 2015 & 2016 & 2017 & 2018 & 2019 & 2020 \\
\hline Air New Zealand & 0 & 0 & 0 & 0 & 0 & 1 & 1 & 1 & 1 & 1 & 1 \\
\hline Fonterra & unavail. & unavail. & 0 & 0 & 0 & 1 & 1 & 1 & 1 & 1 & 1 \\
\hline IAG & unavail. & unavail. & unavail. & unavail. & unavail. & unavail. & 0 & 0 & 1 & 1 & 1 \\
\hline KiwiRail & unavail. & unavail. & unavail. & unavail. & unavail. & unavail. & 0 & 1 & 1 & 1 & 1 \\
\hline Ngāi Tahu Holdings & 1 & 0 & 0 & 0 & 0 & 0 & 0 & 0 & 1 & 1 & 0 \\
\hline NZ Post & unavail. & unavail. & unavail. & unavail. & unavail. & unavail. & unavail. & unavail. & 0 & 1 & 1 \\
\hline Ports of Auckland & unavail. & unavail. & unavail. & unavail. & unavail. & 1 & 1 & 1 & 1 & 1 & 1 \\
\hline Spark & Telecom & Telecom & Telecom & Telecom & 1 & 1 & 1 & 1 & 1 & 1 & 1 \\
\hline The Warehouse Group & unavail. & unavail. & unavail. & 0 & 0 & 0 & 1 & 0 & 1 & 1 & 1 \\
\hline Toyota & 1 & 1 & 1 & 1 & 1 & 1 & 1 & 1 & 1 & 1 & 1 \\
\hline Vector & unavail. & unavail. & unavail. & unavail. & unavail. & 1 & 1 & 1 & 1 & 1 & 1 \\
\hline Westpac & 1 & 0 & 0 & 0 & 1 & 0 & 0 & 1 & 1 & 1 & 1 \\
\hline Z Energy & 1 & 1 & 1 & 1 & 1 & 1 & 1 & 1 & 1 & 1 & 1 \\
\hline Total & 4 & 2 & 2 & 2 & 4 & 7 & 8 & 9 & 12 & 13 & 12 \\
\hline
\end{tabular}

*Telecom New Zealand was restrategised and rebranded as Spark in 2014, so only press releases from 2014 onwards are relevant 


\section{Bibliography}

"Deed of Amendment and Restatement". (2013).

https://www.nzpost.co.nz/sites/nz/files/uploads/shared/2013-deed-of-

amendment-restatement.pdf

ABC News. (2021). New Zealand's troubled waters.

https://www.abc.net.au/news/2021-03-16/new-zealand-rivers-pollution-100per-cent-pure/13236174

ACCSR. (2017). Re-imagining sustainable value: the Sustainable Development Goals gather pace / Annual Review of the State of CSR in Australia and New Zealand 2017.

https://www.sbc.org.nz/_data/assets/pdf_file/0007/127591/ACCSR-State-ofCSR-Report-2017.pdf

Agrawala, S., Dussaux, D., \& Monti, N. (2020). What policies for greening the crisis response and economic recovery?

https://doi.org/doi:https://doi.org/10.1787/c50f186f-en

Aguilera, R., \& Jackson, G. (2003). The cross-national diversity of corporate governance: Dimensions and determinants. Acad. Manage. Rev., 28(3), 447465. https://doi.org/10.5465/AMR.2003.10196772

Aguinis, H., \& Glavas, A. (2012). What We Know and Don't Know About Corporate Social Responsibility. Journal of Management, 38(4), 932-968.

https://doi.org/10.1177/0149206311436079

Air NZ. (2008). A sustainable future.

https://web.archive.org/web/20100602115704/http://www.airnewzealand.co.nz /assets/Resources-AirNZ/Environment/environment-booklet-november08.pdf

Air NZ. (2011). Boeing 787 Dreamliner to touch down in Auckland this Saturday. https://web.archive.org/web/20160202001854/http://www.airnewzealand.co.nz /press-release-2011-boeing787-dreamliner-to-touch-down-in-auckland-thissaturday

Air NZ. (2015a). 2015 Annual Shareholder Review. https://pairnz.com/cms/assets/NZ/PDFs/2015-Annual-Shareholder-Review.pdf

Air NZ. (2015b). 2015 Sustainability Report. https://pairnz.com/cms/assets/NZ/PDFs/sustainability-report-2015.pdf 
Air NZ. (2015c, September 16). Air New Zealand launches Sustainability Framework https://www.airnewzealand.co.nz/media-releases

Air NZ. (2017a). 2017 Annual Shareholder Review. https://indd.adobe.com/view/b08432be-a034-4ffa-9972-2e8078fbe67b

Air NZ. (2017b). 2017 Sustainability Report. https://adobeindd.com/view/publications/ba876813-8fcc-4c0a-bff9bd8dae07b0aa/e74d/publication-webresources/pdf/J010536_Sustainabiltity_2017_Online_Report_FA.pdf

Air NZ. (2018a). 2018 Sustainability Report. https://pairnz.com/cms/assets/PDFs/2018-Sustainability-Report.pdf

Air NZ. (2018b, September 26). Air New Zealand's new A321neo nears take-off http://web.archive.org/web/20210219225259/https://www.airnewzealand.co.nz /press-release-2018-a321neo-take-off

Air NZ. (2019a, August 22). Media release Air New Zealand announces earnings before taxation of $\$ 374$ million, maintains final dividend https://pairnz.com/cms/assets/PDFs/airnz-2019-annual-results-media-release.pdf

Air NZ. (2019b). Sustainability Report 2019. https://pairnz.com/cms/assets/PDFs/2019-sustainability-report-v7.pdf

Air NZ. (2020a). 2020 Annual Shareholder Review. https://www.airnewzealand.co.nz/financial-information

Air NZ. (2020b). 2020 Greenhouse Gas Inventory Report. https://www.airnewzealand.com.sg/sustainability-about-our-report

Air NZ. (2020c). 2020 Sustainability Report. https://p-airnz.com/cms/assets/PDFs/airnew-zealand-sustainability-report-2020.pdf

Air NZ. (n.d.). Frequently asked questions about Investing in Air New Zealand. Retrieved 27 Aug 2021 from https://www.airnewzealand.co.nz/investor-centrefrequently-asked-questions

American Meteorological Society. (2018). State of the Climate in 2017. The Bulletin of the American Meteorological Society, Si-S332. https://doi.org/10.1175/2018BAMSStateoftheClimate.1 
Amran, A., Ooi, S. K., Wong, C. Y., \& Hashim, F. (2016). Business Strategy for Climate Change: An ASEAN Perspective. Corporate Social Responsibility and Environmental Management, 23(4), 213-227. https://doi.org/10.1002/csr.1371

Anthony, J. (2021, September 14). Air NZ plans to be flying electric aircraft by 2030, chief pilot says. Stuff.

Aragòn-Correa, J. A., Marcus, A. A., \& Vogel, D. (2019). The Effects of Mandatory and Voluntary Regulatory Pressures on Firms' Environmental Strategies: A Review and Recommendations for Future Research. Academy of Management Annals, 14(1), 339-365. https://doi.org/10.5465/annals.2018.0014

Auckland Council. (2018). Submission: Zero Carbon Bill Discussion Document. http://www.mfe.govt.nz/sites/default/files/media/Consultations/FINAL\%20Zero\%20Carbon\%20Bill\%20-\%20Discussion\%20Document.pdf

Baggaley, D. (2019). 2019 Toitū te Ao-Sustainability Week. https://www.wgtn.ac.nz/sustainability/about-us/toitu-te-aosustainability-week2019

Bailis, R., Broekhoff, D., \& Lee, C. M. (2016). Supply and sustainability of carbon offsets and alternative fuels for international aviation. www.jstor.org/stable/resrep02822

Baker, D. (2020, August 31). Eighty years after Hindenburg, startup pitches hydrogen flight. Stuff. https://www.stuff.co.nz/travel/greentravel/300095712/eighty-years-after-hindenburg-startup-pitches-hydrogenflight

Banerjee, S. B., lyer, E. S., \& Kashyap, R. K. (2003). Corporate Environmentalism: Antecedents and Influence of Industry Type. Journal of Marketing, 67(2), 106122. http://www.jstor.org.helicon.vuw.ac.nz/stable/30040526

Bansal, P., Jiang, G. F., \& Jung, J. C. (2015). Managing Responsibly in Tough Economic Times: Strategic and Tactical CSR During the 2008-2009 Global Recession. Long Range Planning, 48(2), 69-79. https://doi.org/https://doi.org/10.1016/j.lrp.2014.07.002

Barnett, M. L., Darnall, N., \& Husted, B. W. (2015). Sustainability Strategy in Constrained Economic Times. Long Range Planning, 48(2), 63-68. https://doi.org/10.1016/j.Irp.2014.07.001 
Baskin, K. (2020). Supply chain resilience in the era of climate change. Spectrum. https://mitsloan.mit.edu/ideas-made-to-matter/supply-chain-resilience-eraclimate-change

Baumgartner, R. J. (2014). Managing Corporate Sustainability and CSR: A Conceptual Framework Combining Values, Strategies and Instruments Contributing to Sustainable Development. Corporate Social Responsibility and Environmental Management, 21(5), 258-271. https://doi.org/10.1002/csr.1336

BBC. (2011, May 10). [Video]. Hardtalk.

BBC. (2020, 17 September 2020). Covid pushes New Zealand into worst recession in years. https://www.bbc.com/news/business-54186359

Beck, A. C., Campbell, D., \& Shrives, P. J. (2010). Content analysis in environmental reporting research: Enrichment and rehearsal of the method in a BritishGerman context. The British Accounting Review, 42(3), 207-222. https://doi.org/https://doi.org/10.1016/j.bar.2010.05.002

Benn, S., Dunphy, D., \& Griffiths, A. (2014). Organizational Change for Corporate Sustainability ( 3 ed.). Routledge.

BIS. (2011). The Guide to PAS 2050: 2011.

Bjørn, A., Kalbar, P., Nygaard, S. E., Kabins, S., Jensen, C. L., Birkved, M., Schmidt, J., \& Hauschild, M. Z. (2018). Pursuing necessary reductions in embedded GHG emissions of developed nations: Will efficiency improvements and changes in consumption get us there? Global Environmental Change, 52, 314-324. https://doi.org/https://doi.org/10.1016/j.gloenvcha.2018.08.001

Blanco, C., Caro, F., \& Corbett, C. J. (2016). The state of supply chain carbon footprinting: analysis of CDP disclosures by US firms. Journal of Cleaner Production, 135, 1189-1197.

https://doi.org/https://doi.org/10.1016/j.jclepro.2016.06.132

BloombergNEF. (2021). Electric Vehicle Outlook 2021. https://about.bnef.com/electric-vehicle-outlook/

Boiral, O., Heras-Saizarbitoria, I., \& Testa, F. (2017). SA8000 as CSR-Washing? The Role of Stakeholder Pressures. Corporate Social Responsibility and Environmental Management, 24(1), 57-70. https://doi.org/10.1002/csr.1391 
Boley, A., Harvey-Green, A., Leadbetter, C., Henry, M., Hooper, G., Simpson, J., McManus, W., \& Walton, J. (2019). The Carbon Report - Counting Carbon Costs: Climate Change and NZX Companies. https://investmentnews.co.nz/wp-content/uploads/The-Carbon-Report-201912-05-Counting-Carbon-Costs-Climate-Change-and-NZX-Companies.pdf

Bonn, I., \& Fishe, J. (2011). Sustainability: the missing ingredient in strategy. Journal of Business Strategy, 32(1), 5-14.

https://doi.org/10.1108/02756661111100274

Breeze, R. (2013). Corporate Discourse. Bloomsbury.

Brulle, R. J. (2018). The climate lobby: a sectoral analysis of lobbying spending on climate change in the USA, 2000 to 2016. Climatic Change, 149(3), 289-303. https://doi.org/10.1007/s10584-018-2241-z

Bui, B., \& Houqe, M. N. (2015). Corporate environment strategy, lobby group participation and political reaction to New Zealand's Emission Trading Bill. Accounting, Accountability \& Performance, 18(2), 5-32.

Bullis, C., \& Ie, F. (2007). Corporate Environmentalism. In S. May, G. Cheney, \& J. Roper (Eds.), The debate over corporate social responsibility (pp. 321-335). Oxford University Press.

Busch, T., Richert, M., Johnson, M., \& Lundie, S. (2020). Climate inaction and managerial sensemaking: The case of renewable energy. Corporate Social Responsibility and Environmental Management, 27(6), 2502-2514. https://doi.org/https://doi.org/10.1002/csr.1972

Business Roundtable. (2019, August 19). Business Roundtable Redefines the Purpose of a Corporation to Promote 'An Economy That Serves All Americans'. Business Roundtable. Retrieved 11 Jul 2021 from https://www.businessroundtable.org/business-roundtable-redefines-thepurpose-of-a-corporation-to-promote-an-economy-that-serves-all-americans

BusinessNZ. (n.d.). Major Companies Group. https://www.businessnz.org.nz/majorcompanies-group

BusinessNZ Major Companies Group. (2020). Guidance on Economic Plan for New Zealand Post Covid-19.

https://www.businessnz.org.nz/_data/assets/pdf_file/0013/202063/Economic GuidancePlanMCG.pdf 
Cadez, S., \& Czerny, A. (2016). Climate change mitigation strategies in carbonintensive firms. Journal of Cleaner Production, 112, 4132-4143. https://doi.org/https://doi.org/10.1016/j.jclepro.2015.07.099

Cadez, S., Czerny, A., \& Letmathe, P. (2019). Stakeholder pressures and corporate climate change mitigation strategies. Business Strategy and the Environment, 28(1), 1-14. https://doi.org/10.1002/bse.2070

Cambridge Dictionary. (n.d.). Value. In Cambridge Dictionary. Retrieved 11 Jul 2021, from https://dictionary.cambridge.org/dictionary/english/value

Cames, M., Harthan, R., Füssler, J., Lazarus, M., Lee, C. M., Erickson, P., \& Spalding-Fecher, R. (2016). How additional is the Clean Development Mechanism?: Analysis of the application of current tools and proposed alternatives. Institute for Applied Ecology. Retrieved 21 Dec 2018 from https://ec.europa.eu

Campbell, J., Herremans, I. M., \& Kleffner, A. (2018). Barriers to achieving additionality in carbon offsets: a regulatory risk perspective. Journal of Environmental Planning and Management, 61(14), 2570-2589. https://doi.org/10.1080/09640568.2017.1406340

Cao, S. (2020, December 17). Toyota Boss Warns That The Electric Vehicle Shift May Cause Big Problems. Observer. https://observer.com/2020/12/toyotaakio-toyoda-electric-vehicle-japan-transition/

Caprar, D., \& Neville, B. (2012). "Norming" and "Conforming": Integrating Cultural and Institutional Explanations for Sustainability Adoption in Business. Journal of Business Ethics, 110(2), 231-245. https://doi.org/10.1007/s10551-0121424-1

Carrington, D. (2020, May 27). World's largest all-electric aircraft set for first flight. The Guardian. https://www.theguardian.com/world/2020/may/27/worldslargest-all-electric-aircraft-set-for-first-flight

Carroll, A. (1979). A Three-Dimensional Conceptual Model of Corporate Social Performance. The Academy of Management Review, 4(4), 497. https://doi.org/10.2307/257850

Carroll, A. (1999). Corporate social responsibility: evolution of a definitional construct. Business and Society and Natural Resources(38), 268-295. https://doi.org/https://doi.org/10.1177/000765039903800303 
Carroll, A. (2015). Corporate social responsibility: The centerpiece of competing and complementary frameworks. Organizational Dynamics, 44(2), 87-96. https://doi.org/https://doi.org/10.1016/j.orgdyn.2015.02.002

Carroll, A. B. (2016). Carroll's pyramid of CSR: taking another look. International Journal of Corporate Social Responsibility, 1, 8. https://doi.org/10.1186/s40991-016-0004-6

Casey, A. (2020, February 20). The journey to turn the red shed green. The Spinoff. https://thespinoff.co.nz/partner/the-warehouse/20-02-2020/the-journey-to-turnthe-red-shed-green/

CDP. (2019). The A List 2019. Retrieved 30 May 2020 from https://www.cdp.net/en/companies/companies-scores

CDP. (2020a). CDP Climate Change 2020 Questionnaire. CDP. Retrieved 25 Sep 2020 from https://www.cdp.net

CDP. (2020b). Spark New Zealand Climate Change 2020. https://www.cdp.net/en

CDP. (2020c). Who we are. Retrieved 30 May 2020 from https://www.cdp.net/en/info/about-us

CDP. (2021). The A List 2020. CDP. https://www.cdp.net/en/companies/companiesscores

Chapman Tripp. (2019). Sustainable Finance Forum: Legal Opinion 2019. https://chapmantripp.com/media/r30jdd05/climate-change-risk-legal-opinion2019.pdf

Chrun, E., Dolšak, N., \& Prakash, A. (2016). Corporate Environmentalism: Motivations and Mechanisms. Annual Review of Environment and Resources, 41(1), 341-362. https://doi.org/10.1146/annurev-environ-110615-090105

CLC. (2019a). 2019 Statement. https://www.climateleaderscoalition.org.nz/about/2019-statement

CLC. (2019b). 2019 Statement: The Warehouse Group. https://www.climateleaderscoalition.org.nz/who/2019-statement/2019statement/the-warehouse-group 
CLC. (n.d.-a). Background on the Climate Leaders Coalition. NZ Sustainable Business Council. Retrieved 30/04/2020 from https://www.climateleaderscoalition.org.nz/news-and-resources/news/climateleaders-coalition-backgrounder

CLC. (n.d.-b). Founding signatories. NZ Sustainable Business Council. Retrieved 30/04/2020 from https://www.climateleaderscoalition.org.nz/who/foundingsignatories

Climate Action 100+. (2020). 2020 Progress Report. C. A. 100+. https://www.climateaction100.org/news/climate-action-100-progress-reportrecords-accelerated-company-commitments-to-net-zero-emissions-but-gapsremain/

Climate Action Tracker. (2020). A Government Roadmap for Addressing the Climate and Post Covid-19 Economic Crises. Climate Analytics and NewClimate Institute https://climateactiontracker.org/documents/706/CAT_2020-0427_Briefing_COVID19_Apr2020.pdf

Climate Change Act, Chapter 27 (2008).

https://www.legislation.gov.uk/ukpga/2008/27/contents

Climate Change Commission. (2020). Letter to Minister regarding COVID response: 7 April 2020 https://ccc-production-media.s3.ap-southeast2.amazonaws.com/public/Letter-to-Minister-Covid-Response-7-April2020.pdf

Climate Change Commission. (2021). Ināia tonu nei: a low emissions future for Aotearoa. https://www.climatecommission.govt.nz/get-involved/our-adviceand-evidence/

Climate Change Response (Zero Carbon) Amendment Act, 404 (2019). https://www.mfe.govt.nz/climate-change/zero-carbon-amendment-act

Climate Change Response (Zero Carbon) Amendment Act No 61, (2019). https://www.legislation.govt.nz/act/public/2019/0061/latest/LMS183736.html

Climate Change Response Act 2002 No 40 (15 March 2021). https://www.legislation.govt.nz/act/public/2002/0040/latest/whole.html\#DLM15 8584 
Colmar Brunton. (2018). Environmental attitudes baseline. MfE.

https://www.mfe.govt.nz/sites/default/files/media/Extra\%20downloads/Other\% 20documents/new-zealanders-environmental-attitudes.pdf

Companies Act 1993 No 105 (30 January 2021), (1993).

https://www.legislation.govt.nz/act/public/1993/0105/latest/versions.aspx

Corbett, J., Webster, J., \& Jenkin, T. A. (2015, November 17). Unmasking Corporate Sustainability at the Project Level: Exploring the Influence of Institutional Logics and Individual Agency. Journal of Business Ethics. https://doi.org/10.1007/s10551-015-2945-1

Cosbey, A., Droege, S., Fischer, C., \& Munnings, C. (2019). Developing Guidance for Implementing Border Carbon Adjustments: Lessons, Cautions, and Research Needs from the Literature. Review of environmental economics and policy, 13(1), 3-22. https://doi.org/10.1093/reep/rey020

cost-benefit analysis. In. (2016). A Dictionary of Business and Management (6 ed.).

Crane, A., \& Matten, D. (2016). Business Ethics: Managing Corporate Citizenship and Sustainability in the Age of Globalization (4 ed.). Oxford University Press.

Creswell, J. W. (2014). Research design : qualitative, quantitative, and mixed method approaches (Fourth edition, international student edition. ed.). SAGE.

Creswell, J. W. (2015). A concise introduction to mixed methods research. SAGE.

Crockford, V. (2020, April 6). Z Energy helps St John keep ambulances on the road during COVID-19 response https://z.co.nz/about-z/news/general-news/zenergy-helps-st-john-keep-ambulances-on-the-road-during-covid-19response/

Cuming, A. (2019). What if homes become uninsurable? CoverNote. https://covernote.co.nz/covernote/feature/what-if-homes-become-uninsurable/

Daalder, M. (2020, February 19). How this seaweed could slash dairy emissions. Stuff. https://www.stuff.co.nz/environment/119628355/how-this-seaweedcould-slash-dairy-emissions

Dahlmann, F., Branicki, L., \& Brammer, S. (2019). Managing Carbon Aspirations: The Influence of Corporate Climate Change Targets on Environmental 
Performance. Journal of Business Ethics, 158(1), 1-24.

https://doi.org/10.1007/s10551-017-3731-z

Dairy Industry Restructuring Amendment Act 2020. (46).

https://legislation.govt.nz/act/public/2020/0046/latest/whole.html?search=ts_a ct\%40bill\%40regulation\%40deemedreg_dairy_resel_25_y\&p=1\#whole

Daly, H. (2007). Ecological Economics and Sustainable Development, Selected Essays of Herman Daly. Edward Elgar Publishing.

Damert, M., Paul, A., \& Baumgartner, R. J. (2017). Exploring the determinants and long-term performance outcomes of corporate carbon strategies. Journal of Cleaner Production, 160, 123-138.

https://doi.org/https://doi.org/10.1016/j.jclepro.2017.03.206

Dang, V. T., Nguyen, N., Bu, X., \& Wang, J. (2019). The Relationship between Corporate Environmental Responsibility and Firm Performance: A Moderated Mediation Model of Strategic Similarity and Organization Slack. Sustainability (Basel, Switzerland), 11(12), 3395. https://doi.org/10.3390/su11123395

Dawkins, C., \& Fraas, J. W. (2011). Coming Clean: The Impact of Environmental Performance and Visibility on Corporate Climate Change Disclosure. Journal of Business Ethics, 100(2), 303-322. http://www.jstor.org/stable/41475843

de los Reyes, G., \& Scholz, M. (2019). The limits of the business case for sustainability: Don't count on 'Creating Shared Value' to extinguish corporate destruction. Journal of Cleaner Production, 221, 785-794. https://doi.org/https://doi.org/10.1016/j.jclepro.2019.02.187

de los Reyes, G., Scholz, M., \& Smith, N. C. (2017). Beyond the "Win-Win": Creating Shared Value Requires Ethical Frameworks. California Management Review, 59(2), 142-167. https://doi.org/10.1177/0008125617695286

Dean, J. W., \& Sharfman, M. P. (1996). Does Decision Process Matter? A Study of Strategic Decision-Making Effectiveness. The Academy of Management Journal, 39(2), 368-396. https://doi.org/10.2307/256784

Deegan, C. (2017). Twenty five years of social and environmental accounting research within Critical Perspectives of Accounting: Hits, misses and ways forward. Critical Perspectives on Accounting, 43, 65-87. https://doi.org/10.1016/j.cpa.2016.06.005 
Delmas, M., Lim, J., \& Nairn-Birch, N. (2016). Corporate Environmental Performance and Lobbying. Academy of Management Discoveries, 2(2), 175-197. https://doi.org/10.5465/amd.2014.0065

Delmas, M. A., \& Montes-Sancho, M. J. (2010). Voluntary agreements to improve environmental quality: symbolic and substantive cooperation. Strategic Management Journal, 31(6), 575-601. https://doi.org/10.1002/smj.826

Deloitte. (2017). Global Dairy Sector - Trends and opportunities. https://www2.deloitte.com/content/dam/Deloitte/ie/Documents/ConsumerBusi ness/ie_Dairy_Industry_Trends_and_Opportunities.pdf

Dobers, P., \& Springett, D. (2010). Corporate social responsibility: discourse, narratives and communication. Corporate Social Responsibility and Environmental Management, 17(2), 63-69. https://doi.org/doi:10.1002/csr.231

Doda, B., Gennaioli, C., Gouldson, A., Grover, D., \& Sullivan, R. (2016). Are Corporate Carbon Management Practices Reducing Corporate Carbon Emissions? Corporate Social Responsibility and Environmental Management, 23(5), 257-270. https://doi.org/10.1002/csr.1369

Donaldson, T., \& Preston, L. E. (1995). The Stakeholder Theory of the Corporation: Concepts, Evidence, and Implications. The Academy of Management Review, 20(1), 65-91. https://doi.org/10.2307/258887

Dowling, J., \& Pfeffer, J. (1975). Organizational Legitimacy: Social Values and Organizational Behavior. Pacific Sociological Review, 18(1), 122. https://doi.org/https://doi.org/10.2307/1388226

Downie, J., \& Stubbs, W. (2012). Corporate Carbon Strategies and Greenhouse Gas Emission Assessments: The Implications of Scope 3 Emission Factor Selection. Business Strategy and the Environment, 21(6), 412-422. https://doi.org/10.1002/bse.1734

Dragomir, V. D. (2012). The disclosure of industrial greenhouse gas emissions: a critical assessment of corporate sustainability reports. Journal of Cleaner Production, 29-30, 222-237. https://doi.org/10.1016/j.jclepro.2012.01.024

Dunn, S. (2019, March 7). The Warehouse Group talks sustainability, accessibility and $\$ 20$ tents. The Register. https://theregister.co.nz/2019/03/07/warehousegroup-talks-sustainability-accessibility-and-20-tents/ 
Dyllick, T., \& Muff, K. (2016). Clarifying the Meaning of Sustainable

Business:Introducing a Typology From Business-as-Usual to True Business Sustainability. Organization \& Environment, 29(2), 156-174. https://doi.org/10.1177/1086026615575176

Eccles, R. G., \& Klimenko, S. (2019). The Investor Revolution. Harvard Business Review. https://hbr.org/2019/05/the-investor-revolution

EEA. (2020a). Annual European Union greenhouse gas inventory 1990-2018 and inventory report 2020. https://www.eea.europa.eu/publications/europeanunion-greenhouse-gas-inventory-2020

EEA. (2020b, December 3). Average CO2 emissions from new cars and new vans increased again in 2019 https://www.eea.europa.eu/highlights/average-co2emissions-from-new-cars-vans-2019

Ekwurzel, B., Boneham, J., Dalton, M. W., Heede, R., Mera, R. J., Allen, M. R., \& Frumhoff, P. C. (2017). The rise in global atmospheric CO2, surface temperature, and sea level from emissions traced to major carbon producers. Climatic Change, 144(4), 579-590. https://doi.org/10.1007/s10584-017-1978-0

Electoral Commission. (2017, October 7). New Zealand 2017 General Election Official Results https://elections.nz/media-and-news/2017/new-zealand-2017general-election-official-results/

Elijido-Ten, E. O. (2017). Does recognition of climate change related risks and opportunities determine sustainability performance? Journal of Cleaner Production, 141, 956-966. https://doi.org/10.1016/j.jclepro.2016.09.136

Elijido-Ten, E. O., \& Clarkson, P. (2017). Going Beyond Climate Change Risk Management: Insights from the World's Largest Most Sustainable Corporations. Journal of Business Ethics, 1-23. https://doi.org/10.1007/s10551-017-3611-6

Elsayih, J., Tang, Q., \& Yi-Chen, L. (2018). Corporate governance and carbon transparency: Australian experience. Accounting Research Journal, 31(3), 405-422. https://doi.org/http://dx.doi.org/10.1108/ARJ-12-2015-0153

Endrikat, J., Guenther, E., \& Hoppe, H. (2014). Making sense of conflicting empirical findings: A meta-analytic review of the relationship between corporate environmental and financial performance. European Management Journal, 32(5), 735-751. https://doi.org/http://dx.doi.org/10.1016/j.emj.2013.12.004 
Environmental Protection Authority. (2020). Changes to the Emissions Trading Scheme. Retrieved 1 July 2021 from https://www.epa.govt.nz/industryareas/emissions-trading-scheme/changes-to-the-ets/

Eweje, G. (2011). A Shift in corporate practice? Facilitating sustainability strategy in companies. Corporate Social Responsibility and Environmental Management, 18(3), 125-136. https://doi.org/https://doi.org/10.1002/csr.268

Fankhauser, S., Averchenkova, A., \& Finnegan, J. (2018). 10 years of the UK Climate Change Act. http://www.Ise.ac.uk/GranthamInstitute/publication/10years-climate-change-act/

Farrer, M. (2021, March 18). Why Japan's carmaking heavyweights could be facing an electric shock. The Guardian.

https://www.theguardian.com/environment/2021/mar/18/why-japanscarmaking-heavyweights-could-be-facing-an-electric-shock

Ferguson, J. (2016). Corporate response to climate change: language, power and symbolic construction. Accounting, Auditing \&amp; Accountability Journal, 29(2), 278-304. https://doi.org/10.1108/AAAJ-09-2013-1465

Fernando, S. P., \& Lawrence, S. P. (2014). A theoretical framework for CSR practices: integrating legitimacy theory, stakeholder theory and institutional theory. The Journal of Theoretical Accounting Research, 10(1), 149-178. https://www-proquest-com.helicon.vuw.ac.nz/docview/1629406998

FMA NZ. (2014). Corporate governance in New Zealand: Principles and guidelines. Retrieved 17 July 2021 from https://www.fma.govt.nz/compliance/guidancelibrary/corporate-governance-in-new-zealand-principles-and-guidelines/

Fonterra. (2017). Dairy for Life Annual Report 2017. https://www.fonterra.com/nz/en/investors/results-and-reporting.html

Fonterra. (2018a). Submission on The Zero Carbon Bill: Fonterra Co-operative Group Limited. http://www.mfe.govt.nz/sites/default/files/media/Consultations

Fonterra. (2018b). Sustainability Report 2018. Fonterra Co-operative Group Limited. https://www.fonterra.com/nz/en/investors/financial-results.html 
Fonterra. (2019a, October 8). Fonterra appoints Chief Operating Officer https://www.fonterra.com/nz/en/our-stories/media/fonterra-appoints-chiefoperating-officer.html

Fonterra. (2019b, April 2). Fonterra to recognise high performing farms as part of new approach to sustainability https://www.fonterra.com/nz/en/ourstories/media/fonterra-to-recognise-high-performing-farms-as-new-approachto-sustainability.html

Fonterra. (2019c). Submission on Process Heat in New Zealand: Opportunities and barriers to lowering emissions. https://www.mbie.govt.nz/dmsdocument/5368fonterra-process-heat-technical-paper-submission

Fonterra. (2019d). Sustainability Report 2019. Fonterra Co-operative Group Limited. https://www.fonterra.com/nz/en/investors/financial-results.html

Fonterra. (2020a). Fonterra reports its Interim Results.

https://www.fonterra.com/nz/en/our-stories/media/fonterra-reports-its-interimresults.html

Fonterra. (2020b, December 14). Fonterra, Nestlé and DairyNZ join forces to tackle nitrogen leaching https://www.fonterra.com/nz/en/our-stories/media/fonterranestle-and-dairynz-join-forces-to-tackle-nitrogen-leaching.html

Fonterra. (2020c). Good Together Annual Report 2020.

https://www.fonterra.com/nz/en/investors/results-and-reporting.html

Fonterra. (2020d, April 15). Partnering to help out where we can - delivering milk and food to those in need https://www.fonterra.com/nz/en/our-

stories/articles/partnering-to-help-out-where-we-can-delivering-milk-and-foodto-those-in-need.html

Fonterra. (2020e). Sustainability Report 2020. Fonterra Co-operative Group Limited. https://www.fonterra.com/content/dam/fonterra-public-website/fonterra-newzealand/documents/pdf/sustainability/fonterra-sustainability-report-2020.pdf

Fonterra. (2021, February 15). Dairy still the most nutritious option https://www.fonterra.com/nz/en/our-stories/articles/dairy-still-the-mostnutritious-option.html

Fonterra. (n.d.). Media releases. https://www.fonterra.com/nz/en/ourstories/media.html 
Forsyth Barr. (2021). Air New Zealand Limited.

https://www.forsythbarr.co.nz/markets-and-research/companies/NZX/AIR

Francis, G. (2019). Economic Feasibility and Sustainability of Jatropha as a Crop. In S. Mulpuri, N. Carels, \& B. Bahadur (Eds.), Jatropha, Challenges for a New Energy Crop: Volume 3: A Sustainable Multipurpose Crop (pp. 495-506). Springer Singapore. https://doi.org/10.1007/978-981-13-3104-6_24

Friedman, M. (1970). The Social Responsibility of Business is to Increase its Profits. New York Times. http://doc.catv.org/economics/milton_friedman/business_social_responsibility

Galbreath, J. (2010). The impact of strategic orientation on corporate social responsibility. International Journal of Organizational Analysis. https://doi.org/https://doi.org/10.1108/19348831011033195

Garcés-Ayerbe, C., Scarpellini, S., Valero-Gil, J., \& Rivera-Torres, P. (2016). Proactive environmental strategy development: from laggard to eco-innovative firms. Journal of Organizational Change Management, 29(7), 1118-1134. https://doi.org/10.1108/JOCM-05-2016-0081

Gartenberg, C., \& Serafeim, G. (2019). 181 Top CEOs Have Realized Companies Need a Purpose Beyond Profit. Harvard Business Review. https://hbr.org/2019/08/181-top-ceos-have-realized-companies-need-apurpose-beyond-profit

Geiselhart, K. (2020). Truth and academia in times of fake news, alternative facts and filter bubbles: A pragmatist notion of critique as mediation. In J. Wills \& R. W. Lake (Eds.), The power of pragmatism (1 ed., pp. 139-156). Manchester University Press. http://www.jstor.org/stable/j.ctv11vc913.12

Gemmell, N. (2020, April 10). Coronavirus: The shape of New Zealand's post-Covid19 economy. Stuff. https://www.stuff.co.nz/business/120912250/coronavirusthe-shape-of-new-zealands-postcovid19-economy

Gibson, E. (2020, May 12). Z Energy puts biofuel plant to sleep, asks for Govt money. Stuff. https://www.stuff.co.nz/environment/climate-news/300010423/zenergy-puts-biofuel-plant-to-sleep-asks-for-govt-money

Gillenwater, M., \& Seres, S. (2011). The Clean Development Mechanism: a review of the first international offset programme. Greenhouse Gas Measurement and Management, 1(3-4), 179-203. https://doi.org/10.1080/20430779.2011.647014 
Gluckman, P., \& Bardsley, A. (2020). THE FUTURE IS NOW: Implications of COVID-19 for New Zealand. https://informedfutures.org/wpcontent/uploads/Koi-T\%C5\%AB-The-Future-is-Now.pdf

Grantham Research Institute. (2021). New Zealand in Litigation Cases. Retrieved 3 April 2021 from https://climatelaws.org/litigation_cases?last_change_from $=1990 \&$ last_change_to $=2021 \& q=$ New\%20Zealand

Gray, J. (2021, July 4). Dairy giant Fonterra looks to offset bovine decline with plantbased milks. NZ Herald,. https://www.nzherald.co.nz/business/dairy-giantfonterra-looks-to-offset-bovine-decline-with-plant-basedmilks/7B6DTXTCMBRGYPPT7WGBEN7YYY/

Gray, R., \& Milne, M. (2002). Sustainability reporting: who's kidding whom? Chartered Accountants Journal of New Zealand, 81(6), 66-70. http://www2.accaglobal.com/pdfs/environment/newsletter/gray_milne.pdf

Greenberg, J., Knight, G., \& Westersund, E. (2011). Spinning climate change: Corporate and NGO public relations strategies in Canada and the United States. International Communication Gazette, 73(1-2), 65-82. https://doi.org/10.1177/1748048510386742

Grunig, J. E., \& Hunt, T. (1984). Managing Public Relations. Harcourt Brace Jovanovich College Publishers.

Gunarathne, N., \& Lee, K.-H. (2019). Institutional pressures and corporate environmental management maturity. Management of Environmental Quality: An International Journal, 30(1), 157-175. https://doi.org/10.1108/MEQ-022018-0041

Haack, P., Schoeneborn, D., \& Wickert, C. (2012). Talking the Talk, Moral Entrapment, Creeping Commitment? Exploring Narrative Dynamics in Corporate Responsibility Standardization. Organization Studies, 33(5-6), 815845. https://doi.org/10.1177/0170840612443630

Haffmans, S., Gelder, M. v., Hinte, E. v., \& Zijlstra, Y. (2018). Products that flow : circular business models and design strategies for fast moving consumer goods. BIS Publishers.

Hahn, T., Preuss, L., Pinkse, J., \& Figge, F. (2014). Cognitive frames in corporate sustainability: managerial sensemaking with paradoxical and business case 
frames.(Report). Academy of Management Review, 39(4), 463.

https://doi.org/10.5465/amr.2012.0341

Hale, T. N., Chan, S., Hsu, A., Clapper, A., Elliott, C., Faria, P., Kuramochi, T., McDaniel, S., Morgado, M., Roelfsema, M., Santaella, M., Singh, N., Tout, I., Weber, C., Weinfurter, A., \& Widerberg, O. (2021). Sub- and non-state climate action: a framework to assess progress, implementation and impact. Climate Policy, 21(3), 406-420. https://doi.org/10.1080/14693062.2020.1828796

Hall, D. (2020, May 15). New Zealand's COVID-19 budget delivers on one crisis, but largely leaves climate change for another day. The Conversation. https://theconversation.com/new-zealands-covid-19-budget-delivers-on-onecrisis-but-largely-leaves-climate-change-for-another-day-138524

Hancock, F. (2021, July 14). NZ has reached 'peak milk', Fonterra CFO warns. NZ Herald,. https://www.nzherald.co.nz/business/nz-has-reached-peak-milkfonterra-cfo-warns/W45I6TXRLZFR6KDABBV57WDWBQ/

Harris, C. (2014, May 8). IAG cleared to buy Lumley. Stuff. https://www.stuff.co.nz/business/industries/10018411/IAG-cleared-to-buyLumley

Harris, C. (2020, February 8). The Warehouse faces carbon challenge. Dominion Post,. https://www.pressreader.com/new-zealand/the-dominionpost/20200208/282226602720495

Harrison, J. S., \& Freeman, R. E. (1999). Stakeholders, Social Responsibility, and Performance: Empirical Evidence and Theoretical Perspectives. The Academy of Management Journal, 42(5), 479-485. https://doi.org/10.2307/256971

Harvey, F. (2021, August 8). World's climate scientists to issue stark warning over global heating threat. The Guardian,. https://www.theguardian.com/environment/2021/aug/08/worlds-climatescientists-to-issue-stark-warning-over-global-heating-threat

He, H., \& Harris, L. (2020). The impact of Covid-19 pandemic on corporate social responsibility and marketing philosophy. Journal of Business Research, 116, 176-182. https://doi.org/https://doi.org/10.1016/j.jbusres.2020.05.030

Hepburn, C., O'Callaghan, B., Stern, N., Stiglitz, J., \& Zenghelis, D. (2020). Will COVID-19 fiscal recovery packages accelerate or retard progress on climate change? Oxford Review of Economic Policy, 36(Supplement_1), S359-S381. https://doi.org/10.1093/oxrep/graa015 
Hickel, J., \& Kallis, G. (2020). Is Green Growth Possible? New Political Economy, 25(4), 469-486. https://doi.org/10.1080/13563467.2019.1598964

Hopkins, D., Campbell-Hunt, C., Carter, L., Higham, J. E. S., \& Rosin, C. (2015). Climate change and Aotearoa New Zealand. Wiley Interdisciplinary Reviews: Climate Change, 6(6), 559-583. https://doi.org/doi:10.1002/wcc.355

Hörisch, J., \& Windolph, S. E. (2014). Overview of the Aggregate Results of the International Corporate Sustainability Barometer. In S. Schaltegger, S. E. Windolph, D. Harms, \& J. Hörisch (Eds.), Corporate Sustainability in International Comparison: State of Practice, Opportunities and Challenges (pp. 21-33). Springer International Publishing. https://doi.org/10.1007/978-3319-06227-3_3

Hrasky, S. (2011). Carbon footprints and legitimation strategies: symbolism or action? Accounting, Auditing \& Accountability Journal, 25(1), 174-198. https://doi.org/https://doi.org/10.1108/09513571211191798

Huang, Y. A., Weber, C. L., \& Matthews, H. S. (2009, 2009/11/15). Categorization of Scope 3 Emissions for Streamlined Enterprise Carbon Footprinting. Environmental science \& technology, 43(22), 8509-8515. https://doi.org/10.1021/es901643a

Hughey, K., Kerr, G., \& Cullen., R. (2019). Public Perceptions of New Zealand's Environment 2019. L. University. https://www.lincoln.ac.nz/Research/Research/rc/leap/researchthemes/nrm/?sti=5

Hutt, K. (2021, March 29). School Strike 4 Climate: Young people to march again in April. Stuff. https://www.stuff.co.nz/environment/climatenews/124684929/school-strike-4-climate-young-people-to-march-again-inapril

Hyatt, D. G., \& Berente, N. (2017). Substantive or Symbolic Environmental Strategies? Effects of External and Internal Normative Stakeholder Pressures. Business Strategy and the Environment, 26(8), 1212-1234. https://doi.org/https://doi.org/10.1002/bse.1979

IAG. (2020a, August 21). IAG completes review of its Repairhub trial https://www.iag.co.nz/latest-news/articles/repairhub.html

IAG. (2020b, July 23). IAG completes review of retail network https://www.iag.co.nz/latest-news/articles/Review-of-retail-network.html

Page | 153 
IAG. (2020c, March 26). IAG introduces support measures for customers impacted by coronavirus https://www.iag.co.nz/latest-news/articles/Covid-19.html

IAG. (n.d.). IAG. https://iag.co.nz/

IATA. (2021). Industry Statistics Fact Sheet: April 2021. https://www.iata.org/en/iatarepository/publications/economic-reports/airline-industry-economicperformance---april-2021---data-tables/

iCOntainers. (2020). New Zealand's Top 5 Major Ports. https://www.icontainers.com/us/2020/01/24/5-major-ports-new-zealand/

ICSA | The Chartered Governance Institute. (2017, September 26). ICSA and The Investment Association launch guidance to help firms improve decision making for the benefit of all https://www.icsa.org.uk/about-us/pressoffice/news-releases/icsa-and-the-investment-association-launch-guidance-tohelp-firms-improve-decision-making-for-the-benefit-of-all

IEA. (2021). Sustainable Recovery Tracker. https://www.iea.org/reports/sustainablerecovery-tracker

Ihlen, Ø. (2009). Business and Climate Change: The Climate Response of the World's 30 Largest Corporations. Environmental Communication, 3(2), 244262. https://doi.org/10.1080/17524030902916632

Ihlen, Ø., \& Roper, J. (2014). Corporate Reports on Sustainability and Sustainable Development: 'We Have Arrived'. Sustainable Development, 22(1), 42-51. https://doi.org/10.1002/sd.524

IIRC. (2019). Driving Alignment in Climate-related Reporting. https://integratedreporting.org/wpcontent/uploads/2019/09/CRD_BAP_Report_2019.pdf

Inland Revenue NZ. (2021). Employer provided motor vehicles for private use. Retrieved 27 August 2021 from https://www.ird.govt.nz/employingstaff/paying-staff/fringe-benefit-tax/types-of-fringe-benefits/employer-providedmotor-vehicles-for-private-use

Insurance Australia Group Limited. (2006, November 15). IAG to be carbon neutral by 2012 https://www.iag.com.au/iag-be-carbon-neutral-2012-0 
Insurance Australia Group Limited. (2017). Carbon neutrality and IAG.

https://www.iag.com.au/sites/default/files/Documents/Safer\%20Communities/

FY17-Carbon-Neutral-Disclosure.pdf

Insurance Australia Group Limited. (2019). Annual Review and Safer Communities Report 2019.

https://www.iag.com.au/sites/default/files/Documents/Results\%20\%26\%20rep orts/2019-annual-review-safer-communities-report.pdf

Insurance Australia Group Limited. (2020). Annual Review and Safer Communities Report 2020.

https://www.iag.com.au/sites/default/files/Documents/Results\%20\%26\%20rep orts/2020-annual-review-safer-communities-report.pdf

IPCC. (2018). Summary for Policymakers. In: Global Warming of $1.5^{\circ} \mathrm{C}$. An IPCC Special Report on the impacts of global warming of $1.5^{\circ} \mathrm{C}$ above pre-industrial levels and related global greenhouse gas emission pathways, in the context of strengthening the global response to the threat of climate change, sustainable development, and efforts to eradicate poverty. World Meteorological Organization. https://www.ipcc.ch/sr15/

IPCC. (2019). 2019 Refinement to the 2006 IPCC Guidelines for National Greenhouse Gas Inventories. https://www.ipcc.ch/report/2019-refinement-tothe-2006-ipcc-guidelines-for-national-greenhouse-gas-inventories/

IPCC. (2021). Sixth Assessment Report (AR6), Climate Change 2021: The Physical Science Basis. https://www.ipcc.ch/assessment-report/ar6/

Ipsos-IAG. (2021). IAG Climate Change Poll 2021. https://www.iag.co.nz/latestnews/articles/climate-poll-2021.html

Jeswani, H. K., Wehrmeyer, W., \& Mulugetta, Y. (2008). How warm is the corporate response to climate change? Evidence from Pakistan and the UK. Business Strategy and the Environment, 17(1), 46-60. https://doi.org/10.1002/bse.569

Kaefer, F. (2016). Origins and Meaning of 'Clean, Green' New Zealand. https://placebrandobserver.com/country-reputation-origins-clean-green-newzealand/

Kasser, T. (2016). Materialistic Values and Goals. Annual Review of Psychology, 67(1), 489-514. https://doi.org/10.1146/annurev-psych-122414-033344 
Keall, C. (2020, March 18). Coronavirus: Spark latest ISP to remove caps on all broadband plans. NZ Herald.

https://www.nzherald.co.nz/business/coronavirus-spark-latest-isp-to-removecaps-on-all-broadband-plans

Khan, M., \& Lockhart, J. (2019). Embedding Corporate Social Responsibility into Business Practice: Lessons Learned from New Zealand. In G. Eweje \& R. Bathurst (Eds.), Clean, Green and Responsible? Soundings from Down Under (1st ed. 2019. ed.). Springer International Publishing. https://doi.org/10.1007/978-3-030-21436-4

KiwiBank. (2020). Responsible Business Banking Policy. https://media.kiwibank.co.nz/media/documents/Responsible_Business_Banki ng_policy_Jul20.pdf

KiwiRail. (2010). Statement of corporate intent 2010-2013. https://web.archive.org/web/20160124053853/http://www.kiwirail.co.nz/upload s/Publications/statement-of-corporate-intent-2010-2013.pdf

KiwiRail. (2018). Submission by KiwiRail on the Zero Carbon Bill. http://www.mfe.govt.nz/sites/default/files/media/Consultations

KiwiRail. (2019, May 8). KiwiRail ready to play part in reducing greenhouse gas https://www.kiwirail.co.nz/media/kiwirail-ready-to-play-part-in-reducinggreenhouse-gas/

KiwiRail. (2020a). Briefing to incoming ministers November 2020. https://www.beehive.govt.nz/sites/default/files/202012/KiwiRail\%20BIM\%202020.pdf

KiwiRail. (2020b). Building on Recovery, Looking Ahead: KiwiRail Integrated Report 2020. https://www.kiwirail.co.nz/media/annual-reports/

KiwiRail. (2020c). World-renowned shipyard chosen to build new Interislander ferries https://www.kiwirail.co.nz/media/world-renowned-shipyard-chosen-to-buildnew-interislander-ferries/

Klein, N. (2014). This changes everything : capitalism vs. the climate / Naomi Klein (First Simon \& Schuster hardcover edition.. ed.). New York : Simon \& Schuster.

Köhler, J., Geels, F. W., Kern, F., Markard, J., Onsongo, E., Wieczorek, A., Alkemade, F., Avelino, F., Bergek, A., Boons, F., Fünfschilling, L., Hess, D., 
Holtz, G., Hyysalo, S., Jenkins, K., Kivimaa, P., Martiskainen, M., McMeekin, A., Mühlemeier, M. S., Nykvist, B., Pel, B., Raven, R., Rohracher, H., Sandén, B., Schot, J., Sovacool, B., Turnheim, B., Welch, D., \& Wells, P. (2019). An agenda for sustainability transitions research: State of the art and future directions. Environmental Innovation and Societal Transitions, 31, 1-32. https://doi.org/10.1016/j.eist.2019.01.004

Kolk, A., \& Levy, D. (2001). Winds of Change:: Corporate Strategy, Climate change and Oil Multinationals. European Management Journal, 19(5), 501-509. https://doi.org/https://doi.org/10.1016/S0263-2373(01)00064-0

Kolk, A., Levy, D., \& Pinkse, J. (2008). Corporate Responses in an Emerging Climate Regime: The Institutionalization and Commensuration of Carbon Disclosure. European Accounting Review, 17(4), 719-745. https://doi.org/10.1080/09638180802489121

Kolk, A., \& Pinkse, J. (2005). Business responses to climate change: identifying emergent strategies. California Management Review, 47(3), 6-20. https://doi.org/https://doi.org/10.2307/41166304

Koteyko, N. (2012). Managing carbon emissions: A discursive presentation of 'market-driven sustainability' in the British media. Language \& Communication, 32(1), 24-35. https://doi.org/https://doi.org/10.1016/j.langcom.2011.11.001

KPMG. (2017). The road ahead: KPMG's Survey of Corporate Responsibility Reporting 2017: New Zealand Supplement October 2017. https://home.kpmg/content/dam/kpmg/nz/pdf/November/KPMG_NZ_Supplem ent_Corporate_Responsibility_Reporting\%202017.pdf

KPMG. (2021). Financial Institutions Performance Survey: Banks Review of 2020 https://assets.kpmg/content/dam/kpmg/nz/pdf/2021/02/fips-banks-2020.pdf

Lacina, L. (2020). COVID-19: What you need to know about the coronavirus pandemic on 29 April. 2020. Retrieved 2 May 2020, from https://www.weforum.org/agenda/2020/04/covid-19-what-you-need-to-knowabout-the-coronavirus-pandemic-on-29-april/

Lamb, W. F., Mattioli, G., Levi, S., Roberts, J. T., Capstick, S., Creutzig, F., Minx, J. C., Müller-Hansen, F., Culhane, T., \& Steinberger, J. K. (2020). Discourses of climate delay. Global Sustainability, 3. https://doi.org/10.1017/sus.2020.13 
Landrum, N. E. (2018). Stages of Corporate Sustainability: Integrating the Strong Sustainability Worldview. Organization \& Environment, 31(4), 287-313. https://doi.org/10.1177/1086026617717456

Lantos, G. P. (2001). The boundaries of strategic corporate social responsibility. Journal of Consumer Marketing, 18(7), 595-632. https://doi.org/10.1108/07363760110410281

Laville, S. (2021, June 2). G7 nations committing billions more to fossil fuel than green energy. The Guardian,. https://www.theguardian.com/world/2021/jun/02/g7-nations-committingbillions-more-to-fossil-fuel-than-green-energy

Lawrence, S., Collins, E., \& Roper, J. (2013). Expanding Responsibilities of Corporate Governance: The Incorporation of CSR and Sustainability. Indian Journal of Corporate Governance, 6(1), 49-63. https://doi.org/10.1177/0974686220130104

Le Quéré, C., Jackson, R. B., Jones, M. W., Smith, A. J. P., Abernethy, S., Andrew, R. M., De-Gol, A. J., Willis, D. R., Shan, Y., Canadell, J. G., Friedlingstein, P., Creutzig, F., \& Peters, G. P. (2020). Temporary reduction in daily global $\mathrm{CO} 2$ emissions during the COVID-19 forced confinement. Nature Climate Change. https://doi.org/10.1038/s41558-020-0797-x

Lee, S.-Y. (2012). Corporate Carbon Strategies in Responding to Climate Change. Business Strategy and the Environment, 21(1), 33-48. https://doi.org/10.1002/bse.711

Lefsrud, L. M., \& Meyer, R. E. (2012). Science or Science Fiction? Professionals' Discursive Construction of Climate Change. Organization Studies, 33(11), 1477-1506. https://doi.org/10.1177/0170840612463317

Leining, C., \& Kerr, S. (2018). A Guide to the New Zealand Emissions Trading Scheme. M. E. a. P. P. Research.

Leining, C., Kerr, S., \& Bruce-Brand, B. (2020, 2020/02/07). The New Zealand Emissions Trading Scheme: critical review and future outlook for three design innovations. Climate Policy, 20(2), 246-264. https://doi.org/10.1080/14693062.2019.1699773

Li, M., Wiedmann, T., \& Hadjikakou, M. (2020, 2020/01/07). Enabling Full Supply Chain Corporate Responsibility: Scope 3 Emissions Targets for Ambitious Climate Change Mitigation. Environmental science \& technology, 54(1), 400411. https://doi.org/10.1021/acs.est.9b05245

Page | 158 
Liao, L., Luo, L., \& Tang, Q. (2015). Gender diversity, board independence, environmental committee and greenhouse gas disclosure. The British Accounting Review, 47(4), 409-424.

https://doi.org/https://doi.org/10.1016/j.bar.2014.01.002

Liu, Y., Yang, D., \& Xu, H. (2017). Factors Influencing Consumer Willingness to Pay for Low-Carbon Products: A Simulation Study in China. Business Strategy and the Environment, 26(7), 972-984. https://doi.org/10.1002/bse.1959

Liu, Y. S., \& Yang, J. H. (2018). A longitudinal analysis of corporate greenhouse gas disclosure strategy. Corporate Governance: The international journal of business in society, 18(2), 317-330. https://doi.org/10.1108/CG-11-2016-0213

Loorbach, D., \& Wijsman, K. (2013). Business transition management: exploring a new role for business in sustainability transitions. Journal of Cleaner Production, 45, 20-28.

https://doi.org/https://doi.org/10.1016/j.jclepro.2012.11.002

Lourenço, I., Branco, M., Curto, J., \& Eugénio, T. (2012). How Does the Market Value Corporate Sustainability Performance? Journal of Business Ethics, 108(4), 417-428. https://doi.org/10.1007/s10551-011-1102-8

Lovell, H., Bulkeley, H., \& Liverman, D. (2009). Carbon Offsetting: Sustaining Consumption? Environment and Planning A: Economy and Space, 41(10), 2357-2379. https://doi.org/10.1068/a40345

Lu, W., Chau, K. W., Wang, H., \& Pan, W. (2014). A decade's debate on the nexus between corporate social and corporate financial performance: a critical review of empirical studies 2002-2011. Journal of Cleaner Production, 79, 195-206. https://doi.org/http://dx.doi.org/10.1016/j.jclepro.2014.04.072

Mason, C. F., \& Plantinga, A. J. (2013, 2013/07/01/). The additionality problem with offsets: Optimal contracts for carbon sequestration in forests. Journal of Environmental Economics and Management, 66(1), 1-14. https://doi.org/https://doi.org/10.1016/j.jeem.2013.02.003

Mazareanu, E. (2020, March 10). Global air traffic - annual growth of passenger demand 2006-2020. Statista.

http://web.archive.org/web/20200401130951/https://www.statista.com/statistic s/193533/growth-of-global-air-traffic-passenger-demand/

Mazzetto, A., Falconer, S., \& Ledgard, S. (2020). Mapping the carbon footprint of milk for dairy cows (RE450/2020/081).

Page | 159 
https://www.dairynz.co.nz/environment/climate-change/dairy-sector-action/nzdairy-sectors-carbon-footprint/

MBIE. (2015). Chronology of New Zealand electricity reform. https://www.mbie.govt.nz/assets/2ba6419674/chronology-of-nz-electricityreform.pdf

MBIE. (2018). Energy in NZ 2018. https://www.mbie.govt.nz/assets/d7c93162b8/energy-in-nz-18.pdf

MBIE. (2019). A Vision for Hydrogen in New Zealand. https://www.nzhydrogen.org/

MBIE. (2020). Energy in NZ 2020. https://www.mbie.govt.nz/dmsdocument/11679energy-in-new-zealand-2020

MBIE. (2021). Increasing the use of sustainable biofuels in Aotearoa New Zealand. Ministry of Business, Innovation and Employment. Retrieved 19 Jul 2021 from https://www.mbie.govt.nz/have-your-say/increasing-the-use-of-sustainablebiofuels-in-aotearoa-new-zealand

McNally, B. (2014). The CEO role in New Zealand: perceptions and interpretative schema tensions and paradoxes Victoria University of Wellington]. Wellington, New Zealand.

MfE. (2016). The New Zealand Emissions Trading Scheme Evaluation 2016. https://www.mfe.govt.nz/sites/default/files/media/Climate\%20Change/etsevaluation-report.pdf

MfE. (2018a, July 12). Ministry for the Environment welcomes Climate Leaders Coalition http://web.archive.org/web/20191111213615/http://www.mfe.govt.nz/newsevents/ministry-environment-welcomes-climate-leaders-coalition

MfE. (2018b). New Zealand's Greenhouse Gas Inventory: 1990-2016: Fulfilling reporting requirements under the United Nations Framework Convention on Climate Change and the Kyoto Protocol http://www.mfe.govt.nz/climatechange/state-of-our-atmosphere-and-climate/new-zealands-greenhouse-gasinventory

MfE. (2018c). Zero Carbon Bill consultation: Summary of submissions. https://environment.govt.nz/publications/zero-carbon-bill-consultationsummary-of-submissions/ 
MfE. (2019a). Action on climate change: What organisations are doing. Minstry for the Environment.

http://web.archive.org/web/20210204150216/https://www.mfe.govt.nz/climatechange/we-all-have-role-play/initiatives-business-community

MfE. (2019b). Climate Change Response (Zero Carbon) Amendment Bill: Summary. https://environment.govt.nz/publications/climate-change-response-zerocarbon-amendment-bill-summary/

MfE. (2019c). Improvements to the New Zealand Emissions Trading Scheme: Summary of Consultation Responses.

https://www.mfe.govt.nz/publications/climate-change/improvements-newzealand-emissions-trading-scheme-summary-of

MfE. (2019d). Measuring Emissions: A Guide for Organisations. 2019 Quick Guide. Minstry for the Environment. https://environment.govt.nz/publications

MfE. (2019e). Measuring Emissions: A Guide for Organisations. 2019 Summary of emission factors. Minstry for the Environment. https://environment.govt.nz/publications

MfE. (2019f). New Zealand's Greenhouse Gas Inventory: 1990-2017: Fulfilling reporting requirements under the United Nations Framework Convention on Climate Change and the Kyoto Protocol http://www.mfe.govt.nz/publications/climate-change/new-zealandsgreenhouse-gas-inventory-1990-2017

MfE. (2020). New Zealand's Greenhouse Gas Inventory 1990-2018. Snapshot April 2020. https://www.mfe.govt.nz/publications/climate-change/newzealand\%E2\%80\%99s-greenhouse-gas-inventory-1990-2018-snapshot

MfE. (2021a). About the New Zealand Emissions Trading Scheme. Ministry for the Environment. https://www.mfe.govt.nz/climate-change/new-zealandemissions-trading-scheme/about-nz-ets

MfE. (2021b). He Waka Eke Noa - Primary Sector Climate Action Partnership. Retrieved 23 September 2021 from https://environment.govt.nz/whatgovernment-is-doing/areas-of-work/climate-change/he-waka-eke-noa-primarysector-climate-action-partnership/

MfE. (2021C). New Zealand's Greenhouse Gas Inventory Snapshot 1990-2019. https://environment.govt.nz/publications/new-zealands-greenhouse-gasinventory-1990-2019-snapshot/ 
MfE \& Stats NZ. (2017). New Zealand's Environmental Reporting Series: Our atmosphere and climate 2017.

http://www.mfe.govt.nz/publications/environmental-reporting/our-atmosphereand-climate-2017

Milne, M. J., \& Gray, R. (2013). W(h)ither Ecology? The Triple Bottom Line, the Global Reporting Initiative, and Corporate Sustainability Reporting. Journal of Business Ethics, 118(1), 13-29. https://doi.org/10.1007/s10551-012-1543-8

Ministry of Health. (2020). Guidance for implementing the COVID-19 Public Health Response (COVID-19 Testing) Order 2020 - Ports of Auckland and Tauranga. https://www.poal.co.nz/communityenvironment/Documents/Guidance\%20for\%20implementing\%20the\%20COVI D-19\%20testing\%20order\%20Port\%20Akld\%20\%20and\%20Tauranga.pdf

Ministry of Transport. (2021). Ngā Waka Mā | Clean Cars, . Retrieved 22 Jul 2021 from https://www.transport.govt.nz/area-of-interest/environment-and-climatechange/clean-cars/

Minstry of Transport. (2020). Government support for the transport sector. https://www.transport.govt.nz/area-of-interest/air-transport/governmentsupport-for-the-transport-sector/

Mishler, E. G. (1986). Research Interviewing : Context and Narrative. Harvard University Press.

http://ebookcentral.proquest.com/lib/vuw/detail.action?doclD=3300745 (1986)

Mishler, E. G. (1991). Research interviewing context and narrative / Elliot G. Mishler (Ist Harvard University Press paperback ed.. ed.). Cambridge, MA : Harvard University Press.

https://doi.org/http://ebookcentral.proquest.com/lib/vuw/detail.action?doclD=3 300745

Mitchell, C. (2019, April 6). 'The world's least unsustainable airline': Air New Zealand's climate dilemma. Stuff. https://www.stuff.co.nz/business/107455477/the-worlds-least-unsustainableairline-air-new-zealands-climate-dilemma

Mitchell, C. (2020, February 21). Confused? Why not understanding the Emissions Trading Scheme is the point. Stuff. https://www.stuff.co.nz/environment/climate-news/119665441/if-youreconfused-you-understand-why-not-understanding-the-emissions-tradingscheme-is-the-point 
Mitchell, J. R., Shepherd, D. A., \& Sharfman, M. P. (2011). Erratic strategic decisions: When and why managers are inconsistent in strategic decision making. Strategic Management Journal, 32(7), 683-704.

http://www.jstor.org/stable/27975931

Mitchell, P. (2021, January 31). Protecting Aotearoa's food supply in wake of Covid19. https://www.stuff.co.nz/national/300217606/protecting-aotearoas-foodsupply-in-wake-of-covid19

Moon, B. K. (2020, April 16). I Was the Secretary-General of the U.N. Here's How the Coronavirus Crisis Can Bring the World Together. Time.

https://time.com/collection/finding-hope-coronavirus-pandemic/5820650/banki-moon-global-relations-coronavirus/

Morris, M. C. (2011). The Use of Animals in New Zealand: Regulation and Practice. Society \& Animals, 19(4), 368-382.

https://doi.org/https://doi.org/10.1163/156853011X590024

Motor Industry Association. (2020a). EV Stats 2019.

https://www.mia.org.nz/Portals/0/MIA-

Sales\%20Data/Vehicle\%20Sales/EV/EV\%20Stats\%202019.pdf

Motor Industry Association. (2020b). Vehicle Sales. Retrieved 6 Sep 2020 from https://www.mia.org.nz/Sales-Data/Vehicle-Sales

Neilson, M. (2021, June 10). Climate change: New Zealand burns most coal for electricity in nearly a decade. NZ Herald.

https://www.nzherald.co.nz/nz/climate-change-new-zealand-burns-most-coalfor-electricity-in-nearly-a-decade/MH6J3LMMFMMHRY2TH44G2PJSRU/

New Zealand Government. (2016). Managing New Zealand's International and Domestic Aviation Emissions: New Zealand's response to the International Civil Aviation Organisation 2010 Assembly Resolution A37-19 and 2013 Assembly Resolution A38-18. N. Z. Government. https://www.transport.govt.nz/assets/Uploads/Air/Documents/AviationEmissions-Reduction-Plan.pdf

New Zealand Parliament. (n.d.). Members of Parliament. https://www.parliament.nz/en/mps-and-electorates/members-of-parliament/

Newsroom. (2018). Z ousts Mobil in supermarket petrol deal. https://www.newsroom.co.nz/z-ousts-mobil-in-supermarket-petrol-deal 
NIWA. (2020, September 3). Winter 2020 - NZ's warmest winter on record https://niwa.co.nz/news/winter-2020-\%E2\%80\%93-nzs-warmest-winter-onrecord

NZ Climate Change Commission. (2021). Ināia tonu nei: the time is now for climate action. https://www.climatecommission.govt.nz/news/inaia-tonu-nei-the-timeis-now-for-climate-action/

NZ Government. (2007, February 14). Government requires Biofuels sales https://www.beehive.govt.nz/release/government-requires-biofuels-sales-0

NZ Government. (2016). Managing New Zealand's International and Domestic Aviation Emissions.

https://www.transport.govt.nz/assets/Uploads/Air/Documents/AviationEmissions-Reduction-Plan.pdf

NZ Government. (2018a, October 18). PM's Business Advisory Council membership announced https://www.beehive.govt.nz/release/pm\%E2\%80\%99s-businessadvisory-council-membership-announced

NZ Government. (2018b). The Prime Minister's Business Advisory Council: Terms of Reference. https://www.beehive.govt.nz/sites/default/files/2018-

10/1810\%20Terms\%20of\%20Reference\%20PM\%27s\%20Business\%20Advis ory\%20Council.pdf

NZ Government. (2019). Transitioning to a low-emissions future - the Government response to the Productivity Commission's Low Emissions Economy report. https://www.productivity.govt.nz/assets/Documents/c3bc644f30/Governmentresponse_Transitioning-to-a-low-emissions-future-v2.pdf

NZ Government. (2020a). Alert Level 4. Retrieved 27 Apr 2020 from https://web.archive.org/web/20200427222701/https://covid19.govt.nz/alertsystem/alert-level-4/

NZ Government. (2020b, March 30). Government supports Air NZ freight flights https://www.beehive.govt.nz/release/government-supports-air-nz-freightflights

NZ Government. (2020c). Summary of Initiatives in the COVID-19 Response and Recovery Fund (CRRF) Foundational Package. https://www.treasury.govt.nz/publications/summary-intiatives/summaryinitiatives-crrf-budget2020 
NZ Government. (2021, April 13). NZ becomes first in world for climate reporting https://www.beehive.govt.nz/release/nz-becomes-first-world-climate-reporting

NZ Herald. (2017, April 7). The slow journey to greener air travel. NZ Herald,. https://www.nzherald.co.nz/business/the-slow-journey-to-greener-airtravel/LZVWCE45FYP4EQNASLEMJ5TFLI/

NZ Herald. (2018, November 9). Air New Zealand working with ATR to develop hybrid electric planes. NZ Herald,. https://www.nzherald.co.nz/business/airnew-zealand-working-with-atr-to-develop-hybrid-electricplanes/7MUNZDWRXEUV65HG3WZA5VLLME/

NZ Herald. (2020a, April 22). The Conversation: Here's what the Covid-19 coronavirus pandemic can teach us about tackling climate change. https://www.nzherald.co.nz/world/news/article.cfm?c_id=2\&objectid=1232034 6

NZ Herald. (2020b, March 26). Covid 19 coronavirus: Vector halts planned outages. NZ Herald. https://www.nzherald.co.nz/nz/covid-19-coronavirus-vector-haltsplanned-outages/EF43NWXHCMSD3HYOMHRULR23XA/

NZ Ministry of Health. (2021). History of the COVID-19 Alert System. New Zealand Government. Retrieved 15 July 2021 from https://covid19.govt.nz/alert-levelsand-updates/history-of-the-covid-19-alert-system/

NZ Post. (2010). Annual Report 2010: From yesterday to tomorrow https://www.nzpost.co.nz/about-us/investor-centre/reports-presentations

NZ Post. (2013). Annual Review 2013. https://www.nzpost.co.nz/about-us/investorcentre/reports-presentations

NZ Post. (2014). Annual Review 2014. https://www.nzpost.co.nz/about-us/investorcentre/reports-presentations

NZ Post. (2015). Annual Review 2015. https://www.nzpost.co.nz/about-us/investorcentre/reports-presentations

NZ Post. (2016). NZ Post Integrated Report 2016. https://www.nzpost.co.nz/aboutus/investor-centre/reports-presentations 
NZ Post. (2017). NZ Post Tukurau Aotearoa Integrated Report 2017. https://www.nzpost.co.nz/about-us/investor-centre/reports-presentations

NZ Post. (2018). History of NZ Post. https://www.nzpost.co.nz/about-us/who-weare/history-of-new-zealand-post

NZ Post. (2019). Delivered. Integrated Report 2019. https://www.nzpost.co.nz/aboutus/investor-centre/reports-presentations

NZ Post. (n.d.). YouShop. https://www.nzpost.co.nz/tools/youshop

NZTA. (2021). Clean Car Discount. New Zealand Transport Agency. https://www.nzta.govt.nz/vehicles/clean-car-programme/clean-car-discount/

O'Carroll, D. (2021, September 21). When will an EV cost the same as a petrol car? Stuff. https://www.stuff.co.nz/motoring/evs/126218598/when-will-an-ev-costthe-same-as-a-petrol-car

OECD. (2015). G20/OECD Principles of Corporate Governance. https://doi.org/http://dx.doi.org/10.1787/9789264236882-en

Okereke, C. (2007, 2007/12/01/). An Exploration of Motivations, Drivers and Barriers to Carbon Management:: The UK FTSE 100. European Management Journal, 25(6), 475-486. https://doi.org/https://doi.org/10.1016/j.emj.2007.08.002

Okereke, C., \& Russel, D. (2010). Regulatory pressure and competitive dynamics: Carbon management strategies of UK energy-intensive companies. California Management Review, 52(4), 100-124.

OPMSAC. (2013). The role of evidence in policy formation and implementation: $A$ report from the Prime Minister's Chief Science Advisor. O. o. t. P. M. s. S. A. Committee. https://www.pmcsa.org.nz

Ormazabal, M., Rich, E., Sarriegi, J. M., \& Viles, E. (2017). Environmental Management Evolution Framework: Maturity Stages and Causal Loops. Organization \& Environment, 30(1), 27-50. https://doi.org/10.1177/1086026615623060

Ormazabal, M., \& Sarriegi, J. M. (2012). Environmental management: Understanding its evolution through maturity states. Environmental Quality Management, 22(1), 31-42. https://doi.org/10.1002/tqem.21315 
Ortiz-de-Mandojana, N., Aguilera-Caracuel, J., \& Morales-Raya, M. (2016).

Corporate Governance and Environmental Sustainability: The Moderating Role of the National Institutional Context. Corporate Social Responsibility and Environmental Management, 23(3), 150-164. https://doi.org/10.1002/csr.1367

Ortiz-De-Mandojana, N., Aguilera-Caracuel, J., \& Morales-Raya, M. (2016).

Corporate Governance and Environmental Sustainability: The Moderating Role of the National Institutional Context. Corporate Social Responsibility and Environmental Management, 23(3), 150-164. https://doi.org/10.1002/csr.1367

Ostrom, E. (2000). Collective action and the evolution of social norms. Journal of Economic Perspectives, 14(3), 137-158.

https://www.aeaweb.org/articles?id=10.1257/jep.14.3.137

PAK'nSAVE. (n.d.). About PAK'nSAVE. PAK'nSAVE. Retrieved 28 Jul 2021 from https://www.paknsave.co.nz/about-us

Parker, T. (2018, February 26). Union warns of risks in moving IAG jobs overseas. $N Z$ Herald. https://www.nzherald.co.nz/business/union-warns-of-risks-inmoving-iag-jobs-overseas/VEYHLHHB6Y3NUK7WL43EQR5JMY/

Patchell, J. (2018). Can the implications of the GHG Protocol's scope 3 standard be realized? Journal of Cleaner Production, 185, 941-958.

https://doi.org/10.1016/j.jclepro.2018.03.003

Patel, R., \& Moore, J. (2018). A History of the world in seven cheap things: A guide to nature, capitalism, and the future of the planet (2nd ed.). Black Inc.

Patton, M. Q. (1999). Enhancing the quality and credibility of qualitative analysis. Health Services Research, 34(5 Pt 2), 1189-1208. http://www.ncbi.nlm.nih.gov/pmc/articles/PMC1089059/

Patton, M. Q. (2014). Qualitative research \& evaluation methods: Integrating theory and practice. Sage publications.

Paul, A., Lang, J. W. B., \& Baumgartner, R. J. (2017). A multilevel approach for assessing business strategies on climate change. Journal of Cleaner Production, 160, 50-70.

https://doi.org/https://doi.org/10.1016/j.jclepro.2017.04.030 
Peel, J., \& Osofsky, H. M. (2018). A Rights Turn in Climate Change Litigation? Transnational Environmental Law, 7(1), 37-67. https://doi.org/10.1017/S2047102517000292

Penz, E., \& Polsa, P. (2018). How do companies reduce their carbon footprint and how do they communicate these measures to stakeholders? [Article]. Journal of Cleaner Production, 195, 1125-1138.

https://doi.org/10.1016/j.jclepro.2018.05.263

Peters, G. F., \& Romi, A. M. (2014, 2014/12/01). Does the Voluntary Adoption of Corporate Governance Mechanisms Improve Environmental Risk Disclosures? Evidence from Greenhouse Gas Emission Accounting. Journal of Business Ethics, 125(4), 637-666. https://doi.org/10.1007/s10551-0131886-9

Pham, H. P. (2021). Rationales for corporate climate change target setting and reporting : an investigation University of Canterbury]. New Zealand. https://ir.canterbury.ac.nz/handle/10092/102096

PoAL. (2010). 2010 Ports of Auckland Annual Review: Working for New Zealand. http://www.poal.co.nz/media/reviews

PoAL. (2013). Ports of Auckland Annual Review 2012/13. http://www.poal.co.nz/media/reviews

PoAL. (2016). Working hard for Auckland: Annual Review 2016. http://www.poal.co.nz/media/reviews

PoAL. (2017, August 4). Ports of Auckland welcomes rail investment https://www.poal.co.nz/media/ports-of-auckland-welcomes-rail-investment

PoAL. (2018). Annual Report 2018. http://www.poal.co.nz/media/reviews

PoAL. (2019a). Investing in the future: 2019 Annual Report. http://www.poal.co.nz/media/reviews

PoAL. (2019b, May 3). Waikato to the world: Ports of Auckland opens new Waikato Freight Hub https://www.poal.co.nz/waikato-to-the-world-ports-of-aucklandopens-new-waikato-freight-hub

PoAL. (2020a). Rebuilding our economy: 2020 Annual Report. http://www.poal.co.nz/media/reviews 
PoAL. (2020b). Statement of Corporate Intent. PoAL. https://www.poal.co.nz/aboutus/Documents/Draft\%20SCl\%202019-2022.pdf

PoAL. (2020c). We have a plan. PoAL.

https://poal.maps.arcgis.com/apps/Cascade/index.html?appid=de22907ddb78 4d26bf60639763828d2d

PoAL. (2021). Tāmaki Herenga Waka | Ports of Auckland (POAL). Ports of Auckland Limited. Retrieved 7 Jul 2021 from https://www.aucklandcouncil.govt.nz/about-auckland-council/how-aucklandcouncil-works/council-controlled-organisations/Pages/ports-of-auckland.aspx

PoAL. (n.d.). Our History. PoAL. Retrieved 3 July 2021 from https://www.poal.co.nz/our-story/history

Port Companies Act 1988.

https://legislation.govt.nz/act/public/1988/0091/13.0/whole.html

Porter, M., \& Kramer, M. (2006). Strategy \& Society: The Link Between Competitive Advantage and Corporate Social Responsibility. Harvard Business Review, 84(12), 78-85,88+. https://hbr.org/2006/12/strategy-and-society-the-linkbetween-competitive-advantage-and-corporate-social-responsibility

Porter, M. E., \& Kramer, M. R. (2011). Creating shared value (CSV). Journal of Direct, Data and Digital Marketing Practice, 12(4), 380. https://link.springer.com/journal/41263/volumes-and-issues

Prideaux, B., Thompson, M., \& Pabel, A. (2020, 2020/05/26). Lessons from COVID19 can prepare global tourism for the economic transformation needed to combat climate change. Tourism Geographies, 22(3), 667-678. https://doi.org/10.1080/14616688.2020.1762117

PwC. (2018). Business Investment Decision Making: Large process heat users and energy efficiency in New Zealand. Energy Efficiency and Conservation Authority/PwC (PricewaterhouseCoopers NZ). https://www.eeca.govt.nz/assets/EECA-Resources/Research-papersguides/Large-process-heat-users-and-energy-efficiency-in-New-Zealand.pdf

Qian, W., \& Schaltegger, S. (2017). Revisiting carbon disclosure and performance: Legitimacy and management views. British Accounting Review, 49(4), 365379. https://doi.org/10.1016/j.bar.2017.05.005 
Qin, R., \& Nembhard, D. A. (2015, 2015/12/01/). Workforce agility in operations management. Surveys in Operations Research and Management Science, 20(2), 55-69. https://doi.org/https://doi.org/10.1016/j.sorms.2015.11.001

Rahman, S. (2011). Evaluation of definitions: ten dimensions of corporate social responsibility. World Review of Business Research, 1(1), 166-176.

Rees, W. E. (1992). Ecological footprints and appropriated carrying capacity: what urban economics leaves out. Environment and Urbanization, 4(2), 121-130. https://doi.org/10.1177/095624789200400212

Reinert, K. A. (2018). Basic goods. In No small hope : towards the universal provision of basic goods (pp. 29-54). Oxford University Press.

Richter, J. L., \& Chambers, L. (2014). Reflections and outlook for the New Zealand ETS: must uncertain times mean uncertain measures? Policy Quarterly, 10(2). https://doi.org/10.26686/pq.v10i2.4485

Rickards, L., Wiseman, J., \& Kashima, Y. (2014). Barriers to effective climate change mitigation: the case of senior government and business decision makers. 5 , 753-773. https://doi.org/10.1002/wcc.305

Ritchie, H., \& Roser, M. (2020). $\mathrm{CO}_{2}$ and Greenhouse Gas Emissions.

OurWorldlnData.org. https://ourworldindata.org/co2-and-other-greenhousegas-emissions

RNZ. (2020, September 28). Sounds Air aims to offer first regional zero-emission flights. https://www.rnz.co.nz/news/business/427098/sounds-air-aims-to-offerfirst-regional-zero-emission-flights

Rosenbloom, D., \& Markard, J. (2020). A COVID-19 recovery for climate. Science, 368(6490), 447. https://doi.org/10.1126/science.abc4887

Roulet, T., \& Touboul, S. (2015). The Intentions with Which the Road is Paved: Attitudes to Liberalism as Determinants of Greenwashing. Journal of Business Ethics, 128(2), 305-320. https://doi.org/10.1007/s10551-014-2097-8

Roy, E. A. (2019, April 18). 'Decades of denial': major report finds New Zealand's environment is in serious trouble. The Guardian. https://www.theguardian.com/world/2019/apr/18/decades-of-denial-majorreport-finds-new-zealands-environment-is-in-serious-trouble 
Ruggie, J. G. (2013). Just business: Multinational corporations and human rights (Norton global ethics series). WW Norton \& Company.

Russ-Eft, D. F., Sleezer, C., Sampson Gruener, G., \& Leviton, L. C. (2017). Consider the Worldviews. In Managing Applied Social Research (1 ed., pp. 149-156). John Wiley \& Sons, Inc. https://doi.org/10.1002/9781119408581.ch11

Sadler, R. (2020, May 21). Backlogged NZ Post parcels will start to be sent this week after COVID-19 lockdown delays. Newshub. https://www.newshub.co.nz/home/new-zealand/2020/05/backlogged-nz-postparcels-will-start-to-be-sent-this-week-after-covid-19-lockdown-delays.html

Safire, W. (2008). Footprint. The New York Times Magazine. https://www.nytimes.com/2008/02/17/magazine/17wwln-safire-t.html

SBNNZ. (2021). 20/21 Impact Report. SBNNZ. http:|Iwww.sustainable.org.nz

Schaltegger, S., Harms, D., Hörisch, J., \& Windolph, S. E. (2014). General Patterns and Conclusions. In A. Tukker, S. Schaltegger, S. E. Windolph, D. Harms, \& J. Hörisch (Eds.), Corporate Sustainability in International Comparison: State of Practice, Opportunities and Challenges (2014 ed., Vol. 31, pp. 241-252). Springer International Publishing. https://doi.org/10.1007/978-3-319-06227-3

Schmidt, V. A. (2010). Taking ideas and discourse seriously: explaining change through discursive institutionalism as the fourth 'new institutionalism'. European Political Science Review, 2(1), 1-25. https://doi.org/10.1017/S175577390999021X

Schreck, P., \& Raithel, S. (2018). Corporate Social Performance, Firm Size, and Organizational Visibility: Distinct and Joint Effects on Voluntary Sustainability Reporting [Article]. Business and Society, 57(4), 742-778. https://doi.org/10.1177/0007650315613120

Science-Based Targets initiative. (2020). Science-Based Target Setting Manual Version 4.1 (April 2020).

Scoop. (2016, November 18). Air New Zealand wins New Zealand's top sustainability award. Scoop.

https://www.scoop.co.nz/stories/BU1611/S00756/air-new-zealand-wins-newzealands-top-sustainability-award.htm

Selznick, P. (1996). Institutionalism "Old" and "New". Administrative Science Quarterly, 41(2), 270-277. https://doi.org/10.2307/2393719 
Setzer, J., \& Byrnes, R. (2020). Global trends in climate change litigation: 2020 snapshot. T. L. S. o. E. a. P. Science.

https://www.lse.ac.uk/granthaminstitute/publication/global-trends-in-climatechange-litigation-2020-snapshot/

Setzer, J., \& Vanhala, L. C. (2019). Climate change litigation: A review of research on courts and litigants in climate governance. Wiley interdisciplinary reviews. Climate change, 10(3), e580-n/a. https://doi.org/10.1002/wcc.580

Shah, O. (2020, August 9). BP boss Bernard Looney: My work is socially challenging. The Sunday Times. https://www.thetimes.co.uk/article/bp-bossbernard-looney-my-work-is-socially-challenging-zvqb9h302

Shaw, A. (2019, June 24). New Zealand e-commerce figures hit new highs: Kiwis spent $\$ 4.2$ billion online last year. https://www.nzherald.co.nz/business/newzealand-e-commerce-figures-hit-new-highs-kiwis-spent-42-billion-online-lastyear/

Shaw, J. (2020a, April 23). The Covid-19 crisis creates a chance to reset economies on a sustainable footing. The Guardian.

https://www.theguardian.com/world/commentisfree/2020/apr/23/covid-19crisis-reset-economies-sustainable-footing

Shaw, J. (2020b). Emission trading reforms another step to meeting climate targets https://www.beehive.govt.nz/release/emission-trading-reforms-another-stepmeeting-climate-targets

Shaw, J. (2020c). New Zealand first in the world to require climate risk reporting. https://www.beehive.govt.nz/release/new-zealand-first-world-require-climaterisk-reporting

Silver, J., Brown, P., Brunel, N., Cortés-Acosta, S., Frazer, S., Macey, A., Salmon, G., Young, P., Leining, C., \& Kerr, S. (2017). An effective NZ ETS: clear price signals to guide low-emission investment. Motu. https://www.motu.nz/ourresearch/environment-and-resources/emission-mitigation/emissionstrading/an-effective-nz-ets-clear-price-signals-to-guide-low-emissioninvestment/

Skjott Linneberg, M., \& Korsgaard, S. (2019). Coding qualitative data: a synthesis guiding the novice. Qualitative research journal, 19(3), 259-270. https://doi.org/10.1108/qri-12-2018-0012 
Sklair, L. (2017). Facing the Anthropocene: Fossil capitalism and the crisis of the earth system. Br. J. Sociol., 68, 775-784. https://doi.org/10.1111/14684446.12304

Spark. (2020a). Annual Report 2020: Connections matter now more than ever. http://investors.sparknz.co.nz/Investor-Centre/?page=Annual-Reports

Spark. (2020b, July 21). Spark starts roll out of new faster, 'self healing' network technology.

https://www.sparknz.co.nz/news/Spark_rolls_out_new_faster_self_healing_ne twork_technology/

Spark. (2021). Our History. Retrieved 17 Jul 2021 from https://www.sparknz.co.nz/about/about-spark/history/

Sprengel, D. C., \& Busch, T. (2011). Stakeholder engagement and environmental strategy - the case of climate change. Business Strategy and the Environment, 20(6), 351-364. https://doi.org/10.1002/bse.684

Steeman, M. (2011, December 16). Insurance giant buys AMI. Stuff. http://www.stuff.co.nz/business/6151120/Insurance-giant-buys-AMI

Steeman, M. (2020, January 27). Climate change actions of more than 30 listed NZ companies rated low. Stuff.

https://www.stuff.co.nz/business/119001117/climate-change-actions-of-morethan-30-listed-nz-companies-rated-low

Stern, N. (2006). What is the economics of climate change? World Economics, Henley-on-Thames, 7(2), 1.

Stewart, M. (2016, May 11). Activists blockade Wellington ANZ branch, demand fossil fuel divestment. Stuff.

https://www.stuff.co.nz/business/79854844/activists-blockade-wellington-anzdemand-fossil-fuel-divestment

Stiglitz, J. E. (2017). The overselling of globalization. Business Economics, 52(3), 129-137. https://doi.org/10.1057/s11369-017-0047-z

Sullivan, R. (2009). The management of greenhouse gas emissions in large European companies. Corporate Social Responsibility and Environmental Management, 16(6), 301-309. https://doi.org/https://doi.org/10.1002/csr.187 
Supran, G., \& Oreskes, N. (2017). Assessing ExxonMobil's climate change communications (1977-2014). Environ. Res. Lett., 12(8). https://doi.org/10.1088/1748-9326/aa815f

Swiss Re Institute. (2021). The economics of climate change: no action not an option. https://www.swissre.com/institute/research/topics-and-riskdialogues/climate-and-natural-catastrophe-risk/expertise-publicationeconomics-of-climate-change.html

Tang, Q., \& Tang, L. M. (2019). Toward a Distributed Carbon Ledger for Carbon Emissions Trading and Accounting for Corporate Carbon Management. Journal of Emerging Technologies in Accounting, 16(1), 37-46. https://doi.org/10.2308/jeta-52409

Tang, S., \& Demeritt, D. (2018). Climate Change and Mandatory Carbon Reporting: Impacts on Business Process and Performance [Article]. Business Strategy and the Environment, 27(4), 437-455. https://doi.org/10.1002/bse.1985

Te Rūnanga o Ngāi Tahu. (2016). 2016 Annual Report: Te Rūnanga o Ngāi Tahu Group. https://ngaitahu.iwi.nz

Te Rūnanga o Ngāi Tahu. (2018). Te tāhū o te whāriki | Anchoring the foundation. https://ngaitahu.iwi.nz/environment/policy/climate-change-strategy/

Te Rūnanga o Ngāi Tahu. (2019a). Climate Change Response (Zero Carbon) Amendment Bill. https://www.parliament.nz/en/pb/sc/submissions-andadvice/document/52SCEN_EVI_87861_EN13349/te-r\%C5\%ABnanga-ong\%C4\%81i-tahu

Te Rūnanga o Ngāi Tahu. (2019b). Te Rūnanga o Ngāi Tahu 2019 Annual Report. https://ngaitahu.iwi.nz

Te Rūnanga o Ngāi Tahu. (2020a). Arahina te iwi ki te ora https://ngaitahu.iwi.nz/our_stories/arahina-te-iwi-ki-te-ora/

Te Rūnanga o Ngāi Tahu. (2020b). Te Rūnanga o Ngāi Tahu Group Annual Report 2019-2020. https://ngaitahu.iwi.nz

Telecom NZ. (2010). Annual Report 2010. http://investors.sparknz.co.nz/InvestorCentre/?page=Annual-Reports 
Telecom NZ. (2011). Annual Report 2011. http://investors.sparknz.co.nz/InvestorCentre/?page=Annual-Reports

Telecom NZ. (2012). Annual Report 2012. http://investors.sparknz.co.nz/InvestorCentre/?page=Annual-Reports

Telecom NZ. (2014). Annual Report 2014. http://investors.sparknz.co.nz/InvestorCentre/?page=Annual-Reports

Testa, F., Boiral, O., \& Iraldo, F. (2018). Internalization of Environmental Practices and Institutional Complexity: Can Stakeholders Pressures Encourage Greenwashing? Journal of Business Ethics, 147(2), 287-307. https://doi.org/10.1007/s10551-015-2960-2

Thaker, J. (2019). Corporate communication about climate science: A comparative analysis of top corporations in New Zealand, Australia, and Global Fortune 500. Journal of Communication Management. www.emeraldinsight.com/1363254X.htm

The Warehouse Group. (2019, August 1). TheMarket is hereyoutube.com.

The Warehouse Group. (2020, May 26). Ensuring Kiwis have healthy homes https://www.thewarehousegroup.co.nz/news-searchresults?search_paths\%5B\%5D=\%2Fnews-updates\&query=covid

Tibshraeny, J. (2017). New Zealand's second largest general insurer aims to increase its market share to $30 \%$, offering to pay more than 'Canada's Berkshire Hathaway' to buy Tower. interest.co.nz. https://www.interest.co.nz/insurance/86141/new-zealands-second-largestinsurer-aims-increase-its-market-share-offering-pay-more

Toitū Envirocare. (2012). Summary of CEMARS@ certification: Toyota New Zealand Limited.

https://www.toitu.co.nz/_data/assets/pdf_file/0005/117608/Disclosure_Toyot aNZ_CE_1112.pdf

Toitū Envirocare. (2019). Summary of carboNZero certification. https://www.toitu.co.nz/our-members/members/the-warehouse-group-limited

Toitū Envirocare. (2020). Summary of Toitū carbonreduce certification: Toyota New Zealand Limited.

https://www.toitu.co.nz/_data/assets/pdf_file/0011/220007/Disclosure_1920 Toyota_CM_Org.pdf 
Toitū Envirocare. (n.d.). Carbon Programmes \& Certification. Toitū Envirocare. Retrieved 21 Jul 2021 from https://www.toitu.co.nz/what-we-offer/carbonmanagement

Topham, G., \& Harvey, F. (2020, April 8). Airlines lobby to rewrite carbon deal in light of coronavirus. The Guardian,. https://www.theguardian.com/business/2020/apr/08/airlines-lobby-to-rewritecarbon-deal-due-to-coronavirus

Toyota. (2017). The Story Behind the Birth of the Prius, Part 1. https://global.toyota/en/prius20th/challenge/birth/01/

Toyota NZ. (2016). Sustainability report 2016. https://www.toyota.co.nz/sustainability

Toyota NZ. (2017). Sustainability report 2017. https://www.toyota.co.nz/sustainability

Toyota NZ. (2018, September 4). Hydrogen-fuelled vehicles will play a part in our transport future. Retrieved 6 September 2020 from https://www.toyota.co.nz/about-toyota/toyota-news/2018/september/loweremissions-needed-for-a-zero-carbon-future/

Toyota NZ. (2020a, January 17). Future of mobility is accelerating https://www.toyota.co.nz/about-toyota/toyota-news

Toyota NZ. (2020b, November 26). Immediate Response to Covid-19 pandemic https://www.toyota.co.nz/about-toyota/sustainability-inaction/2020/adaptation/immediate-response-to-covid-19-pandemic/

Toyota NZ. (2020c, August 19). Low carbon-emitting hybrids dominate sales tables https://www.toyota.co.nz/about-toyota/toyota-news

Toyota NZ. (2020d). Sustainability report 2020. https://www.toyota.co.nz/sustainability/reports/sustainability-report-2020

Toyota NZ. (n.d.). News. Toyota NZ,. https://www.toyota.co.nz/about-toyota/toyotanews

Transpower. (2021). A Roadmap for Electrification: Decarbonising transport and process heat. https://www.transpower.co.nz/sites/default/files/publications/resources/Transp ower_Electrification\%20Roadmap_SCREEN3_LR.pdf 
Trevett, C. (2017, August 20). Jacinda Ardern's rallying cry: Climate change the nuclear-free moment of her generation.

https://www.nzherald.co.nz/nz/jacinda-arderns-rallying-cry-climate-changethe-nuclear-free-moment-of-hergeneration/6LEDCNATMAFX2PWA3GHNLK7NUU/).

Trumpp, C., \& Guenther, T. (2017). Too Little or too much? Exploring U-shaped Relationships between Corporate Environmental Performance and Corporate Financial Performance. Business Strategy and the Environment, 26(1), 49-68. https://doi.org/10.1002/bse.1900

TWG. (2008). The Warehouse Group: 2008 Annual Report. https://www.asx.com.au/asxpdf/20081023/pdf/31d21trz250bwd.pdf

TWG. (2018). The Warehouse Group 2018 Annual Report: Towards Integrated Reporting. https://www.thewarehousegroup.co.nz/investor-centre/companyreports

TWG. (2019). The Warehouse Group 2019 Annual Report: Transformation on track. https://www.thewarehousegroup.co.nz/investor-centre/company-reports

TWG. (2020a). The Warehouse Group 2020 Annual Report: Helping Kiwis live better every day. https://www.thewarehousegroup.co.nz/investor-centre/companyreports

TWG. (2020b, June 28). The Warehouse makes sustainability affordable. Stuff. https://www.stuff.co.nz/partner-content/121909481/the-warehouse-makessustainability-affordable

UN News. (2020, April 22). Fall in COVID-linked carbon emissions won't halt climate change - UN weather agency chief. UN News. https://news.un.org/en/story/2020/04/1062332

Underhill, J. (2016, November 4). Fonterra plays up clean, green credentials with new food quality seal. NBR. https://www.nbr.co.nz/article/fonterra-plays-cleangreen-credentials-new-food-quality-seal-b-196348

UNFCCC. (1998). Kyoto Protocol to the United Nations Framework Convention on Climate Change. https://unfccc.int/process/the-kyoto-protocol

UNFCCC. (2015). Paris Agreement - Status of ratification. https://unfccc.int/process/the-paris-agreement/status-of-ratification 
UNFCCC. (n.d.). UNFCCC Process: Parties. Retrieved 22 Jul 2021 from https://unfccc.int/process/parties-non-party-stakeholders/parties-conventionand-observer-states

Unilever. (2020, June 15). Unilever sets out new actions to fight climate change, and protect and regenerate nature, to preserve resources for future generations https://www.unilever.co.uk/news/press-releases/2020/unilever-sets-out-newactions-to-fight-climate-change-and-protect-and-regenerate-nature-topreserve-resources-for-future-generations.html

United Nations Development Programme. (2019). The Heat is On: Taking Stock of Global Climate Action (NDC Global Outlook Report 2019, Issue. https://www.undp.org/content/undp/en/home/librarypage/environmentenergy/climate_change/ndc-global-outlook-report-2019.html

Van Gorp, B. (2010). Strategies to take subjectivity out of framing analysis. In Doing news framing analysis (pp. 100-125). Routledge.

Vector. (2016). Submission on the New Zealand Emissions Trading Scheme Review 2015/16. https://www.mfe.govt.nz/climate-change/new-zealand-emissionstrading-scheme/reviews-of-nz-ets/nz-ets-review-201516/nz-ets

Vector. (2017, June 15). Vector set to unleash power of EVs via two-way charging. https://www.vector.co.nz/news

Vector. (2019a). Annual report 2019: energy systems to move us all forward. https://www.vector.co.nz/investors/reports

Vector. (2019b, December 3). Sale of Vector's Kapuni assets and entry into new long term natural gas and LPG supply arrangements. Vector.

https://www.vector.co.nz/news/sale-of-vector\%E2\%80\%99s-kapuni-assetsand-entry-into-new

Vector. (2019c). Vector submission for the Climate Change Response (Zero Carbon) Amendment Bill. https://www.parliament.nz/en/pb/sc/submissions-andadvice/document/52SCEN_EVI_87861_EN12521/vector-Itd

Vector. (2020). Annual report 2020: The interplay of today and tomorrow. https://www.vector.co.nz/investors/reports

Vector. (n.d.-a). ownership. Retrieved 27 Sep 2021 from https://www.vector.co.nz/about-us/ownership 
Vector. (n.d.-b). regulatory. Retrieved 27 Sep 2021 from

https://www.vector.co.nz/about-us/regulatory

Vergragt, P., Akenji, L., \& Dewick, P. (2014, 2014/01/15/). Sustainable production, consumption, and livelihoods: global and regional research perspectives. Journal of Cleaner Production, 63, 1-12.

https://doi.org/https://doi.org/10.1016/j.jclepro.2013.09.028

Walenta, J. (2018, 2018/10/20). The Limits to Private-sector Climate Change Action: The Geographies of Corporate Climate Governance. Economic Geography, 94(5), 461-484. https://doi.org/10.1080/00130095.2018.1474078

Walker, K., \& Wan, F. (2012). The Harm of Symbolic Actions and Green-Washing: Corporate Actions and Communications on Environmental Performance and Their Financial Implications. Journal of Business Ethics, 109(2), 227-242. https://doi.org/10.1007/s10551-011-1122-4

Wannan, O. (2015, November 28). New Zealanders rally to global People's Climate March call for action. Stuff. http://www.stuff.co.nz/national/74520024/NewZealanders-rally-to-global-Peoples-Climate-March-call-for-action

Wannan, O. (2021, July 8). Are we about to blow our first-ever carbon budget? Stuff.co.nz. https://www.stuff.co.nz/environment/climate-news/125676561/arewe-about-to-blow-our-firstever-carbon-budget

Watt, I. (2018, October 1). The limits of science-based targets. Forum for the Future. Retrieved 22 Jul 2021 from https://www.forumforthefuture.org/blog/theproblem-with-science-based-targets

WBCSD and WRI. (2011). Corporate Value Chain (Scope 3) Accounting and Reporting Standard. https://ghgprotocol.org/standards/scope-3-standard

WBCSD and WRI. (2015). The Greenhouse Gas Protocol: A corporate accounting and reporting standard (Revised edition). https://ghgprotocol.org/corporatestandard

WBCSD and WRI. (2016). Global Warming Potential Values. https://ghgprotocol.org/sites/default/files/ghgp/Global-Warming-PotentialValues\%20\%28Feb\%2016\%202016\%29_1.pdf

Wegener, M., Labelle, R., \& Jerman, L. (2019). Unpacking carbon accounting numbers: A study of the commensurability and comparability of corporate 
greenhouse gas emission disclosures. Journal of Cleaner Production, 211, 652-664. https://doi.org/https://doi.org/10.1016/j.jclepro.2018.11.156

Weinhofer, G., \& Hoffmann, V. H. (2010). Mitigating climate change - how do corporate strategies differ? Business Strategy and the Environment, 19(2), 77-89. https://doi.org/10.1002/bse.618

Westpac Group. (2017). Climate Change: Position Statement and 2020 Action Plan. https://www.westpac.com.au/content/dam/public/wbc/documents/pdf/aw/susta inability/WestpacCCEActionPlan.pdf

Westpac Group. (n.d.). Our businesses. https://www.westpac.com.au/aboutwestpac/westpac-group/company-overview/our-businesses/

Westpac NZ. (2014, January 23). Westpac to boost its $\$ 1$ bn investment in the New Zealand CleanTech sector https://www.scoop.co.nz/stories/BU1401/S00327/westpac-to-boost-its-1bninvestment-in-nz-cleantech-sector.htm

Westpac NZ. (2016). New Zealand Emissions Trading Scheme Review 2015/6: Discussion document and call for written submissions: Westpac Submission. http://www.mfe.govt.nz/climate-change/new-zealand-emissions-tradingscheme/reviews-of-nz-ets/nz-ets-review-201516/nz-ets-0

Westpac NZ. (2018, April 4). Inaction on climate change puts tens of billions of dollars at stake. https://www.westpac.co.nz/about-us/media/inaction-onclimate-change-puts-tens-of-billions-of-dollars-at-stake/

Westpac NZ. (2019). Submission to the Environment Select Committee on the Climate Change Response (Zero Carbon) Amendment Bill. https://www.parliament.nz/en/pb/sc/submissions-andadvice/document/52SCEN_EVI_87861_EN12883/westpac-new-zealandlimited

Westpac NZ. (2020, November 2). Westpac New Zealand puts customers first in COVID-19 response https://www.westpac.co.nz/about-us/media/westpacnew-zealand-puts-customers-first-in-covid-19-response/

Wiedmann, T. (2009). Editorial: Carbon footprint and input-output analysis - an introduction. Economic Systems Research: Carbon Footprint and InputOutput Analysis, 21(3), 175-186. https://doi.org/10.1080/09535310903541256 
Wiedmann, T., \& Minx, J. (2008). A Definition of 'Carbon Footprint'. In C. C. Pertsova (Ed.), Ecological Economics Research Trends (pp. 1-11). Nova Science Publishers.

https://www.novapublishers.com/catalog/product_info.php?products_id=5999

WorkSafe. (2019). Addenda to Electric vehicle charging safety guidelines - 2nd edition. https://www.worksafe.govt.nz/laws-andregulations/regulations/electrical-regulations/regulatory-guidancenotes/electric-vehicle-charging-safety-guidelines/

World Economic Forum. (2018). The Global Risks Report 2018. http://www3.weforum.org/docs/WEF_GRR18_Report.pdf

World Economic Forum. (2020). The Global Risks Report 2020. https://reports.weforum.org/global-risks-report-2020/a-decadeleft/?doing_wp_cron=1633158582.6170849800109863281250

Wright, C. N., Daniel. (2017). An inconvenient truth: How organizations translate climate change into business as usual. The Academy of Management journal., 60(5), 1633. https://doi.org/10.5465/amj.2015.0718

Yunus, S., Elijido-Ten, E., \& Abhayawansa, S. (2016). Determinants of carbon management strategy adoption. Managerial Auditing Journal, 31(2), 156-179. https://doi.org/10.1108/MAJ-09-2014-1087

Z Energy. (2017, March 6). Z seeks to engage Kiwis on carbon and climate change https://z.co.nz/about-z/news

Z Energy. (2018a, September 1). Kiwi brands unite to bring fuel discounts to customers. Retrieved 17 Jul 2021 from https://z.co.nz/about-z/news/generalnews/kiwi-brands-unite-to-bring-fuel-discounts-to-customers/

Z Energy. (2018b). Z Energy's Submission on Proposals under the Zero Carbon Bill. http://www.mfe.govt.nz/sites/default/files/media/Consultations

Z Energy. (2019a). Z Energy House View: Hydrogen. https://z.co.nz/aboutz/news/submissions-and-presentations/z-energy-house-view-hydrogen/

Z Energy. (2019b). Z Energy Submission on the Climate Change Response (Zero Carbon) Amendment Bill. https://www.parliament.nz/en/pb/sc/submissionsand-advice/document/52SCEN_EVI_87861_EN10367/z-energy 
Z Energy. (2020a). Ko te mea nui... What matters most... Z Energy Annual Report. https://investors.z.co.nz/financials/annual-reports

Z Energy. (2020b, March 13). Waste Watch 2019 https://z.co.nz/aboutz/news/sustainability-news/wastewatch2019/

Z Energy. (2020c). What matters most... Z Energy Annual Report: For the year ended 31 March 2020. https://investors.Z.co.nz/financials/annual-reports

Z Energy. (n.d.-a). About Caltex. Z Energy Ltd. Retrieved 24 Mar 2021 from https://caltex.co.nz/about-caltex/

Z Energy. (n.d.-b). Find a Z near you. Z Energy Ltd. https://z.co.nz/about-z/find-us 